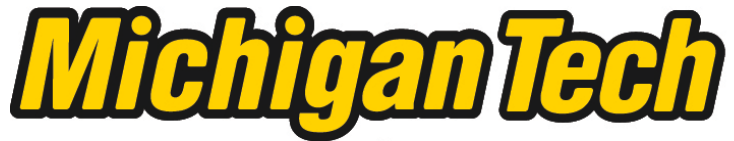 \\ Michigan Technological University Create the Future Digital Commons @ Michigan Tech
}

Dissertations, Master's Theses and Master's Reports - Open

Dissertations, Master's Theses and Master's

Reports

2009

\section{United States certificate programs in technical communication : a feminist-sophistic investigation}

Jim Nugent

Michigan Technological University

Follow this and additional works at: https://digitalcommons.mtu.edu/etds

Part of the Rhetoric and Composition Commons

Copyright 2009 Jim Nugent

\section{Recommended Citation}

Nugent, Jim, "United States certificate programs in technical communication : a feminist-sophistic investigation", Dissertation, Michigan Technological University, 2009.

https://doi.org/10.37099/mtu.dc.etds/92

Follow this and additional works at: https://digitalcommons.mtu.edu/etds

Part of the Rhetoric and Composition Commons 


\section{United States Certificate Programs in Technical Communication: A Feminist-Sophistic Investigation}

by

Jim Nugent

A DisSERTATION Submitted in partial fulfillment of the requirements for the degree of DOCTOR OF PHILOSOPHY (Rhetoric and Technical Communication)

Michigan Technological University 2009

(C) Copyright 2009 Jim Nugent 
This Dissertation, "United States Certificate Programs in Technical Communication: A Feminist-Sophistic Investigation," is hereby approved in partial fulfillment of the requirements for the degree of DOCTOR OF PHILOSOPHY in the field of Rhetoric and Technical Communication.

DEPARTMENT OF HUMANITIES

Michigan TECHNOLOGICAL UnivERSITY

10 August 2009

Advisor: $\quad$ Robert R. Johnson

Committee: $\quad$ Ann Brady

Marika Seigel

Robert Warrington

Department Chair: Ron Strickland 


\section{Abstract}

Technical communication certificates are offered by many colleges and universities as an alternative to a full undergraduate or graduate degree in the field. Despite certificates' increasing popularity in recent years, however, surprisingly little commentary exists about them within the scholarly literature. In this work, I describe a survey of certificate and baccalaureate programs that I performed in 2008 in order to develop basic, descriptive data on programs' age, size, and graduation rates; departmental location; curricular requirements; online offerings; and instructor status and qualifications. In performing this research, I apply recent insights from neosophistic rhetorical theory and feminist critiques of science to both articulate, and model, a feminist-sophistic methodology. I also suggest in this work that technical communication certificates can be theorized as a particularly sophistic credential for a particularly sophistic field, and I discuss the implications of neosophistic theory for certificate program design and administration.

Jim Nugent

10 August 2009 
For Mom and Dad:

Thanks 


\section{Acknowledgements}

My neosophistic theoretical approach compels me to acknowledge the multiple social origins of this work. First, this study was made possible by a research grant from the Council for Programs in Technical and Scientific Communication (CPTSC) and by support from Michigan Technological University's Department of Humanities. I remain grateful to both of these institutions for their generous sponsorship. I am also very grateful to my dissertation committee: thanks to Robert R. Johnson, Ann Brady, Marika Seigel, and Robert Warrington for their careful and constructive assistance during every stage of this work. I simply could not ask for more phronetic, metistic, and kairotic readers and collaborators. I also owe considerable intellectual debts to the wily sophist Jerry Savage and to Ken Lindblom's spring 2003 class in ancient rhetoric at Illinois State University. I remain thankful to Marjorie Lindley, Sue Niemi, and Kim Puuri for their invaluable administrative assistance and breathtaking capacity to make things happen. Thanks to my graduate colleagues Laurence José and Moe Folk for their thoughtful discussions (and for abiding my rants). My thanks as well to the Hayenga family-Molly, Erik, Shalini, Avalon, Rowan, Clea, and Gresham - for the many conversations and chicken dinners. Without such nourishment, this dissertation (and dissertation writer) would no doubt be much slimmer. Finally, my thanks to Lori for reading so many drafts, for seeing ways forward where I could not, and for all her love and support. 


\section{Table of Contents}

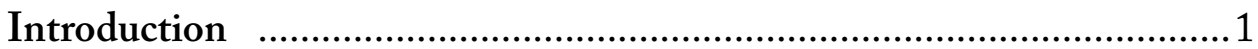

Chapter 1: The Sophists, the Postmodern Context, and Neosophism ..............................................................12

Chapter 2: $\quad$ Toward a Feminist-Sophistic Methodology ........................34

Chapter 3: Rhetorically Enacting a Feminist-Sophistic Method ........57

Chapter 4: Method for Surveying United States Baccalaureate and Certificate Programs in Technical Communication ..........75

Chapter 5: Results and Conclusions....................................................96

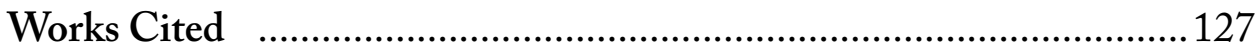

Appendix A： Program Directory...........................................................142

Appendix B： Survey Instrument ..........................................................164

Appendix C: Survey Cover Letter .......................................................168

Appendix D： Survey Reminder Postcard .............................................169 
Dangerous as it may be to do so, I hereby admit that everything after this sentence is sophistry.

$$
\begin{array}{r}
\text {-Jasper Neel, } \\
\text { Plato, Derrida, and Writing } 6
\end{array}
$$




\section{Introduction}

Technical communication certificates are offered by many colleges and universities as an alternative to a full undergraduate or graduate degree in the field. Certificates typically require only one or two years of coursework strictly within technical communication, and can typically be earned while working full time or while seeking another degree. According to the Council for Programs in Technical and Scientific Communication (CPTSC) and the Society for Technical Communication (STC) joint publication Academic Programs in Technical Communication (third edition), there were 16 programs offering technical writing certificates in 1985 (qtd. in Shirk et al. 1). In 2008, I was able to identify at least 89 individual certificate programs, representing a roughly sixfold increase in number over 23 years. Compared to an approximate tripling of the number of technical communication programs overall during the same period, it's clear that certificate programs are an increasingly popular means of meeting the demand for skilled technical communicators. Despite this popularity, however, surprisingly little information or discussion exists in the scholarly literature specifically about certificates.

This informational and conversational void is unusual, as certificate programs are potentially located in the middle of several important conversations in the field of technical communication. With their apparent vocational emphasis, certificate programs are potentially a site of conflict "on the issue of training opposed to education, or in other words, the conflict between theory and practice" (Little, "Designing" 278). With their role in meeting the needs of local industry, and with their potential to serve as the locations for academy-industry cooperation, certificate programs speak to the conversation of who shapes technical communication programs: academy or industry (Anderson; Bosley, 
"Collaborative Partnerships"; Bushnell; Coon and Scanlon; Krestas, Fisher, and Hakos; Yee; Zimmerman). With certificate programs' role as a gatekeeper to the profession — that is, the role of "certifying" implicit in their very name - they also raise questions about what counts as an appropriate academic preparation for practicing technical communicators (Shirk 4) and they present a number of significant implications to the project of professionalizing the field (Savage, "Process" 364-65).

In this dissertation, I describe my efforts to address the informational void surrounding technical communication certificate programs by performing a survey of program administrators. By developing basic, descriptive data on programs' age, size, and graduation rates; departmental location; curricular requirements; online offerings; and instructor status and qualifications, I hope to make way for more situated and productive dialog in the above scholarly conversations. I also hope to provide information, considerations, theoretical reflections, and cautions that are useful for administrators interested in implementing their own certificate programs. As I conduct the present survey with these research aims in mind, however, I also engage self-reflexively with a number of issues concerning epistemology and methodology. Applying recent insights from neosophistic rhetorical theory and feminist critiques of science, I seek within this study to articulate and model revised practices for empirical research. As I suggest, by employing a distinctly feministsophistic methodology, this study can respond to contemporary conversations in the field of technical communication more ethically and rigorously than by using traditional scientific and academic methods alone.

\section{About Certificates}

In 1988, the CPTSC workshop group on certificates advanced the following definition of a certificate program: 
A certificate is a college or university awarded credential granted for successful completion of a defined program of study. Certificates can be awarded at the undergraduate or the graduate level.

A Technical Communication Certificate differs from a Masters Degree in two significant ways. First, a Masters program will require more credit hours and, therefore, a longer period of study. A Masters program will also promote more research into the study of the theory of technical communication. The limited scope of the Certificate in Technical Communication distinguishes it from the undergraduate degree in this area. (28)

The workshop group went on to issue the following call for basic research describing certificates:

We recommend a nationwide survey to gather information on the content of existing Certificate programs. In addition, we recommend that [the] CPTSC survey the number of fulltime to part-time to adjunct faculty teaching in Certificate Programs in Technical Communication to establish a standard for an appropriate ratio. (28)

Despite this call, however, the scholarly literature specifically on technical communication certificate programs is confined to only a pair of book chapters (Little, "Designing”; Nugent, "Looking”) and a dozen or so CPTSC presentations (Bosley, "Building"; Bridgeford, "Academic"; Bridgeford, "Negotiated"; Bridgeford, "Repurposing"; Bridgeford, "Thoughts"; Little, "Problem"; Little, "Proof"; Nugent, 2006; Pfeiffer; Rehling; Shirk; Shirk et al.; Worley). Even though they span over 20 years of scholarship, these works comprise (by my count) fewer than 70 pages of text.

Among the most in-depth treatments of certificate programs is Sherry Burgus Little’s 1997 chapter, “Designing Certificate Programs in Technical Communication." In this work Little provides a general review 
and synthesis of information on certificate programs found in the four editions of Academic Programs in Technical Communication published between 1976 and 1993. As she notes, certificate programs are diverse in their charter and construction. Some programs are geared toward those entering the field, while others are designed to augment the skills of practicing professionals. Some programs are designed to serve those in scientific and technical fields specifically, while others are designed to serve technical communicators more generally. Certificates are offered at both the undergraduate and graduate levels, and the courses they require vary widely (276-77). Little further characterizes certificates as flexible and localized:

They can be modified easily and quickly, adapting to changing demands, because they are generally monitored and scrutinized less closely than other kinds of programs. Because of their flexibility-their content is rarely mandated by degree requirements of educational legislation - they can be individuated for students, adapting to diverse backgrounds and goals. (275)

Little also suggests that certificate programs are comparatively easy to implement (see also Shirk 2). As she describes, the bureaucratic machinations required to establish a new degree program can be considerable:

In most institutions, proposing a degree involves a staggering amount of paperwork and numerous procedures. A chain of approvals needs to be won from committees and administrators at all levels and frequently beyond the local institution itself to centralized administrations, boards of trustees, state-level educational approving agencies, and even state legislators. Such approval processes are timeconsuming, sometimes taking years before a degree comes into existence. (275) 
In contrast, certificate programs are much easier to initiate, as oversight for their creation rarely extends beyond the immediate institution and they can usually take advantage of courses and resources already in place across the university (275). For these reasons, certificates can be an attractive option for emerging programs (see Bridgeford, "Repurposing" 79; Pfeiffer 6; Shirk 1; Worley 110).

In my 2003 study of certificate programs, "Certificate Programs in Technical Communication: Looking Closer, through Sophistic Eyes," I attempt to offer a more systematic response to the CPTSC workshop group's call for research into the content and staffing of certificate programs. In the first part of that study, I closely examine 62 certificate programs in technical communication in order to characterize them in terms of their curricular requirements. In the second part of that study, I perform a survey of certificate program administrators to gauge who teaches in such programs, the age of such programs, and the relationship of such programs to local industry. I conclude that certificate program curricula "are so wildly disparate that no core curriculum can be said to exist among them." I also find that certificate programs demonstrate a concern with the needs of local industry, with most programs recruiting from local industry, making use of industry advisory boards, or employing some other means to gather feedback from local industry. However, in that study I present only limited data about the degrees required of certificate program instructors, leaving many questions about their status unanswered.

Although the scholarship on certificate programs is scant, much of the available commentary expresses a certain wariness about them. For instance, the CPTSC workshop group's 1988 call for research implies their suspicion that certificates are perhaps less ably staffed or of inferior in quality compared other technical communication programs. Little suggests 
that the certificate's relative lack of oversight, its lack of standardization, its localization, and its curricular diversity could possibly lead to its lack of acceptance as a valid credential ("Designing" 276; see also Little, "Problem"). Tracy Bridgeford voices her concern that the label "certificate' could reinforce the 'vocational ethos' often attached to our programs and courses" ("Repurposing" 79). In a 1988 presentation to the CPTSC, Henrietta Nickels Shirk offers a litany of questions that reflect a general suspicion toward certificates:

Who should teach in these programs? Should our instructors have primarily academic backgrounds, should they be current practitioners in the field, or should the "ideal" program have a group of instructors who represent some combination of these different sets of skills? If there are industry advisory boards for our programs, do they recommend course content rather than dictate it? And is this course content balanced with the application of sound theory and effective teaching strategies? Are our certificate programs too focused in their content and therefore on the edge of being parochial? While graduates may meet the immediate job needs of local industries, will they also be equally successful $[\ldots]$ in other parts of the country? (2-3)

In her own 1998 presentation to the CPTSC, meanwhile, Lu Rehling urges the council to "contribute to the evolution of certificate programs in our field by helping to set some standards and publicize some parameters" (51).

And in their 2007 article "Remapping Curricular Geography': A Retrospection," James Porter and Patricia Sullivan implicate certificate programs, at least tangentially, in the marginalization of professional writing. They note that professional writing remains the subject of "indignity and neglect" (16) at many institutions: an indignity

amplified by the number of English departments that start a professional writing certificate by adding an internship to 
a literature major and by insisting that their hire (notice the singular) in professional writing have status in literature (or at least have signed a loyalty oath to the love of it). In other words, English departments often undermine the disciplinarity of professional writing by hiring literary folks to teach it. Unfortunately, this form of colonization continues at many institutions. (16)

It is clear from these accounts that certificates not only provoke anxiety about issues of program quality, but that these issues almost immediately and invariably spill over into a range of important field-wide concerns and conversations. I take it to be indicative of the centrality and significance of certificate programs that the limited scholarly commentary about them touches on such broad issues as:

- the material and professional status of technical communication instructors,

- debates concerning the project of establishing technical communication as a profession and scholarly discipline (i.e., the professionalization debates),

- debates over the establishment of nationwide certification for technical communication practitioners or instructors,

- debates over vocationalism and academy-industry collaboration,

- concerns over the relationship between theory and practice in technical communication, and

- debates over the political and material consequences of technical communication's common disciplinary location within departments of English.

Although I can't hope to satisfactorily address all of the issues and anxieties presented by certificate programs in the present research, I do believe that the basic descriptive data, methodological considerations, and theoretical reflections that I seek to articulate here can be used to support 
more situated and productive conversation about these increasingly popular programs.

\section{About the Present Study}

Proposing to more fully respond to the CPTSC's 1988 call for basic descriptive data regarding certificate program instructors, in 2006 I sought and won support from the council to perform a mailed survey of certificate and baccalaureate program administrators. With this research, I attempt to augment our basic understanding of certificates by answering the following questions:

- What is typical of technical communication certificate programs in terms of their:

o type of department or academic unit,

○ age,

○ size,

- graduation rates,

- course requirements,

- length to program completion,

$\bigcirc$ online offerings, and

$\circ$ internship requirements?

- To provide a baseline for analysis, what is typical for baccalaureate programs in terms of the same attributes above?

- What are the professional qualifications of certificate program instructors, and how do they compare to the qualifications of baccalaureate program instructors? These qualifications include:

- level of academic preparation,

$\bigcirc$ academic specialization,

- possession of industry or professional experience,

○ status as a graduate student, and 
- status as a tenure-track instructor.

- Do technical communication certificate instructors have more or less professional status than baccalaureate program instructors?

Particularly with the air of suspicion surrounding certificates in terms of their perceived quality and their possible implications for the material and political status of the field of technical communication, I also attempt to address the following, more open-ended and theoretical questions:

- Given their shorter time to completion and their relative lack of accreditation and other external oversight, how do certificate program curricula rank relative to baccalaureate programs?

- What are the implications of certificate programs for the disciplinary and professional status of technical communication? How are certificates poised to impact the project of professionalizing the field of technical communication?

- What theoretical models can help us to situate and to make sense of certificate programs? In what ways can these models guide the development and growth of technical communication programs?

In seeking answers to these questions, I draw on neosophism to inform my overall approach. As I detail in the next chapter, a sizable and recent intellectual movement is underway to restore the reputation of the historically maligned, early Greek sophists. A number of scholars are turning to these ancient rhetoricians to develop new conceptions of pedagogy and practice for composition-rhetoric, communication, and technical communication, among other fields. Particularly after modernism, neosophistic scholars find new relevance in the sophists' 
socially engaged, politically potent, and thoroughly rhetorical modes of teaching and practice. In this study, I seek to join this scholarly movement by applying neosophistic theory specifically toward the practical and theoretical questions surrounding certificate programs.

Neosophistic theory informs this study in two key ways. First, I explore the productive intersections of feminist theory and neosophistic theory in order to articulate a feminist-sophistic research methodology for this research. As I describe, such a methodology makes a number of notable departures from traditional scientific and academic methods in terms of its epistemic stance and rhetorical style. Second, I use neosophism as a framework for interpreting the certificate program in technical communication itself. Sophistic rhetoric, as Gerald J. Savage notes, can act as a valuable tool for theorizing the professional identity of the postmodern technical communicator ("Tricksters"). Likewise, I argue, it proves to be a valuable tool for theorizing technical communication certificate programs. As I conclude, the certificate in technical communication can be seen as a particularly sophistic credential for a particularly sophistic field.

In chapter 1 , I set the theoretical scene for this study by describing neosophistic theory. After characterizing the history of ancient sophists and the postmodern context that has led to their contemporary reevaluation, I then describe and situate the present research within the specific genre of neosophistic appropriation. In chapter 2, I work to combine the perspectives of neosophistic rhetorical theory and feminist critiques of science to describe a feminist-sophistic methodology for the present study, and in chapter 3 I overview the specific strategies I use for the rhetorical enactment of such a methodology. In chapter 4, I outline my method for surveying programs in the perhaps more traditional terms of selecting the sample, composing the survey instrument, and conducting 
the survey itself. And in chapter 5, I present the major results of the survey and I offer some conclusions and overall theoretical reflections on the certificate program in technical communication. 


\section{Chapter 1:}

\section{The Sophists, the Postmodern Context, and Neosophism}

At the risk of sounding hackneyed and clichéd, I begin the first chapter of this work by noting that Webster's Dictionary (1913) defines "sophism" as "The doctrine or mode of reasoning practiced by a sophist; hence, any fallacy designed to deceive." The American Heritage Dictionary defines sophism as "A plausible but fallacious argument" or "Deceptive or fallacious argumentation." And Webster's Third International Dictionary (1961) defines sophism as "an argument that is correct in form or appearance but is actually invalid; [especially] an argument used for deception, disputation, or the display of intellectual brilliance," or more simply, "specious reasoning." The everyday understanding of sophism is decidedly negative: the word is pejorative, equated to deception, chicanery, and ethical duplicity. Beneath these unflattering definitions, however, lies more than two millennia of accumulated history, including an intellectual dispute whose territory is as broad as the foundation of Western metaphysics itself.

As Susan C. Jarratt notes, the actual, historical sophists at the heart of these dictionary definitions have been "buried under two millennia of neglect, an outcome of the passionate condemnation they provoked from two of their contemporaries who have fared better in the histories, Plato and Aristotle" ("Rereading" 1; "First Sophists" 67). After modernism, however, Plato and Aristotle's reified position within history-not to mention the foundationalist premises of the intellectual tradition they advanced-have come under suspicion. This has lead a number of scholars to recognize the refigurative potential of the early sophists. Gradually, 
these scholars are working to rewrite our definitions of sophism as mere flattery and chicanery, and are beginning to forge vital connections between the sophists' ancient past and our postmodern present.

In this chapter, I attempt to set the overall historical and theoretical scene for this study by characterizing the contemporary movement to resurrect and restore the sophists. I begin by briefly outlining the history of the ancient sophists, and I describe the postmodern context that has served to draw them back into the purview of serious scholarly and intellectual consideration. Then, I attempt to situate the present study among contemporary scholarship on the sophists. In doing so, I outline a pivotal scholarly debate between the "objectivist" and "rhapsodic" historiographic approaches (Consigny, Gorgias). I then review a number of works within the genre of "neosophistic appropriation" (McComiskey, Gorgias), a scholarly genre made possible by rhapsodic historiography and dedicated to applying the ancient sophists toward a number of contemporary issues. Finally, I conclude by describing how the present study attempts to contribute to this important new genre.

\section{The Ancient Sophists}

The sophists were traveling teachers and rhetoricians in ancient Greece. They were the "visiting professors" of the fifth and fourth centuries BCE, teaching their students skills that went beyond the traditional curriculum of grammatikè, mousikè, logistikè, and gumnastikè to also include preparation for life in the public sphere (Kerferd 17; Matsen 30). The sophists accompanied great historical and cultural change; they flourished as democracy flourished in ancient Greece (Crome 14; Enos 136; Kerferd 1; Jarratt, Rereading 81). They were travelers, and by no coincidence, relativists: they understood that "There is no absolute criterion, divine or human, with which to measure any aspect of reality; thus there is no certainty beyond the certainty that the world is known 
differently from place to place" (Pullman 53). The sophists invented the profession of teaching, and they offered their instruction to any man who was able to pay their fees, regardless of his social status (Jarratt, Rereading $82,84)$.

The term "sophist" itself was initially positive, meaning any "wise man"; the term "philosopher" too meant simply a "lover of wisdom." It wasn't until the critiques of Plato and his contemporaries during the fourth century BCE that "sophist" came to be widely seen as pejorative (Crome 19; McComiskey 3, Jarratt, Rereading 34; Schiappa, Protagoras 4). In the dialogue of the Gorgias, Plato's Socrates declares that rhetoric is not a true art because "it can produce no principle in virtue of which it offers what it does, nor explain the nature thereof, and consequently is unable to point to the cause of each thing it offers" (465a). He goes on to analogized rhetoric to "mere cookery" and to denigrate it as a routine, a knack, and a false art (462e-463b). Rhetoric, according to Plato, is incapable of accounting for its own first principles or productive outcomes in the way that a true art, such as medicine, can (Phaedrus 270b).

In the Phaedrus, Plato's Socrates advances the distinction between dialectic (a philosophic search for Truth) and rhetoric (a mere tool for the dissemination of Truth, as found prior through dialectic) (260d). To Plato, only a privileged class of philosopher-kings are capable of accessing $a$ priori Truth through dialectic, and one of rhetoric's few capacities for virtue is as an instrument of state control: as a means for philosopherkings to convey the Truth to those too inferior to access it on their own (Black 373-4; Kauffman 106-115). As the lowly, deceptive practices of the sophists stand opposed to the lofty goals of philosophy and dialectic (Phaedrus 269b), the sophists remain capable of offering only the merest appearance of Truth (Gorgias 464b-466a). Combined with no small amount of slander-Susan Jarratt notes that Plato's accounts of the 
sophists "take on almost monstrous qualities of greed, exhibitionism, and deceit" ("First Sophists" 68; "Rereading" 3)—Plato's critiques placed rhetoric and the character of its first teacher-practitioners under an enduring pall of opprobrium. By casting the previously benign terms "sophist" and "philosopher" so dramatically into opposition, Plato set the stage for the lasting condemnation of the sophists through subsequent history.

At the hands of his famous student Aristotle, Plato's foundationalist epistemology evolved subtly, but continued to militate against the sophists. To be sure, Aristotle is less directly antagonistic toward them than Plato (Pullman 52; Matsen 30; Poulakos, "Rhetoric" 215) and his theories of rhetoric are in some ways consistent with those of the sophists (McComiskey, "Toward" 6; McComiskey, Gorgias 6; Allen). Nonetheless, Aristotle "toes the party line" by characterizing the sophists as artists of deception (McComiskey, Gorgias 2-3) and by upholding rhetoric as the undeniably weaker counterpart (antistrophos) to dialectic (On Rhetoric 1354a). In Sophistical Refutations, for instance, Aristotle equates sophism with fallacy (165a) and makes persistent attacks on the sophist's character, depicting them-much like Plato did-as opportunistic, greedy, lying quibblers (171b).

Together, Plato and Aristotle were instrumental in forging an attitude toward the sophists and rhetoric that has served to keep them historically on the losing sides of the binaries of rhetoric/dialectic and philosophy/sophistry. As George L. Pullman maintains,

The traditional thinking is that Platonic and Aristotelian rhetorical theory disciplined the sophists' extravagant practices, substantiated their unsubstantiated claims, and transformed their dithyrambic, magical, poetic discourse into a logical, rational theory of argumentation. In other words, Plato and Aristotle transformed mythos into logos. 
[...] Because the Western intellectual tradition has tended to lionize Plato and Aristotle and the positive epistemologies they fostered, the sophists in general and sophistic rhetoric in particular have been much maligned, while Plato and Aristotle have largely remained the first and the last word on legitimate rhetoric. (50-51)

In the historical context of postmodernism, however, this traditional thinking has begun to be seriously challenged and revised. As Bruce McComiskey notes, "a new set of conditions emerged during the latter half of the twentieth century, conditions that enabled the critique of Plato's hegemony, foundational epistemologies, and realist rhetorics" (Gorgias 58). In the following section, I briefly overview the postmodern context that brought about these conditions.

\section{The Postmodern Context}

The latter half of the previous century witnessed the broad intellectual and cultural disruption known as postmodernism. The advent of postmodernism has represented a broad disaffection with, and paradigmatic break from, the tenets of modernism and Enlightenment humanism. The contours of this break are now largely familiar; many of postmodernism's once-radical ideas have become commonplace and its critiques have gradually evolved and passed unmarked into our culture. Formerly obscure and abstruse postmodern theory has (to some irony) been canonized in collections such as the Norton Anthology of Theory and Criticism (Leitch), and it has become accessible in textbooks such as The Portable Postmodernist (Berger) and even a comic book (Powell). Oncepolarizing ideas such as the celebration of diversity and alterity are now the stuff of institutional mission statements. Collaborative, digitally mediated projects such as Wikipedia embody the social construction of knowledge without any explicit acknowledgement of a postmodern theoretical orientation. Meanwhile other digital social networks, 
commons-based peer productions, and "Web 2.0" phenomena subvert modernist notions of the individual genius in their reliance on collaboration and the "wisdom of crowds." To some irony, the success of postmodern theory has threatened to render its critiques invisible, and it has become easy to overlook postmodernism's significance to contemporary history.

By way of definition - and by way of reminder to its often tacit presence-I offer a brief review of this movement. While broad in scope and diverse in its makeup, postmodernism remains a distinct and characterizable intellectual-historical phenomenon. To Terry Eagleton, "Postmodernism means the end of modernity, in the sense of those grand narratives of truth, reason, science, progress and universal emancipation which are taken to characterize modern thought from the Enlightenment onwards" (Literary 200). Meanwhile, Stanley Aronowitz and Henry A. Giroux offer this characterization:

Postmodernism's refusal of grand narratives, its rejection of universal reason as a foundation for human affairs, its decentering of the humanist subject, its radical problematization of representation, and its celebration of plurality and the politics of racial, gender, and ethnic difference have sparked a major debate among conservatives, liberals, and radicals in an increasingly diverse number of fields. (61)

Donna Haraway offers a similar characterization of postmodernism, in a style perhaps more befitting it:

If belief in the stable separation of subjects and objects in the experimental way of life was one of the defining stigmata of modernity, the implosion of subjects and objects in the entities populating the world at the end of the Second Millennium — and the broad recognition of this implosion in both technical and popular cultures-are stigmata of another historical configuration. Many have 
called this configuration "postmodern." (Modest_Witness

42)

Beyond these characterizations, I identify a handful interrelated concepts and critiques that are central to postmodernism (and I note some of their familiar "-isms" and terminologies as well). Postmodernism entails:

1. a strong skepticism concerning the transparency and stability of meaning in language (poststructuralism, Derridian différance and deconstruction);

2. the notion that knowledge is not discovered by individuals describing a prior and independent reality, but rather knowledge is developed within — and determined by-social contexts (social constructionism, Kuhnian paradigm shifts, Rortyian pragmatism);

3. a recognition that certain concepts have been arbitrarily privileged over others through history, and that certain myths play a determining role in culture (logocentrism, Lyotardian metanarratives/grand narratives);

4. the dissolution of the modernist normative subject, and the recognition that subjectivities are socially constituted and are without essentiality (the "death of the subject," postcolonialism, the subaltern, the "Culture Wars"); and

5. a rejection of the inviolability of Enlightenment rationality and the supremacy of scientific knowledge (antifoundationalism, the "Science Wars," the Sokal affair, pragmatism).

As these notions migrated and gained broader acceptance at the end of the previous century, their ramifications were felt both popularly and academically. Outside of the academy, debates raged over "political 
correctness," representing a popular engagement with issues concerning the referentiality and power of language as well as the politics of representation, subjectivity, and diversity. Within the university, the status of previously stable categories of knowledge such as culture and science shifted. The humanities' traditional role as a transmitter of supposed universal human values came into considerable doubt during the "Culture Wars" (Atwill 12). Likewise, critiques of scientific methodology and rationality were waged from many corners during the "Science Wars." These critiques of the social, political, and epistemological machinations of a once innocent and objective science were offered by numerous scholars from the disciplines of feminist studies, the social sciences, the rhetoric of science, science studies, science and technology studies, and the humanities.

Within the academic humanities specifically, postmodernism can be seen as the motive force behind many recent shifts. As the modernist, normative subject dissolved, the formerly cohesive and complete Western literary canon was revealed to be a surprisingly racist, classist, sexist, homophobic, and ultimately hegemonic construction. Literary studies responded to this revelation by diversifying its canon and its methods. The burgeoning field of cultural studies abandoned the notion of a text altogether-and subsequently dodged the controversy surrounding canonicity (see Giroux et al.) — by taking all of culture as a rich "text" for critical evaluation. Elsewhere in the humanities, composition studies rejected the formalist approaches of current-traditional rhetorics, which as Sharon Crowley maintains are complicit in a modern humanist program of exclusion (Composition 94-7). Composition studies also moved to abandon concepts derivative of the modernist subject, such as "voice" and "expression," and has come instead to embrace social and rhetorical concepts such as process, ethos, audience, and collaboration. And consistent 
with postmodernism's suspicion of the transparency and stability of language, linguists have begun to turn away from reductive notions of language such as structuralism and to replace them with more nuanced accounts of language use in context such as discourse analysis, pragmatics, and sociolinguistics.

Even technical communication-a discipline born to meet the technological and bureaucratic needs emerging during the height of modernism at the middle of the twentieth century (see Connors, "Rise")has changed in the face of postmodernism. Much like the field of composition, technical communication has evolved away from formalist approaches in its scholarship, education, and practice. It has distanced itself from what Carolyn Miller calls in her influential 1979 article "A Humanistic Rationale for Technical Writing" the windowpane theory of language: "the notion that language provides a view out onto the real world, a view which may be clear or obfuscated" (611-12). Such an outlook holds that language can accurately and unproblematically re-present-equally, to all audiences—an objective, real, stable, and knowable external reality. Against this view of communication, as Paul Dombrowski notes, the postmodern moment has spurred a broad awakening to the function of rhetoric in technical communication, even "though it was 'always already' there (always operative but only recently recognized and validated)" ("Post-modernism" 179). Much recent scholarship in technical communication joins Miller in her dismissal of the windowpane theory, embracing instead approaches rooted in rhetoric. ${ }^{1}$

\footnotetext{
${ }^{1}$ To review the central debates regarding the role of rhetoric in technical communication, see the works of John Haage, Robert R. Johnson ("Complicating"; "Johnson Responds"), Melinda Kreth, Miller ("Comments"), Patrick M. Moore ("Instrumental”; "Myths"; "Response"; "Rhetorical"), and Janice (Ginny) Redish.
} 
Particularly as new scholarship emerges urging us to shift our attention toward postpostmodernism, a "new" or "leftist" ontology, or whatever lies beyond postmodernism (for example, Strathausen)—and even as some scholars recant their earlier postmodern and relativistic theoretical proclamations (Eagleton, After; Gross) - it is easy to forget just how disruptive, historically significant, and ultimately successful postmodernism has been. As James Berlin notes, "Far from being the selfindulgent musings of careerist academics," the theoretical discussions of postmodernism have responded "to alterations in our basic understanding of self, society, and the nature of human value fostered by today's economic and cultural conditions" (60). As I discuss in the next section, postmodernism has also spurred a large-scale reconsideration of the historic sophists, and it has enabled the application of sophistic theory toward a wide range of contemporary issues.

\section{Sophism's Kairotic, Contemporary Revival}

The context of postmodernism has presented a kairotic moment for the reexamination and revival of sophism. Numerous contemporary scholars in composition, rhetoric, communication studies, technical communication, and the humanities have emerged to resurrect the reputation of the sophists against the slanders of Western metaphysicsscholars such as Michelle Ballif, Scott Consigny, Sharon Crowley, Richard L. Enos, Stanley Fish, Susan C. Jarratt, Michael C. Leff, Kenneth J. Lindblom, Steven Mailloux, Bruce McComiskey, John Poulakos, Takis Poulakos, George L. Pullman, Gerald J. Savage, J. Blake Scott, and Victor J. Vitanza, among others. Counter to the characterization of sophists as mere flatterers and chicaners, these scholars craft revived narratives of the sophists that serve to place them productively within a larger postmodern critique. 
In the accounts of these scholars, the sophists' presumed defects under the hegemonic intellectual shadow of Plato and Aristotle become instead virtues: the sophists were generalists, skeptics, and pragmatists; they were socially engaged in their teaching and practice; they were inherently disruptive and subversive; they were anti-aristocratic, antiindividualistic, and democratic; and they were relativistic in their epistemology. As Sharon Crowley notes,

Despite its great age, ancient rhetorical theory has much to offer postmodernity. Postmodern thought requires attention to location and awareness of contingency. Similar theoretical habits can be found in what we know of (or can read into) the work of ancient rhetorical theorists as well, particularly that generated by the Older Sophists. (Crowley, Toward 45)

At the end of modernism, then, the sophists have come to embody a very potent and timely corrective to the excesses of foundationalism.

I won't attempt a complete rehearsal of the extensive body of scholarship re-examining the sophists. (Excellent bibliographies appear in Bruce McComiskey's 2002 volume Gorgias and the New Sophistic Rhetoric and Steven Mailloux's 1995 volume Rhetoric, Sophistry, Pragmatism.) Rather, I focus here on the more specific genre of neosophistic appropriation. First, I present a brief examination of the pivotal debates that served to justify the methods and aims of this genre. Next, I characterize this genre by presenting an overview a number of works within this genre that I feel demonstrate the particular applicability of the sophists to contemporary history. I then conclude by describing how this study seeks to contribute to the genre of neosophistic appropriation. First, however, I would like to settle a terminological issue. The contemporary movement to resurrect the sophists (and the various strains within this movement) are called by a number of different names: "neosophism" 
(Schiappa), the "Third Sophistic" (Jarratt; Vitanza), "a new sophistry" (Neel 178), "sophistic rhetoric" (Poulakos, Sophistical), "the revival of sophistry" and the "new sophistic rhetoric" (McComiskey, Gorgias). As I use the term "neosophism" or "neosophistic rhetoric," I refer to the contemporary, revisionist historical movement most broadly.

\section{Objectivist and Rhapsodic Historiography}

The most pivotal debates in neosophism concern not so much who the sophists were in the past, but rather how we come to know them in the present. Historical study of the sophists is faced with an immediate and formidable methodological challenge: only scant fragments of their work survive (R. Sprague). Most of the evidence that we have about the sophists is written by their vehement adversary, Plato (Guthrie 9), and is "profoundly hostile" (Kerferd 1 ) in its treatment of them. Further complicating matters, the precise meaning of the term "the sophists" is itself unsettled, as it "does not refer to a group of closely allied thinkers, nor does sophism refer to a distinct school of thought" (Pullman 52; see also McComiskey, Gorgias 7). In light of our historical distance from these ancient rhetoricians - and in light of the paucity and partiality of our extant records-it remains difficult to fashion any historical account of the sophists, let alone a redemptive one (Consigny, Gorgias 4-10). As Keith Crome analogizes:

It is perhaps tempting to imagine that the task of [restoring the sophists] would be akin to the labour of the picture restorer: the delicate removal of the additions of later hands - the various veils imposed by more censorious eras - or the stripping away of accretions of dirt and discouloured varnish, in order to lay bare the original painting in the naked glory of its original colours. Nothing could be farther from the truth. With the sophists, to strip away the additions and accretions would simply leave nothing. (15) 
As a result, neosophistic scholars face what Scott Consigny terms "a hermeneutic aporia, or impasse, in that we appear to have no obvious means of articulating and defending a particular account" of the sophists (Gorgias 9).

At least two contradictory historiographic approaches have emerged in response to this impasse: the "objectivist" and "rhapsodic" approaches. ${ }^{2}$ These approaches stand distinct within neosophistic scholarship, and have been contested in recent debates among its scholars (notably Edward Schiappa and John Poulakos). Most broadly, these debates concern whether the practice of historiography has "more to do with making than finding, with selection and narration rather than report" (Jarratt, "Speaking" 190). The objectivist approach to the historical sophists consists largely of the methodology of traditional historiography, and it attempts to rely on factual evidence as the sole basis for its interpretation. In contrast, the rhapsodic approach denies the possibility for objectivity in historical interpretation and remains aware of the contemporary significance and application of the history it constructs.

In terms of its methodological assumptions, the objectivist approach maintains that it is possible to re-create the sophists' history in the present using data from the past, and that objective facts should

\footnotetext{
${ }^{2}$ Here I adapt and appropriate the terms "objectivist" and "rhapsodic" from Consigny's 2001 volume, Gorgias: Sophist and Artist (10-17). In spite of a general consensus regarding the makeup of these divergent approaches to historiography, there seems to be little agreement about what to call them. For instance, Schiappa refers to "historical reconstruction" and "contemporary appropriation" (Protagoras 64); Sharon Crowley refers to the "essentialist" and "constructionist" approaches ("Let Me" 8); and in an earlier work Consigny refers to the "foundationalist" and "antifoundationalist" camps ("Schipppa's" 253). Victor J. Vitanza refers to the "philological-historiographical methodology of species-genus analytics (diaresis, dividing practices)" (Negation 123), compared to "revisionary" or even "sub/versive" historiographies ("Critical"). Consigny, meanwhile, presents his own cataloging of the various titles used for these approaches (Gorgias 216n29, 216n32).
} 
determine and limit our historical understanding of sophism. This approach is perhaps best articulated by Edward Schiappa, who notes in his 1995 book Protagoras and Logos that "The object of sophistic studies [...] should be a thorough and comprehensive recovery of each Sophist's thinking as far as the available evidence permits. [...] What is needed are more data and an effort to understand sophistic thinking in its own context as best one is able" (81). As Consigny notes, the ultimate goal of this approach "is to articulate an objectively valid or 'correct' account" that is untouched by "our own biased assumptions or conceptual schemes" (Gorgias 10). An objectivist approach requires an examination of the sophist's original words (ipsissima verba) while ignoring subsequent interpretations and commentary (11). Because its goal is to reconstruct the past on its own terms, such an approach "requires some fidelity to the methods and practices of classical philology" (Schiappa, Protagoras 66).

The cardinal sin of the objectivist approach is anachronism, or the imposition of present-day frameworks onto historical data. For instance, as Schiappa contends, placing Gorgias into "anachronistic categories, like 'anti-essentialist"' is anathema to good historical scholarship (207), so too is the notion that "current theoretical pieties" (68) such as postmodernism should shape the practice of historiography. An objectivist historiography should instead aim to be "free from bonds of the present" (69) and to be innocent of larger theoretical frameworks or historiographic motives. Schiappa denies the redemptive goal of many neosophistic scholars. To him, the object of historical scholarship "should not be to redeem or condemn the Sophists, any more than the study of any ancient Greek philosopher should be to redeem or condemn a given class of thinkers" (81).

Contrasting the objectivist approach is the rhapsodic approach. Such an approach is perhaps best articulated by Susan C. Jarratt, who in 
her 1987 article "Toward a Sophistic Historiography" advances the notion of a self-consciously sophistic methodology for the study of history. Speaking of the sophists, Jarratt notes that

They created a discursive practice preceding the hardening of generic categories like "history" but always pervaded by an awareness of the historical. Thus both a general sophistic attitude toward history and specific examples of sophistic historical representation will provide the elements of a revised historiography for rhetoric. (11)

Such a historiography, to Jarratt, entails "a redefinition and consequent expansion of the materials and subject matters of rhetorical history," the eschewal of our received notions of "progressive continuity," and "the employment of two pre-logical language technai, antithesis and parataxis, [to create a] narrative distinguished by multiple or open causality, the indeterminacies of which are then resolved through the self-conscious use of probable arguments" (11).

This sophistic approach to historical scholarship resists the totalizing and reductive expectation to make history "a complete, replete, full, and logically consistent narrative record" (16). It recognizes and takes for granted that "The past is not comprehensible to the present except through intelligible frameworks; it is simply impossible to reconstruct the past as it actually was" (McComiskey, Gorgias 8). Such an approach builds historical understanding of sophistic rhetoric not just for its own sake, but with a eye toward its own present-day relevance (Hawhee 142;

McComiskey, Gorgias 55). Counter to the objectivist proscription against anachronistic interpretation, Susan Jarratt makes clear her "wish to discover who the 'sophists' are for us now" ("First Sophists" 70); similarly, John Poulakos asserts that "classical rhetoric is not only of the past and about the past. It is also about the present and most importantly about the future" ("Testing” 176). 
Debates among proponents of the objectivist and rhapsodic approaches took place primarily through the late 1980s and 1990s within neosophistic scholarship. ${ }^{3}$ In terms of the epistemic viewpoints under contention - that is, the foundationalist and antifoundationalist epistemologies (Consigny, "Edward" 253) represented by each historiographic approach - the debates can themselves be seen as a rehearsal of the ages-old dispute between sophism and philosophy. Although no apparent victors can be said to have emerged from these debates, it is clear that proponents of the rhapsodic approach have succeeded in advancing the notion - counter to received foundationalist epistemologies- that it is possible for historical scholarship to be kairotic and engaged rather than timeless and disinterested. In fact, an entire genre of scholarship has emerged in recent years employing rhapsodic historiography toward contemporary intellectual and political ends, establishing the rhapsodic approach as a legitimate scholarly strategy for addressing present-day issues.

\section{The Genre of Neosophistic Appropriation}

As McComiskey observes, "During the 1970s, 1980s, and 1990s, sophistic rhetoric traveled: it was transported from the fifth century BCE into twentieth century $\mathrm{CE}$ rhetorical theory and composition studies, and this process of transportation has enabled new 'intellectual activities" (Gorgias 57). McComiskey refers to this process of transportation as "neosophistic appropriation": the process of adapting and remolding the ancient sophists to suit the particular exigencies of the present $(55,56)$. In

\footnotetext{
${ }^{3}$ See, for instance, the works of Consigny, John Poulakos ("Interpreting"; "Rhetoric"; Sophistical; "Terms"; "Testing"; "Toward"), McComiskey, Schiappa ("Did"; "History"; "Neo-Sophistic"; Protagoras; "Some"; "Sophistic"), Richard Marback, Murphy et al., and Vitanza ("Critical"; Negation; Writing).
} 
this section I outline a handful of scholarly works within the genre of neosophistic appropriation, works that are engaged in a diverse range of contemporary intellectual and political endeavors: developing a feminist composition pedagogy (Jarratt), building connections to pragmatist philosophy and reforming English Studies (Mailloux), creating new conceptions of ethical practice for the teaching of technical communication (J. Blake Scott), and developing a deconstructive feminist "Third Sophistic" to inform rhetorical education (Ballif). Although there is great breadth in their application, these works are united in that they each seek to "'mine' sophistic doctrines and historical interpretations of these doctrines for theories and methods that contribute solutions to problems in contemporary rhetoric" (McComiskey, Gorgias 55). While the following works are hardly a complete catalog of scholarship in the genre, I believe that they are emblematic of the particular methods, motivations, and diverse applications of neosophistic appropriation.

In her 1991 volume Rereading the Sophists: Classical Rhetoric Refigured, Jarratt appropriates the sophists for a feminist project of revising composition pedagogy. Jarratt notes that "The congruence of logo- and phallocentrism places both sophistic rhetoric and woman at the negative pole against philosophy and man" (65), and she describes the significant theoretical correspondence between the feminist and neosophistic projects. She notes that the sophists speak to a number of contemporary issues in the teaching of composition, and that "analyzing the relationships among their social theory, their pedagogy, and the functioning of democracy in their time can lead to a more pointedly political evaluation of the teaching of writing in our own" (xxiv). Jarratt offers sophistic rhetoric as a way to counter the "powerful ideology of individualism [that] works against a sense of community both in the classroom and outside" (88). Taking her cue from the ancient sophists, 
Jarratt then articulates a feminist/sophistic composition pedagogy as social, political, and democratic, and "distinguished from the detachment of philosophy in its engagement in social action" (94). Such a pedagogycontra feminist pedagogies that "emphasize the nurturing role of the writing teacher" (115)—embraces conflict as a vital and distinctly feminist defining feature (see also Jarratt, "Feminism”; Jarratt, "Reflections"):

The discursive method driving both feminist and sophistic ways of negotiating change through discourse is argument, wherein rhetorical positions stand temporarily as grounds for action in the absence of universally verifiable truth. When we recognizing $[s i c]$ the need to confront the different truths our students bring to our classes-not only through self-discovery but in the heat of argumentfeminism and rhetoric become allies in contention with the forces of oppression troubling us all. (116)

Meanwhile, in his 1995 edited collection Rhetoric, Sophistry, Pragmatism, Steven Mailloux brings together a number of scholars to explore the confluence of sophistic rhetoric and neopragmatism. Citing pragmatist thinkers from both ends of the 20th century - thinkers such as C.S. Pierce, William James, John Dewey, James H. Tufts, F.C.S. Schiller, Richard Rorty, and Stanley Fish-Mailloux maintains that "neopragmatism can be viewed as a postmodernist form [or reception] of sophistic rhetoric" (2; see also Mailloux "Reception" 22). Defining pragmatism in 1909, William James writes that "All the pragmatic method implies is that truths should have practical consequences [...] the word has [also] been used more broadly still, to cover the notion that the truth of any statement consists in the consequences" (52). Pragmatist epistemic viewpoints such as these, as Mailloux and his contributors maintain, are theoretically consistent with the doctrines of the ancient sophists. As Mailloux suggests, the project of drawing connections between the two can speak to the politics of the contemporary, postmodern context: 
Collective action to change society, affirm cultural values, or reform higher education requires some agreement and a measure of solidarity. It requires a lot of give-and-take in rhetorical negotiation. It cannot be guaranteed by either rhetoric or philosophy, by rhetorical pragmatism or foundationalist theory. However, some of us working in the pragmatist tradition think that at this historical moment a strategic emphasis on the first term in each of these pairs might enhance the effectiveness of progressive political activity in and outside our academic institutions. (21; Mailloux "Reception" 41)

In his 1998 volume Reception Histories: Rhetoric, Pragmatism, and American Cultural Politics, Mailloux further articulates how sophistic and pragmatist thought can inform our understanding contemporary problems as he describes responses to the "Culture Wars" and the need for curricular reform in English Studies.

In his 1995 article "Sophistic Ethics in the Technical Writing Classroom: Teaching Nomos, Deliberation, and Action,” J. Blake Scott draws on the ancient sophists to articulate a technical communication pedagogy that is specifically concerned with ethics. He identifies the relativist epistemic stance of the ancient sophists not as "a blatant disregard of ethics, but [as] a recognition of the epistemological power of language as a sign system" (191). He suggests that the sophists' reliance on nomos, or social convention, as the basis for ethical practice can serve as a valid model for contemporary technical communication. As he contends, to treat ethics as sophistic

can empower contemporary technical writing students in at least the three following ways: 1 ) it enables students to recognize versions of truth and goodness, including their own, as culturally determined rather than physis [i.e., determined by nature]; 2) sophistic ethics requires students to deliberate about the power and consequences of their rhetoric and that of others; 3 ) through deliberation and 
responsible action, sophistic ethics invites students to participate in the development of nomoi or ethical codes.

Scott notes that the alternatives to such a sophistic conception of ethical practice "-all of which foreclose ethical debate—are to ignore ethics altogether, to compress all ethics into an utilitarian ethic of expediency, or to present an ethical system based on physis" (195). Scott concludes by calling for technical communication to incorporate "ethical enculturation" into its pedagogy by setting up internships, communicating with businesses, having students work collaboratively, teaching case studies, using class time to interrogate examples of problematic technical writing, and modeling ethical practice as teachers (196-7).

Finally, in her 2001 volume Seduction, Sophistry, and the Woman with the Rhetorical Figure, Michelle Ballif draws from the sophists (and Vitanza's earlier work with the sophists) to develop a fully deconstructive "Third Sophistic" rhetoric. Ballif contends that the work of other neosophistic scholars has only "sought to codify sophistry—to make it something - to give it being and presence" in a metaphysical sense, and to "make sophistry into a true technē not a spurious art" (64). For instance, counter to Mailloux, Ballif denies the connections between neopragmatism and sophism, claiming that neopragmatism is not sufficiently deconstructive, nor is it "sophistic enough" (183); she also sees Jarratt's redemptive, feminist attempt at neosophistic appropriation as only serving to reinforce the modernist binaries that first enable repression. Instead, Ballif offers "Third Sophistic postmodern posthuman transrhetoric(s)" (178) as a more radical alternative. This conception of rhetoric seeks to "stretch the borders of language, render the code liquid, in order to free us, sophistically, from philosophy's demands for faithful reference and undistorted communication and communities" (184). Such a model is enacted in part through Donna Haraway's metaphor of the cyborg and 
through application of the ancient concepts of metis (cunning) and kairos (timeliness). Although deeply theoretical in character, Ballifs work remains conscious of its practical application as it seeks to "question the sophists and Plato's reading of them through the lens of today —of today's argument about subjectivity, agency, and choice in critical pedagogies and composition studies" (33).

While these works are widely divergent in their applications and interpretations, they join in the common cause of translating the history of the ancient sophists into usable theories and guidelines for the present. They also demonstrate that, counter to the methodology of objectivist historiography, history can serve in a capacity beyond the mere fashioning of "objective facts" about the past. With the present study, I seek to join in the rhapsodic and appropriative spirit of these works by employing the strategy of neosophistic appropriation toward current questions and conversations within the discipline of technical communication. In the chapters that follow, I use neosophistic appropriation to connect the ancient sophists to contemporary feminist critiques of science, to articulate a feminist-sophistic methodology for the present research into technical communication certificate programs, and to engage in some rhetorical revisioning of the empirical research genre. In addition to using neosophistic appropriation to inform the methodology and method of this study, I also rely on it as a theoretical lens for interpreting its results at the conclusion of this work.

I make no pretense in this study to contributing to the important genre of objectivist historiography. In this study, I rely largely on secondary resources and contemporary commentary on the sophists, mostly works employing rhapsodic historiography or themselves contributing to the genre of neosophistic appropriation. As I discuss in chapter 3, I also attempt to remain self-consciously aware of the audiences, contexts, and 
purposes of this research; the scholarly conversations that this research addresses; and the practical ends this research will support. And while I frequently resist the foundationalist impulse toward historical particularity and facticity in this work, I believe that this permits me, in turn, to integrate and synthesize ideas in ways that can more productively speak to contemporary issues and conversations. In adopting these overall approaches, I intend to join a recent tradition in neosophistic scholarship of "transporting" the ancient sophists into the present. As McComiskey notes of the ancient sophists,

They are here with us, looking over our shoulders as we write. The sophists have had profound influences on some of the most important developments in rhetorical theory and composition studies, and to neglect their journey into the twentieth century and beyond would be first, to neglect a critical aspect of rhetoric's history and second, to neglect one of the richest historical resources. (Gorgias 141n2)

In the following chapter, I begin to describe how such a rich historical resource will, in part, inform the methodology of the present research project. 


\section{Chapter 2: \\ Toward a Feminist-Sophistic Methodology}

As I noted in the introduction, this study emerges from, and is intended to speak to, conversations within the academic field of technical communication. Among my most immediate goals is to develop data useful to certificate program administrators and to those contemplating the establishment of new certificate programs. In particular, I seek to develop basic data concerning the curricular and faculty makeup of existing certificate programs. But as I first considered the traditional, quantitative/empirical methodologies required to develop these data, I began to feel uneasy. Many aspects of these methodologies stand opposed to emerging postmodern and neosophistic intellectual positions.

For instance, in their implicit assertion of the ideologies of universal truth, objectivity, and an autonomous subject, stock phrases of the empirical research report genre such as "the data show" and "it was observed" reflect a modernist, Platonic-Aristotelian, and foundationalist orientation. I was particularly concerned that I would be compelled by the dictates of a traditional methodology to remain absent as an agentrhetorically, grammatically, and ethically—in this research. In seeming contradiction, I found myself wanting a methodology diverging from foundationalism, while simultaneously supporting broad, persuasive claims about technical communication programs nationwide. In this chapter, I describe my efforts to work out such a methodology. In particular, I describe how I find within both neosophism and feminist critiques of science the basis for new approaches toward the production of knowledge that avoid the totalizing impulses of the Platonic-Aristotelian tradition while still allowing for the positive production of usable knowledge. 
In his 1995 article, "Post-Modernism as the Resurgence of Humanism in Technical Communication Studies," Paul M. Dombrowski characterizes at least four contemporary intellectual projects emerging during the postmodern context: the rhetoric of science, social constructionism, feminist critiques of science, and ethical critiques of science. As he notes, scholars engaged with these projects

challenge specifically the notion that "facts" are supposedly absolute and pre-existent, on the grounds that this decontextualizes facts and tacitly denies the very real social contingencies that create facts. From this perspective, facts become social artifacts, products for consumption, and reinforcers of the value system from which they spring. (166).

As he contends, these four, seemingly disparate projects are united by their humanism, a concept that he defines as "the maximization of human potential, the affirmation of cultural criticism, and the rejection of rigid absolutism" (176). Dombrowski then suggests that postmodernism and humanism are themselves, in turn, linked under sophism (177). In the same spirit as this broadly integrative and important work, in this study I seek to place emphasis on the commonality of specific intellectual projects and to work at their shared borders to address contemporary conversations in technical communication.

Although I began by wanting a research methodology more consistent with emerging neosophistic and postmodern theories, I believe that much of the critical and intellectual work needed to develop such a methodology has already been performed under the aegis of feminist theory. Specifically, I believe that critiques of science found in feminist standpoint theory directly address many of the epistemological and methodological issues that I initially sought to address by way of neosophism. Further, these critiques contend directly with the traditions of 
Western science in ways that neosophism immediately does not. In order to join forces with this feminist theoretical work already underway, in this chapter I draw from - and draw the connections between - both feminist critiques of science and neosophistic perspectives to begin to craft a viable methodology for the present study. This synthetic methodology is, I contend, most aptly described as "feminist-sophistic."

Of course, others have already worked to unite these larger perspectives: Michelle Ballif relies on neosophistic theory in her deconstruction of the very ontic categories of male and female, and Susan C. Jarratt is perhaps the single commentator most defined by her work at the nexus of neosophism and feminist theory. However, I maintain that the combined potential of neosophism and certain feminist critiques of science remains largely unexplored. As I will show in this chapter, these projects already share considerable ethical, epistemological, and political common ground. In addition, the unique methodological insights of feminist critiques of science come together with the unique rhetorical insights of neosophism to suggest a powerful, antifoundationalist methodology. Not only do these projects offer productive critiques of traditional research methodologies, but, as I maintain, they ultimately suggest new alternatives for more ethical and situated inquiry.

\section{My Standpoint}

First, to shed some light on the origins of my methodology, I begin by very briefly describing my own subject position in terms of both my disciplinary/material allegiances and epistemic stance. Beginning with the personal is, I admit, anathema to a traditional understanding of methodology in which the researcher is held to be wholly independent from the act of research and the (purportedly transcendent) knowledge that research produces. However, even given the relatively straightforward design of the present empirical study, I believe that my subject position 
and my so-called "personal" stances are determining influences on the knowledge claims this study supports. It is for these reasons that I feel compelled to foreground my standpoint here.

By way of intellectual autobiography, I developed as a scholar at Midwestern, United States universities within both scientific and humanistic contexts. I hold a bachelor's degree in mathematics and computer science from the University of Illinois at Urbana-Champaign. I am currently vested in the humanities: I hold a master of arts degree in English Studies (specializing in technical writing); as declared on the cover page, this work is submitted in partial fulfillment of the requirements for a $\mathrm{PhD}$ in Rhetoric and Technical Communication from the Department of Humanities at Michigan Technological University; and I began a tenure line job in the department of Writing and Rhetoric at Oakland University in fall 2008. My material and disciplinary allegiances are primarily to the fields of technical communication, rhetoric (in the humanities tradition), and composition.

I would describe myself as a neosophist; a social constructionist; a postmodernist; and a third wave, anti-essentialist feminist. I hold that knowledge is, by definition, intersubjective, and it is socially constructed. I believe that all claims to knowledge are rhetorical, and that rhetoric is fundamentally epistemic. It should (but frustratingly, doesn't) go without saying, though: I am not a nihilist. I believe that those who see relativism and social constructionism precluding the adjudication of competing claims fundamentally misunderstand both concepts. Relativism does not mean "anything goes," and social construction does not mean "arbitrary fabrication." I believe that rhetoric, defined simply as persuasion, is not only a sufficient basis for the peaceful adjudication of competing knowledge or value claims, it is the only such basis we have ever known. As a postmodernist, I eschew notions of the autonomous individual. I 
likewise deny the modernist myth of objectivity, which holds that individuals can transparently describe a prior and independent reality. Finally, as a third wave, anti-essentialist feminist, I believe that sex, gender, and sexuality are not inviolable consequences of biological nature, but are social constructs (which-I'm compelled to repeat the caveat-does not imply that they are arbitrary constructs).

As should be apparent in the sections that follow, the above are some of the key material, ideological, and political factors that inform the feminist-sophistic methodology I seek to develop. Further, these are the factors that I inescapably bring bear on my research-whether acknowledged or not. By foregrounding these factors here, my intent is not to establish this study as subjective, unreliable, or somehow tainted by the personal. Rather, I wish to establish it as intersubjective, situated, and emanating from an identifiable subject position. Remaining ethically situated and self-consciously rhetorical in these ways are, as I show, key components of a feminist-sophistic methodology.

\section{The Methodological Complementarity of Feminism and Neosophism}

On the face of it, there would appear to be fundamental discrepancies between feminism and neosophism most broadly. As several commentators note, ascribing to the ancient sophists any particular political agenda-let alone a feminist or postmodern program - is a tenuous undertaking (McComiskey, Gorgias 75; Consigny, Gorgias 9). The patriarchal and oligarchic culture of ancient Greece can hardly be called "feminist" (Wick 27, Biesecker 99) or even "democratic" (McComiskey, Gorgias 140n2) by contemporary standards (see also Crockett 73-5). History suggests that "material reality for women in Greek antiquity was oppressive" (Jarratt, Rereading 63) and that education in this historical context "was an elitist tradition in which, for the most part, only male 
children of noble families were permitted to participate" (Crowley, "Plea" 319). In her book Speaking for the Polis, Takis Poulakos aptly summarizes why the contemporary relevance of the ancient Greeks at first appears dubious:

Classical Athens was a slave society, a place where Athenian women and non-Athenian-born males were noncitizens and where a few landowners and aristocrats maintained a stranglehold on the economy while the majority of people worked fields in the country, lived as manual laborers, or depended on the public treasury for sustenance. It was a society driven by war, expansion, conquest, and people who understood as an assertion of their own freedom the capacity to extend their borders outward and dominate others by turning them into slaves or imposing on them tributes. From the point of view of our own social values and present commitments to equality, there seems to be no connection at all, no reason whatsoever to study Classical Athens or to expect any similarities between society then and now. (2)

Drawing inspiration from the ancient Greeks-in whose "historical texts are the power relations of their day, complete with all of their cruelties and injustices" (Vitanza, Writing 118)—would initially seem antithetical not only to feminism, but to all progressive, liberatory political projects.

It's important to keep in mind, however, that the historical and theoretical precedents of the sophists do not offer a literal or totalizing model for contemporary practice-even supposing our record of them were complete enough to attempt to fashion one. Although I aim to show that the theoretical connections between neosophism and feminist critiques of science are multiple, the connections between the ancients themselves and contemporary feminist projects remain appropriative at best. Alluding to this, Jarratt notes that "though the sophists may not be 'feminists,' current feminists are becoming sophists in the best sense of the 
word by describing rhetorical solutions to the crucial problems of defining a theory with the most power for changing women's lives" (Rereading 79). As I draw connections between the two perspectives in the following sections, then, I do so not to (further) fetishize a hegemonic rhetorical history, but to critically appropriate from it in order to develop usable theories for the present.

Some commentators maintain that by directly taking on the Platonic-Aristotelian intellectual tradition, the very premise of neosophism represents a feminist political project. As Jarratt notes in Rereading the Sophists,

Indeed, Plato and Aristotle defined philosophy through the exclusion of rhetoric as the degraded term. For Plato, the sophists signified opinion as opposed to Truth, the materiality of the body (e.g., in association with cooking and cosmetics) vs. soul, practical knowledge vs. science, the temporal vs. the eternal, writing (explicitly as an artificial aid to memory) vs. speech (as the vehicle of intuited knowledge). This cluster of terms coincided on many counts with the cultural stereotype of the "feminine" operative in the West for centuries. (65)

Jarratt further notes the gendered implications of Plato's comparisons: "Both rhetoric and women are trivialized by identification with sensuality, costume, and color-all of which are supposed to be manipulated in attempts to persuade through deception" $(65) .{ }^{4}$ In their shared opposition

\footnotetext{
${ }^{4}$ For a contrasting perspective, see C. Jan Swearingen's "Plato's Feminine: Appropriation, Impersonation, and Metaphorical Polemic." While admitting that "Plato is a prime progenitor of masculine logo- and phallo-centrism" (109), Swearingen downplays Plato's apparent misogyny. Countering Jarratt's assertion that Plato's metaphors for rhetorical practice are "feminine" and trivializing, she urges us to read the metaphors and the women characters in his dialogues as more positive acts of appropriation. She notes that our tendency as modern readers to read Plato as "male" is a result of his intellectual
} 
to many of the Platonic ideals of the Western intellectual tradition, then, we can see an immediate cause common to both neosophism and feminism broadly.

But more particular aspects of neosophism overlap with feminist critiques of science as well. Voices in each project foreground the role of the social in epistemology (including in their embrace, to varying degrees, of relativism; in their critiques of modernist, scientific objectivity; and in their recognition of the social construction of knowledge). Voices in each project eschew an epistemology defined by essences, as evidenced by their common critical interrogation of the concepts nature and culture (or, physis and nomos). And finally, while both projects offer compelling critiques of our received epistemologies, they also demonstrate a commitment to developing new, more responsible forms of developing knowledge. That is, even while both projects can be considered devastating in their assessment of traditional epistemologies, unlike Derridian deconstruction and similar “acid tools of postmodern theory" (Haraway, Simians 157) both present optimism toward the possibility of meaning-making and suggest new, positive epistemologies to displace those that they critique. I discuss each of these specific areas of congruence in further detail in the following sections.

\section{A Shared Recognition of the Social Situation of Knowledge Production}

In the previous chapter, I explored the emergence of neosophism at the latter half of the twentieth century. Susan Hekman notes that, during this time, "a paradigm shift has been under way in epistemology, a movement from an absolutist, subject-centered conception of truth to a 
conception of truth as situated, perspectival, and discursive" ("Truth" 233). This paradigm shift entails a recognition that our traditional activities of knowledge production and research fall short of their purported abilities to transcend social context. As Sandra Harding notes in her introduction to The Feminist Standpoint Theory Reader,

The idea that the very best research, no less than the worst, does and should "speak" from particular, historically specific, social locations has been out of the question for standard research norms. [...] the whole point of scientific knowledge in the Modern West, in contrast to "folk knowledge," is supposed to be that its adequacy should transcend the particular historical projects that produce it or, at any given moment, happen to find itself useful. (4)

Counter to the decidedly Platonic notion of truth as eternal and prior which informs the Western model of knowledge Harding characterizes here-and consistent with the emerging paradigm that Hekman identifies - both neosophism and feminist critiques of science hold that knowledge claims are born of and bound to particular social contexts.

Many feminist critiques of science begin with the material and social aspects of knowledge production, most particularly those aspects that serve to subjugate and marginalize women. Doing more than just pointing out simple instances of "bias" or "bad science" (Haraway, Simians 186; Harding, "Introduction" 4; Harding, Science 138; Alcoff and Potter 30), however, such critiques go on to deeply problematize our received epistemologies of scientific objectivity by establishing their foundation in the material and social. As Lorraine Code notes, these feminist critiques

have demonstrated that the ideals of the autonomous reasoner-the dislocated, disinterested observer - and the epistemologies they inform are the artifacts of a small, privileged group of educated, usually prosperous, white men [...]. Their circumstances enable them to believe that they 
are materially and even affectively autonomous and to imagine that they are nowhere or everywhere, even as they occupy an unmarked position of privilege. (21)

Feminist standpoint theory (which grew from the work of Patricia Hill Collins, Donna Haraway, Sandra Harding, Nancy C.M. Hartsock, and Dorothy E. Smith, among others) further refines this broad epistemic critique by maintaining that the practices of scientific research and knowledge production are tied — materially, socially, and politically-to the subjectivity of researchers working from specific standpoints.

Early proponents of standpoint theory claimed an epistemological superiority for research performed from standpoints of the marginalized (Hekman, “Truth” 227). For instance, Allison M. Jaggar, in her 1983 article "Feminist Politics and Epistemology: The Standpoint of Women," holds that "the special social or class position of women gives them a special epistemological standpoint which makes possible a view of the world that is more reliable and less distorted than that available either to capitalist or to working-class men" (56). Jaggar continues:

The standpoint of the oppressed is not just different from that of the ruling class; it is also epistemologically advantageous. It provides the basis for a view of reality that is more impartial than that of the ruling class and also more comprehensive. It is more impartial because it comes closer to representing the interests of society as a whole [...]. (57)

As Susan Hekman maintains in her 1997 article "Truth and Method: Feminist Standpoint Theory Revisited," however, standpoint theory has evolved away from its initial impulse toward universal truth, impartiality, and privileged perspectives as found in Jaggar's position. She contends that, "The new paradigm of knowledge of which feminist standpoint theory is a part involved rejecting the definition of knowledge and truth as 
either universal or relative in favor of a conception of all knowledge as situated and discursive" (234).

Although feminist standpoint theory is multiple in its stancesand is perhaps more akin to a nuanced conversation than it is to simple sloganeering (Mann and Kelly 392) — it presents a consistent epistemic critique foregrounding the role of the social in knowledge production. Likewise, neosophistic theorists recognize within the ancient sophists a vital epistemology that, counter to our received Platonic-Aristotelian epistemologies, is discursive and socially situated. For these scholars, the sophists present an ancient historical precedent for, and a metaphorical embodiment of, epistemic critiques emerging during the postmodern moment.

The ancient sophists present some fairly direct evidenceinasmuch as our historical record of them of them can be considered "direct"- that they viewed knowledge construction as a social process. Several scholars (Mailloux, Rhetoric; Jarratt, Rereading; McComiskey, Gorgias; Pullman) point to Protagoras' famous fifth century dictum, "Man is the measure of all things" (antrhoppos metron) as evidence of a relativistic stance for Protagoras and the ancient sophists. Although there is considerable debate over the status of the word "man" as a collective noun or not (Guthrie 188; Mailloux, Rhetoric 10), it is clear from this dictum that Protagoras believed that humankind "determined the contents of reality for itself” (Pullman 54). Likewise, drawing from Mario Untersteiner, Susan Jarratt interprets Protagoras' saying “Concerning the gods, I cannot know either that they exist or that they do not exist, or what form they might have, for there is much to prevent one's knowing" ( $R$. Sprague 20) as a "Careful expression of ignorance [that] directs energy away from the search for an external knowledge source and throws the 
responsibility for determining the nature of things onto humans" (Rereading 50).

Similarly, in his volume Gorgias: Sophist and Artist, Scott Consigny analyzes Gorgias' extant fragments in order to join in the "interpretive game" of making sense of this early sophist and his doctrines. Consigny draws from The Encomium of Helen to argue that Gorgias-reflecting a trait we can see in contemporary feminist critiques-was skeptical of the practitioners of science in his day:

Gorgias does not construe science as an empirical study [...] wherein one attains an increasing approximation of the "real nature of things"; and he does not construe scientific discourse as the articulation or communication of such truths. Instead, he suggests that scientific discourse, like the discourse of poets, philosophers, and popular orators, is thoroughly rhetorical, concerned with demolishing opinions and displacing them with others. (59)

By establishing scientific knowledge-making as rhetorical in this way, knowledge production comes to be seen occurring at the sites of the communal and public. To Consigny, "Rather than originating from a solitary inward experience or a journey beyond the everyday, Gorgias indicates that the origin of his speech lies entirely within an established and recognized agon" (83). Furthermore,

The community or audience is engaged in the process of inquiry from the very inception of the agon, for it is their beliefs that demarcate the conceptual site of the inquiry. It is within the domain of the audience's beliefs that the rhetors operate, and if they "stray" from this domain of beliefs, they risk losing the contests. (84)

Ultimately then, we can see Gorgias holding truth not as emanating from individual observers in the form of empirical, objective facts, but closer to holding "truth as an endorsement awarded by a community to an account 
that it finds most persuasive" (Jarratt, Rereading 60). Neosophistic scholars find within these Gorgian epistemological stances the historical precedents for postmodern conceptions of knowledge production as socially situated and discursive. These stances are likewise common to many feminist theoretical voices.

\section{A Shared Interrogation of the Concepts Nature and Culture}

In addition to drawing our attention toward the social dimension of knowledge production, both neosophistic rhetoric and feminist critiques of science can be seen to reject an epistemology predicated on essences. This is evidenced by both projects' preoccupation with "exploring physis and nomos" (Wick 30) - that is, the respective concepts of "nature" and "culture." Of course, these two terms are of immediate concern for many feminist projects, and represent the conceptual sites of much of feminism's political agon. As Susan Hekman notes in her 1990 book Gender and Knowledge: Elements of a Postmodern Feminism:

The dichotomy between nature and culture as it has been articulated in western thought since Plato is defined by the masculine/feminine dichotomy and characterized by the assumption that woman has an essential nature that is linked in some special way to the natural world. [...] Furthermore, the notion that woman does have a special nature and that this nature does and should define her social role, is, like the link between woman and nature, rooted in the origins of western thought. (135-6)

\footnotetext{
${ }^{5}$ According to W.K.C. Guthrie, physis "can be safely translated 'nature,' though when it occurs in conjunction with nomos the word 'reality' will sometimes make the contrast more immediately clear" (55). Nomos, as Jarratt defines it, "refers to provisional codes (habits or customs) of social and political behavior, socially constructed and historically (even geographically) specific" (Rereading 74). I will move unmarked between the correlating English and Greek terms here.
} 
At issue is the extent to which difference is seen as premeditated by the natural (essentialism) or the extent to which it is socially constituted (social constructionism). Feminist considerations of this dichotomy have led to a critical examination — and in some cases deconstruction —of the very categories nature and culture.

For example, socialist-feminist critic Donna Haraway offers a potent exploration and deconstruction of the nature/culture binary in her 1991 collection of essays Simians, Cyborgs, and Women, a project to which she holds is "about the invention and reinvention of nature-perhaps the most central arena of hope, oppression, and contestation for inhabitants of the planet earth in our times" (xi). In this project, she demonstrates how conceptions of "nature" (constructed against a counterpart "culture") have broad implications for science, technology, gender, identity, sexual politics, and other significant loci of contest within feminist theory.

In an essay examining studies in biology and sociobiology, for instance, Haraway explores how our supposedly disinterested scientific study of the "natural world" serves to rationalize and reinscribe unjust human social orders. Drawing from primate bioantrhopology, biology, medicine, and elsewhere, she demonstrates how scientific, "sociobiological reasoning applied to human societies easily glides into facile naturalization of job segregation, dominance hierarchies, racial chauvinism, and the 'necessity' of domination in sexually based societies to control the nastier aspects of genetic competition" (67). In her essay "'Gender' for a Marxist Dictionary: The Sexual Politics of a Word," Haraway traces the evolution of the sex-gender distinction and its historical intertwining with the concepts of nature and culture. And, of course, her most familiar (and vivid) embodiment of the deconstructive impulse is her metaphor of the Cyborg: within this figure (among other Western binarisms) "Nature and 
culture are reworked; the one can no longer be the resource for appropriation or incorporation by the other" (151).

The ancient sophists were similarly concerned with the concepts of nature and culture, including the particular ways that these concepts came to determine social orders. As W.K.C. Guthrie notes in his volume The Sophists, the terms nomos and physis

are key-words-in the fifth and fourth centuries one might rather say catch-words - of Greek thought. In earlier writers they do not necessarily appear incompatible or antithetical, but in the intellectual climate of the fifth century, they came to be commonly regarded as opposed and mutually exclusive: what existed 'by nomos' was not 'by physis' and vice versa. (55)

As Guthrie describes it, in ancient Greece "Once the view had gained currency that laws, customs and conventions were not part of the immutable order of things, it was possible to adopt very different attitudes toward them" (21). As the conceptual distinctions emerged between nature and culture, many began to question things previously held only to be of natural or divine ordinance, such as the existence of the gods, the creation of states, divisions within the human race, the inevitability of human rule over others, etc. (57-8).

By throwing into doubt the primacy of physis in human affairs and by presenting the possibilities attendant to nomos, the sophists were able to employ "narratives to radically reconstruct their own histories in terms which opened space for difference" (Jarratt, Rereading 74). Again, while no figures in ancient Greece would likely be called liberatory or progressive by today's standards, the sophists were able to at least question the presumed natural origins of social divisions. Referring to Gorgias' Encomium of Helen, Susan Jarratt notes that 
In Gorgias's imaginative reconstruction of Helen's abduction, desire, will, and language throw open the traditional causal logic of her case and, in so doing, dislodge a mythic source for misogynism. In Protagoras's revisionary retelling of the Promethean creation myth, we find laid out the process for the social construction of identity: an explanation of how family and school teach codes which determine the modes of expression available. (Rereading 75)

Likewise, the sophist Antiphon employed the physis-nomos distinction to argue against notions of "high and low birth," and to argue that there was "no difference in nature between barbarians and Greeks" (Guthrie 24).

As practicing rhetors, the sophists knew that they only stood to gain rhetorical agency by advancing the scope of nomos, since no amount of persuasive discourse can successfully argue against immutable physis. By bringing social orders previously determined by physis into the realm of nomos, the sophists opened them up for rhetorical deliberation, and created new possibilities for their construction. Many feminist projects likewise recognize that conceptions of nature and culture determine their rhetorical agency. While not all feminisms concur, certainly many of the antiessentialist, social constructionist viewpoints found within third wave feminism work to bring social orders previously determined by nature into the realm of culture. Social orders predicated on the constructs of sex and gender are then opened for deliberation, and new possibilities are created for their construction. These shared interrogations of the concepts nature and culture concern more than just social and political possibilities, though: they also reflect a antifoundationalist epistemology common to voices in feminist theory and neosophism. By recognizing the fluidity and constructedness of the categories nature and culture, these voices can be seen rejecting an epistemology predicated on the notion of inviolable and immutable essences. 


\section{A Shared Optimism and Commitment to New Epistemic Projects}

Finally, even while critical of traditional epistemologies, voices from feminist critiques of science and neosophism are consistent in their optimism toward the possibility for meaning-making and-unlike certain postmodern projects-attempt to create new frameworks for the creation of knowledge. Neosophism, in spite of the overall epistemological relativism it presents, can be seen as very much concerned with the creation of (if not eternal, then at least provisional) truths. Likewise, several feminist critiques of science work to fashion new and productive models for research, even as they stand in critical opposition to traditional methods. Both of these critical approaches, in turn, suggest positive responses to the epistemic dilemmas presented by postmodernism.

As Consigny notes, the prospects of a sophistic epistemology may at first seem to be quite dismal: If Gorgias

repudiates the foundationalist notion that there is a truth in the world that is independent of our contingent discourses, it would seem that he rejects the possibility of truth, knowledge, and meaningful discourse altogether. As such, he would seem to abandon us to a radical solipsism, in which we are not only prevented from apprehending anything about the world itself, but in which we are prevented from experiencing kairotic moments that are replete with meaning. Unable to apprehend or experience the truth, we would appear to be condemned [...]. (73)

But Consigny contends that this is not the actually the case, as Gorgias views the agon as a viable and meaningful source of truth (73-4). Likewise, as Jarratt notes, "Despite the radical propositions of On the Nonexistent, often taken to lead to complete solipsism, Gorgias does not deny any possibility for communication" (Rereading 55). And Bruce McComiskey suggests that, "Although Gorgias is clearly an ontological skeptic, he is 
not, as is often incorrectly assumed, an epistemological skeptic" (Gorgias 35; "Toward" 8). These characterizations run counter to many prevalent depictions of Gorgias as a "glib nihilist who advanced no positive theories" (Enos 73).

Similarly, sophistic theory productively addresses a more recent epistemic impasse. In her 1992 article "The Praise of Folly: The Woman Rhetor, and Post-Modern Skepticism,” Patricia Bizzell notes that, while the perspective of Derridian deconstruction is "a liberating one, freeing us from oppressive traditional sexisms, racism, classisms, and other culturally sanctioned forms of discrimination and exploitation" (14), it nonetheless

seems to tear down without building up, to undermine our confidence in the possibility of shared mental powers and egalitarian values that would enable people to work toward a new and more just social order. [...] Enveloped by an otherwise anti-position-taking theoretical climate, we nevertheless find ourselves wanting to advocate positions. (14-15).

Bizzell's critique is that deconstruction appears to leave little space left for political agency; she compares the postmodern stance to Pyrrhonian skepticism: a radical form of skepticism that doubts whether anything can ever be known at all (9).

In his 1996 article "Toward a Neosophistic Writing Pedagogy," Kenneth J. Lindblom directly responds to Bizzell's critique. As a solution to the apparent impasse presented by postmodern deconstruction, Lindblom suggests turning toward "the early Greek sophists," who he believes "offer a theoretical base to Bizzell and all of us who are interested in professing left-oriented values in our writing classrooms" (93). Developing "a sophistic understanding of the progress of knowledge," he suggests, "can enable us to avoid the trap of Pyrrhonian skepticism" (93). 
Lindblom demonstrates specific teaching methods that he considers to be sophistic in construction, and concludes by asserting that

The constant attention to the sociopolitical construction of knowledge that a neosophistic pedagogy demands explicitly and unquestionably interconnects the operations of communities and the operations of writers, making sociopolitical action not only a valid element but a necessary component of composition curricula. (105)

The answer to the postmodern impasse for Lindblom, then, lies in the historical precedent of the sophists. Again, while he speaks specifically about their application in composition, we can see Lindblom's turn toward the sophists suggesting a broader, productive epistemology beyond the classroom. To him, the sophists represent a legitimate source of political agency, and authorize us to take stances and hold values in Derrida's deconstructive wake.

The sophists and neosophism can ultimately be seen as retaining an optimism toward the possibility of persuasion and truth, an optimism that is alien to deconstruction. ${ }^{6}$ As Jasper Neel maintains, "In contrast to Derrida [...] the sophists allow themselves to be persuaded by an argument, while never forgetting the inadequate, deceitful foundation that enabled

\footnotetext{
${ }^{6}$ I do not intend to imply a dualism between neosophism and Derridian deconstruction - these antifoundationalist projects are in many ways quite complimentary. In fact, Victor J. Vitanza warns us against dividing the two in his 1997 volume Negation, Subjectivity, and the History of Rhetoric: "Those of us in rhetoric $\mathrm{im} /$ proper need to understand that the argument to reject deconstruction would be comparable to the argument to reject rhetoric itself because it has no content, truth, and politics!" (213). (Vitanza's playful, punning, and sometimes frustrating writing style echoes Derrida's own, and is intended to remind us that postmodern academic prose styles find historical precedent in the dithyrambic, "Gorgian" oratory style of the ancient sophists.) Derrida himself, however, does not see deconstruction as a new sophistic project. In his Dissemination he notes that the work is "at no time spurred on by some slogan or a password of a 'back-to-the-sophists' nature" (108).
} 
the argument" (207, emphasis added). To Neel, sophism embraces the possibility of meaning-making, but as he also clearly implies, this optimism does not come at the expense of its central criticalness.

Feminist standpoint theory similarly retains an optimism toward the possibility of knowledge creation, even as it is critical of traditional epistemologies. Much like Bizzell, Haraway is also troubled by the postmodern impasse. In her much-cited article "Situated Knowledges: The Science Question in Feminism and the Privilege of Partial Perspective" (first published in 1988), Haraway writes:

I, and others, started out wanting a strong tool for deconstructing the claims of hostile science by showing the radical historical specificity, and contestability, of every layer of the onion of scientific and technological constructions, and [instead] we end up with a kind of epistemological electro-shock therapy, which far from ushering into the high stakes tables of the game of contesting public truths, lays us out on the table with self-induced multiple personality disorder. (Simians 186)

Like Bizzell, Haraway is troubled by how the "acid tools of critical discourse in the human sciences" (185) have seemingly eaten away at the foundations of political agency and our grounds for making claims to knowledge. She articulates the dilemma facing us as "how to have simultaneously an account of radical historical contingency for all claims" on one hand, while retaining "a no-nonsense commitment to faithful accounts of a 'real' world" on the other hand (187).

Haraway's response to this dilemma is to develop a critical, yet positive epistemology, which she articulates as feminist objectivity rooted in situated knowledges. In such an epistemology, rather than being minimized or ignored as in traditional Western approaches, attention is actually drawn toward the subjectivity and situatedness of the knowledge producer-so that "partiality and not universality" then becomes "the 
condition of being heard to make rational knowledge claims" (195). She notes:

All Western cultural narratives about objectivity are allegories of the ideologies of the relations of what we call mind and body, of distance and responsibility, embedded in the science question in feminism. Feminist objectivity is about limited location and situated knowledge, not about transcendence and splitting of subject and object. In this way we might become answerable for what we learn how to see. (190)

Haraway then identifies a historical precedent for the epistemic practice that she describes. Parallel to Neel's characterization of a sophistic epistemology that recognizes the "deceit" inherent to all knowledge claims, Haraway notes that "The Coyote or Trickster, embodied in American Southwest Indian accounts, suggests our situation when we give up mastery but keep searching for fidelity, knowing all the while we will be hoodwinked" (199). Although the models and metaphors that Haraway offers are decidedly positive, as with neosophism, their optimism toward meaning-making does not come at the expense of their central criticalness.

Haraway joins a number of other feminist critiques in adopting such an optimistic epistemic stance. In The Science Question in Feminism, Sandra Harding writes:

I do not wish to be understood as recommending that we throw out the baby with the bathwater. We do not imagine giving up speaking or writing just because our language is deeply androcentric; nor do we propose an end to theorizing about social life once we realize that thoroughly androcentric perspectives inform even our feminist revisions of the social theories we inherit. Similarly, I am not proposing that humankind would benefit from renouncing attempts to describe, explain, and understand the regularities, underlying causal tendencies, and meanings 
of the natural and social worlds just because the sciences we have are androcentric. (10).

Even while participating in a direct critique of traditional scientific and empiricist methodologies, Harding asserts the "need to work out an epistemology that can account for both this reality that our best knowledge is socially constructed, and also that it is empirically accurate" ("Introduction" 12). She offers her own critical, yet productive epistemology through the notion of strong objectivity: a feminist epistemic stance which sees knowledge as "fully saturated with history and social life rather than abstracted from it" ("Rethinking" 128).

Similarly, Kathi Weeks asserts the possibility of political agency and meaning-making when she notes our desire to "endorse the critiques of humanism, functionalism, determinism, and essentialism without denying the possibility of agency" (181). As Susan Hekman notes, "the postmoderns are correct: we live in a world devoid of a normative metanarrative. But we can offer persuasive arguments in defense of our values and the politics they entail" ("Truth" 238). And as Linda Alcoff and Elizabeth Potter maintain, feminist epistemological projects have "sparked a determination to reconstruct epistemology on newer, more self-conscious ground" (3). So, while many feminist critiques are damning of our received epistemologies, they also express a consistent optimism toward the prospect of political agency and toward the possibility of knowledge construction. This optimism, which is shared with many neosophistic projects, stands as a compelling response to the postmodern impasse.

\section{Conclusion}

By showing - in parallel — the epistemic traces common to both feminist critiques of science and neosophism, my intent in this chapter has been twofold. First, I have sought to establish the overall methodological complementarity of these two intellectual and political projects. Second, I 
have sought to describe the epistemic assumptions upon which a feministsophistic methodology is based. Such a methodology explicitly foregrounds the role of the social in epistemology; denies any notion of inviolable essences as the basis for epistemology; and not only remains optimistic toward the possibility of meaning-making, but works actively to create new epistemologies. Such a methodology stands in opposition to traditional, foundationalist methodologies predicated on the modernist notions of the autonomous subject and objectivity. In the next chapter, I will work from the feminist-sophistic ideals sketched in this chapter toward enacting them rhetorically in method. As I show, such a method demands new critical attention to the ethical posture of researchers and their presence as an agent within published research, demands recognition of the practical disciplinary contexts that researchers address, and demands a vigilant awareness of the rhetoricity of all scholarship. 


\section{Chapter 3: \\ Rhetorically Enacting a Feminist-Sophistic Method}

In the previous chapter, I described the overall epistemic stance that informs this study. I argued that the connections between neosophism and feminist critiques of science are multiple and complimentary, and, taken together, these perspectives suggest the need for new epistemologies to displace our received Platonic-Aristotelian tools for knowledge production. I noted my wish to join feminist and neosophistic projects not only in their critical opposition to many traditional epistemologies, but also in their optimism toward the possibility of meaning-making and their efforts to actively develop new ways of knowing. But most importantly, I wish to engage in the sort of situated, ethical research that I find these projects endorsing. In this chapter, I work from the feminist-sophistic principles described in the previous chapter to describe their enactment in method. More specifically, I describe how these principles are realized in terms of the rhetorical stance I assume as a researcher.

My primary goal as a rhetor-researcher is to avoid what Donna J. Haraway terms the "god-trick": the act of producing knowledge that pretends "to be from everywhere and so nowhere, to be free from interpretation, from being represented, to be fully self-contained or fully formalizable" (Simians 196). Similarly, paraphrasing Gorgias' On Nature or the Non-Existent, Bruce McComiskey asserts that in the genre of neosophistic appropriation,

Historical reality does not exist in any essential form; even if historical reality exists, historians can not know it except through the process of interpretation; even if historians can 
know historical reality as it exists external to interpretation, they cannot convey that historical reality to another person, since language, like reality, is always interpreted. (Gorgias

56)

More pointedly, he notes, reality "is always already a politicized representation with no originary presence" (80). Drawing from both feminist and neosophistic stances, I attempt to remain mindful in this study of the fact that the contemporary historical instance I examine "does not exist in any essential form," and that even if it did, I "can not know it except through the process of interpretation" (56). To attempt otherwise, as Haraway might note, is to attempt the god-trick. It is the ethical and rhetorical posture of the god-trick that I believe a feminist-sophistic method is ultimately articulated against.

In composing this study, I have done my best to avoid the rhetorical moves common to god-trick scientific narratives. I try to resist using the passive voice to disguise my own interpretive role as a researcher, and I try to avoid the other familiar conceits of academic and scientific report genres that would serve to obscure this study's constructedness. I attempt to couch my findings not as universal truths, but as paths for moving forward in the conversation of a disciplinary community. And I try to remain self-consciously aware that this study is a thoroughly rhetorical act - it is only a single, (hopefully) persuasive account that I've composed for specific audiences and specific purposes. I believe that these approaches, which I will discuss in detail in the following sections, are necessary to remain consistent with the feminist-sophistic principles I outline in the previous chapter.

\section{A Caveat}

I begin with a caveat. Although I adopt a critical stance toward traditional scientific epistemologies_-and I take notable departures from 
traditional scientific methodologies-I do not wish to contribute to facile generalizations and stereotyping about the epistemic activities of the sciences, or to reduce nuanced considerations of epistemology to "us vs. them" battles over academic turf. From C. P. Snow's "two cultures," to the Sokal Affair and the "Science Wars" of the 1990s, there is no shortage of recent warrants to further dichotomize the scientific and humanistic perspectives. As Haraway bemusedly confesses, she has, at times, held her own "paranoid fantasies and academic resentments" toward those in scientific fields:

The imagined 'they' constitute a kind of invisible conspiracy of masculinist scientists and philosophers replete with grants and laboratories; and the imagined 'we' are the embodied others, who are not allowed not to have a body, a finite point of view, and so an inevitably disqualifying and polluting bias in any discussion of consequence outside our own little circles, where a 'mass'-subscription journal might reach a few thousand readers composed mostly of sciencehaters. (Simians 183)

But like Haraway, I wish to move beyond the scenario depicted in such a characterization, and to avoid relying on "the mythic cartoons of physics and mathematics-incorrectly caricatured in anti-science ideology as exact, hyper simple knowledges - that have come to represent the hostile other to feminist paradigmatic models of scientific knowledge" (196). I do not want to articulate a feminist-sophistic method against inaccurate or unfair depictions of what goes on "on the other end of campus."

In fact, despite my own situation within the humanities, I would concede that in many ways knowledge produced in the sciences can be more self-consciously social, timely, and assailable than knowledge produced in the humanities; likewise, scientific research practices can in many ways be more situated and responsible. Here I turn to the example of 
our respective academic editorial styles, the most popular of which are the Modern Language Association (MLA) style and the American

Psychological Association (APA) style. These styles, I believe, reflect some of the central epistemic presumptions and scholarly values of the humanistic and social scientific traditions. ${ }^{7}$ In her 2000 volume Composing Research: A Contextualist Paradigm for Rhetoric and Composition, Cindy Johanek notes that the use of MLA style in rhetoric, composition, and literature makes research in those fields appear timeless and unassailable. The MLA style manual's insistence on using the present tense lends cited research an aura of eternality, a grammatical feature that suggests "Once it is published, it's published. It's 'there.' Forever" (191). As Johanek notes, MLA style

ties the theories, research, and pedagogies to their authors in the present tense as if those authors still believe-still currently "live" in-that theory, research, and pedagogy. In other words, the present tense that MLA requires for treatment of text, is transferred instead, in composition, to treatment of authors. As a result, our criticism, citations, and use of composition scholarship locks the author-rather than the text-in present tense. (191)

\footnotetext{
${ }^{7}$ Robert R. Connors provides a compelling account of the history and significance of academic citation practices in his 1998 and 1999 articles "The Rhetoric of Citation Systems, Part I: The Development of Annotation Structures from the Renaissance to 1900" and "The Rhetoric of Citation Systems, Part II: Competing Epistemic Values in Citation.” In these articles, Connors works to reveal the material, political, epistemic, disciplinary, and practical factors that determine scholarly citation practices. As he notes, while these practices have "silently undergirded the enterprise of Western intellectual activity" and "Though these systems constrain many of the ways we deal with each other and each other's work, they have largely gone unremarked" ("Part II" 242).
} 
At least the within the field of composition, she advocates the use of APA style, which instead permits the use of the past and present tenses for different contexts and purposes.

This seemingly minor editorial feature is quite telling. Much scholarly work in the humanities, whether consciously or not, reflects a Platonic epistemology by adhering to MLA style. Contrary to the sophist's goal of inducing time-bound, kairotic beliefs within an audience through rhetoric, Plato insisted on the philosophic goal of discovering eternal knowledge (Truth) through dialectic (irrespective of any audience or particular "knower"). The use of the present tense in MLA style is arguably a latter-day incarnation of Plato's insistence on the eternality of knowledge claims achieved through dialectic: to Plato, true knowledge transcends time. Meanwhile, the use of the past tense in APA style-not to mention its explicit foregrounding of publication dates within parenthetical citations - can be seen as a sophistic epistemic trait: it reflects an informing presumption in the social sciences that knowledge claims are temporary, assailable, time-bound, and even kairotic. ${ }^{8}$

Similarly, the use of MLA style in the humanities can be seen to counter feminist epistemologies. Feminist standpoint theory and the notion of situated knowledges suggest an explicit foregrounding of the subjectivity and positionality of the researcher. By asserting the

\footnotetext{
${ }^{8}$ In describing why scientific disciplines were among the first to abandon footnote citation styles, Robert R. Connors notes that

footnote dating obscures chronological relationships, making assessments about authorial relations and cumulating knowledge more difficult. For the sciences, this lack of easy chronological access was keenly felt, because new scientific discoveries do displace older ones, and footnotes by 1900 were becoming a very troubling and cumbersome way to report that reality. ("Part II," 223)
} 
timelessness and context-independence of scholarly literature through use of the present tense, the MLA style precludes the very sort of contextual foregrounding that these feminist critiques advocate. The APA style, by contrast, at least permits scholars and their ideas to be contextualized chronologically by tense.

The use of verb tense in our academic styles is admittedly only one small example - but I believe it demonstrates why it would be unfair and inaccurate to critique the epistemic speck in the eye of the sciences (from either a feminist or sophistic stance) given the log in the eye of the humanities. As humanistic scholarship practices show us, a foundationalizing impulse is not the hallmark of traditional science alone. So I offer the disclaimer that the feminist-sophistic methods I describe should be seen as articulated against not only traditional scientific methods, but against foundationalism inscribed in any disciplinary tradition.

\section{Remaining Present in the Text}

In rhetorically enacting a feminist-sophistic method, I first attempt to avoid composing this study in ways that conceal my role as a researcher, beginning with grammatical agency. As Joey Sprague notes in her 2005 volume Feminist Methodologies for Critical Researchers: Bridging Differences,

Passive voice does not just hide the agency of the researcher; explanations in the passive voice hide social power. [...] In passive voice, people are fired or impoverished, or rebellions are crushed. There may be victims, but there are not clear agents, no one to whom we can assign responsibility for outcomes. [...] Using passive voice when there are clear agents amounts to hiding the exercise of power. (24) 
Although I hold no illusions about the gravity of the research I present here- or about the power I hold as a graduate researcher in an obscure scholarly niche-I do want to ensure that I remain present as an agent in the text of this study. I intend to accomplish this in part by using the active voice and the first person singular consistently in this work, with the marked exception of a section appearing near the end of the study.

Although stylistically this approach may be at odds with accepted academic and scientific report genres, I intend for my subtle shift in grammatical agency to carry with it a (likewise subtle) shift in ethical agency. As Haraway notes in her call to develop a feminist objectivity rooted in situated knowledges, "Feminists don't need a doctrine of objectivity that promises transcendence, a story that loses track of its mediations just where someone might be held responsible for something, and unlimited instrumental power" (Simians 187). By "appearing" grammatically within the text of this study, I hope to write a story where my mediate role is foregrounded and my subjectivity is evident, and I hope to at least begin to remain accountable in the way that Haraway calls for. ${ }^{9}$

My use of the active voice and the first person are also consistent with a sophistic theoretical orientation. In his 1988 volume Plato, Derrida, and Writing, Japer Neel explores how voice and textual "presence" work within Plato's Phaedrus. He notes that "Perhaps Plato's most brilliant insight was to realize how difficult disputing his texts would be if he removed himself from them by taking on the role of recording secretary for the martyred, authoritatively dead Socrates" (9). Plato, he notes, is

\footnotetext{
${ }^{9}$ To be sure, I am not calling for textual presence in the sense of an "authorial voice" or "personal style." The individualistic and modernist assumptions attendant to these expressivist ideals, I hold, ultimately contradict my feminist-sophistic stance. For a thoughtful consideration of the personal voice in scholarship, see Johanek, ch. 7.
} 
utterly absent as an agent within the Phaedrus $(15,17)$, representing a written style and ethical posture intended to "Have us believe that no one is in control, that it is a disinterested movement toward truth set in operation and kept in motion by the power of dialectic as exercised by the superior philosopher, Socrates" (14).

Plato's absence/deferral of agency in the Phaedrus represents a historical precedent for our inherited academic and scientific writing styles—styles that likewise project a character of innocence and disinterestedness through the artful determination of voice and agency. Neel, like Sprague, identifies within such writing the machinations of power:

Undeniably, Platonic writing has a powerful attraction. Those who embark on it can believe themselves to have superior souls, souls that wish to escape the limitations of the human condition. Merely embarking on the never-tobe-completed journey toward truth sets these people apart as philosopher-kings who can revel in the satisfaction of knowing their love of wisdom should place them in roles of social authority. (97)

By attempting to give up the passive, disinterested voice of the Platonic writing style, I hope to shed any indications of a metaphysical orientation or any aspirations to the superior status of a philosopher-king.

This sophistic move potentially threatens my most immediate rhetorical goals: by taking this approach, I will give up the suasive power attendant to an objectivist, disembodied textual voice. Whatever rhetorical power my argument can be said to have, then, will remain a closer function of the ethos I actively work to develop in this study, rather than the ethos I work to disguise. As I hope to show in the course of this study, this apparently weaker role not only represents a more ethical and accountable 
means of knowledge production, but it can also represent a persuasive, reliable, and ultimately truthful account of our shared experience. While using the active voice and the first person are admittedly minor grammatical moves, I believe their ethical, epistemic, and rhetorical consequences are appreciable.

\section{Remaining Grounded in a Practical Disciplinary Context}

Second, I attempt to couch the results of this study not as universal truths, but as paths for moving forward in the conversation of a discipline-specifically the discipline of technical communication. As I alluded to in my introduction, Mailloux and other scholars have argued that there is a notable complementarity between sophism and pragmatist philosophy (Rhetoric). Pragmatism holds that

the whole "meaning" of a conception expresses itself in practical consequences, consequences either in the shape of conduct to be recommended, or in that of experiences to be expected, if the conception be true; which consequences would be different if it were untrue, and must be different from the consequences by which the meaning of other conceptions is in turn expressed. (William James, qtd. in Mailloux, Rhetoric 4)

Contrary to a Platonic stance holding that the pursuit of knowledge is its own reward and that the discovery of knowledge is its own justification, pragmatism asserts that the very notions of knowledge and theory are always already circumscribed and determined by their practical application. Rather than aspiring to the status of transcendent and eternal truth, knowledge and theory instead find their significance only when articulated against specific problems within specific contexts.

Like pragmatism, a sophistic epistemology is concerned with the practical effects of the knowledge it produces. As Michael C. Leff notes in 
his 1987 chapter "Modern Sophistic and the Unity of Rhetoric," "Sophistic implies a pluralism in which methods of inquiry and argument are adapted to the particular subject under investigation. It seeks to solve situated problems rather than to formulate abstract theoretical principles" (24). He goes on to note that

The philosophy of action advocated by both the ancient and modern sophists has little meaning until it engages specific activities. Sophistic is a field-dependent approach that relies on concrete [as opposed to abstract] models. Thus, the coherence of the program requires the generation of a model that encompasses the unity of form and content, of perspective and action, in respect to some domain of practice. (24)

The study I am composing, then, should not be seen as engaging in the production of abstract, theoretical knowledge for knowledge's sake. Rather, this study emerges from specific scholarly conversations arising within the context of the North American, postmillennial, academic field of technical communication. It seeks only to meet the practical needs of that field and to solve a finite number of problems relevant to its members. Far from a contemplative, disinterested search for a universal or totalizing Truth, this study self-consciously emerges from - and is intended to speak to- the practices of this specific scholarly community.

In a similar fashion, feminist critiques of science also serve to draw our attention to the practical ends of research and knowledge making. As Linda Alcoff and Elizabeth Potter note in the introduction to their 1993 collection Feminist Epistemologies, feminist scholarship first emerged in practical, "applied" academic fields such as applied ethics. As they note, it is no coincidence that these fields 
were and are viewed by most professional philosophers as "on the periphery" of central philosophical work, where the virtue of centrality is accorded to work with a greater degree of abstraction from concrete material reality and with pretensions to universality. Feminist philosophers began work in the applied areas because feminism is, first and last, a political movement concerned with practical issues, and feminist philosophers understood their intellectual work to be a contribution to the public debate on crucial practical issues. (2)

Reflecting their own political origins, then, many feminist projects eschew the conception of epistemology as idle abstraction in favor of its conception as active, practical engagement.

In their article “Are 'Old Wives' Tales' Justified?” Vrinda Dalmiya and Linda Alcoff offer a vivid illustration of the dangers of separating the act of knowledge production from its practical ends. Here they relate the historical example of midwifery's displacement by medical obstetrics, which had disastrous effects on quality of care for women:

In Europe, when physicians were finally able to wrest obstetrics from the monopoly of the midwife, the result was an epidemic of death for the mothers. The cause was puerperal, or "childbed," fever, which afflicted women by the thousands across European cities in the nineteenth century. This fever was produced by the unclean hands of the birth attendant, and although midwives at the time were just as ignorant as physicians about the bacterial sources of diseases, they had the advantage over physicians in that they saw no other patients and were unlikely to carry germs from dying patients to the absorptive tissues of the open womb. (222-23)

The significance of this story, Dalmiya and Alcoff note, is that the epistemic and professional success of obstetrics was in no way predicated 
on its practical success-it held no instrumental advantage over midwifery. Rather, obstetrics' success was held in delegitimizing the practical, noncodifiable knowledges of the midwife, and by extension, delegitimizing their profession. It was, as Dalmiya and Alcoff note, simply a "triumph of propositional knowledge over practical knowledge" (223).

This historical example demonstrates how traditional epistemologies can serve to render invisible other valid and successful practical knowledges. It demonstrates that the preoccupation with disengagement and abstraction found in Western scientific epistemologies carries with it clear moral and ethical consequences. And it cautions researchers against separating the creation of knowledge from the practical ends of that knowledge. As Dalmiya and Alcoff note:

Knowing is not necessarily a matter of saying and representing what is the case but can also be a kind of practical involvement with the world. So the short and direct route of justifying the cognitive import of knowing how is to simply take the bull by the horns and deny the watertight distinction between the pragmatic and the epistemic. (235)

In composing this study rhetorically, I attempt to remain mindful of this conception of knowing, as well as the consequences of ignoring the practical roots of knowledge claims. The pragmatic orientation common to both feminist theory and neosophism informs this study by cautioning me to remain attentive to the specific audiences and contexts that I intend this study to speak to, and the specific problems that I intend for it to address. So rather than articulating the findings of this study as revealed universal truths or transcendent theories, I hope the rhetoric of this study will instead reflect humbler aims: to help administrators, scholars, and teachers in the field of technical communication better understand baccalaureate 
and certificate programs and to help them achieve practical ends within their own contexts (such as making decisions about the programs they administer, marshaling arguments for material support, benchmarking their programs, etc.).

\section{Remaining Aware of the Inherent Rhetoricity of Scholarship}

Finally, I try to remain self-consciously aware of the fact that this study, like all studies, is thoroughly rhetorical. In his 1966 article "On Viewing Rhetoric as Epistemic," Robert L. Scott argues that rhetoric is more than simply "a matter of giving effectiveness to truth," but rather of actually "creating truth" (135). By suggesting the possibility of an epistemic role to rhetoric, Scott's article went on to spark an extensive awakening to the role of rhetoric in the human sciences, and launched what is known as the "rhetoric of science" movement. This body of scholarship emerged from speech communication during the 1970s (Mailloux, Disciplinary 26), but draws on voices from a number of disciplines to describe the persuasive functioning of scientific research and academic scholarship (Kinneavy 197-8).

As Herbert W. Simons notes in his 1990 introduction to The Rhetorical Turn: Invention and Persuasion in the Conduct of Inquiry, it isn't just "that scientific discourse is inherently rhetorical at the point of paradigm clash" (8) - that is, the point at which new theories must gain sufficient assent to displace older, disproven theories. Rather,

Broadly speaking, virtually all scholarly discourse is rhetorical in the sense that issues need to be named and framed, facts interpreted and conclusions justified; furthermore in adapting arguments to ends, audiences, and circumstances, the writer (or speaker) must adopt a persona, choose a style, and make judicious use of what Kenneth 
Burke has called the "resources of ambiguity" in language.

(9)

Following this central premise of the rhetoric of science movement, the present study can only claim to be what all scholarship is: a rhetorical act. This study cannot claim to articulate universal truth; its persuasive effect very much depends on the rhetorical variables of audience, context, kairos, and to prepon. This study also cannot claim to be equally persuasive to all audiences; I do not presume that those who remain unpersuaded by the logic of this study (as, say, an articulation of universal reason) are defective. Instead, this study only claims to be a concerted attempt to coalesce my own disparate observations, and the observations of others, into an account that is persuasive to a specific scholarly audience in the field of technical communication.

By asserting the inherent rhetoricity of this study, I don't mean to suggest that it's only “mere” rhetoric-I don't, in other words, hold that this study is just a load of opportunistic, untethered blather. Rather, in asserting the rhetoricity of this work, I believe I also assert its fundamental connections to an audience and-socially constructed as they may be-the standards that audience holds for what constitutes a persuasive claim. Asserting the rhetoricity of this work in no way constitutes license to arbitrarily write my own epistemic and scholarly conventions; rather, it is a reminder that I defy existing conventions only at my own rhetorical peril. I believe this approach to be both rigorous and ethical.

Although by foregrounding this work's status as rhetoric I open myself up to the charge that I'm unconcerned with methodological rigor, I believe that this is not the case. By abandoning the powerfully suasive godtricks of a disembodied scholarly ethos, I believe that I am compelled to state my case even more explicitly than I would be otherwise. That is, 
rather than relying on the god-trick to present an infallible account of the "real world," my accounts must instead be couched solely in terms of my, and my audience's, justifications for knowing. At no time can I defer the proclamation of knowledge to an invisible, textual deity. My "presence" as a fallible researcher in the text of this study, I believe, actually encourages more rigor, since it invites my audience to doubt me and my accounts in a way that the god-trick does not.

Likewise, by foregrounding this work's status as rhetoric, I open myself up to the millennia-old charge that I'm unconcerned with ethics. That is, if this study is "nothing more than" rhetoric, surely I as the rhetor must be concerned with "nothing more than" winning assent at any cost. However, my desire to succeed rhetorically within the specific, socially situated agon that this study speaks to compels me toward ethical action: it compels me to articulate my argument in terms of the values held by my audience. As Jarratt notes, the etymology of the word "ethics" reminds us of their connection to the social: "ethics," she notes "are inseparable from ethe, a word meaning 'haunts,' or, even more colloquially, 'hang outs' and by extension 'habits' or 'practices." (Rereading 96). What constitutes the standard of ethical action for this study, then, are the values common to the "haunt" that I inhabit and speak to: in this case, a community of careful, committed, and critical scholars in the academic field of technical communication.

This audience would rightfully be alarmed-and would ultimately discount my arguments — if, say,

- I showed no evidence of obtaining Institutional Review Board (IRB) oversight for my research;

- if my survey didn't live up to the commonly accepted standards of research design; 
- if I presented hasty, illogical, or irresponsible conclusions from the data I develop;

- if I demonstrated significant conflicts of interest; or

- if I committed any one of countless other ethicalmethodological transgressions determined by the discursive community of academic technical communication.

I want to be absolutely clear, however, that my concern with the values of this community are not just instrumental: I don't follow these ethical guidelines simply because I stand to win or lose a particular argument, or because I stand to craft a persuasive claim or not. I am concerned with these values because, as a member of the discursive community of academic technical communication myself, they are my values as well. As Jarratt's etymology reminds us, what I describe above aren't simply ethos problems - they are substantial ethics problems.

Although the relativist ethical stance I am describing can seem terrifying to staunch foundationalists (see Harris), I, for one, take comfort knowing that the values I speak from (and to) are shared, and not the product of a pernicious solipsism. As R. Scott reminds us, the alternative to a socially oriented stance is dangerous: "The man $[$ sic $]$ who views himself as the instrument of the state, or of history, or of certain truth of any sort puts himself beyond ethical demands, for he says, in effect, 'It is not I who am responsible"' ("On Viewing" 137). It bears pointing out that the stance Scott characterizes here is, in essence, the god-trick. Contrasting such a stance, he notes, "one who acts without certainty must embrace the responsibility for making his acts the best possible" (137). It is this very sort of accountability that the feminist-sophistic method in this study aspires to. 
Finally, by asserting the rhetoricity of this work, I believe that I also assert the collective role we play in the social construction of our ethics. In other words, by foregrounding the epistemic function of persuasion in this study (rather than using the god-trick to obscure it), I believe I also draw attention to how we collectively maintain (or as necessary, resist and revise) what we count as persuasive- that is, what we decide to value. To Scott, this sort of collective participation is vital: "Inaction, failure to take on the burden of participating in the development of contingent truth, ought to be considered ethical failure" (16). Following this, it is my contention, and the contention of many feminist and neosophistic voices, that the time has come to resist and revise certain aspects of our received scientific and academic methods. As a necessary first step toward such revision, I argue, we must foreground the mutability and rhetoricity of our methods.

In this chapter, I have sketched a number of pathways for rhetorically enacting a feminist-sophistic method. Admittedly, they represent only small starts toward the end of realizing a more embodied, situated, and ultimately ethical epistemology; my shifts in written style and rhetorical and ethical posture do not, in their sum, represent an entirely radical overhaul of our received methods of knowledge production. In fact, I suspect that the chapters that follow may come across as more evolutionary than revolutionary. But as Elizabeth Fee notes, simply imagining - let alone realizing - a wholly feminist epistemology may be impossible in the current androcentric paradigm:

For us to imagine a feminist science in a feminist society is rather like asking a medieval peasant to imagine the theory of genetics or the production of a space capsule; our images are, at best, likely to be sketchy and unsubstantial. (qtd. in Harding, Science 138) 
Still, I believe that the attempts I have made to enact a feminist-sophistic method in this study draw critical attention toward the rhetorical techniques common to traditional scientific and academic research. These subtle shifts serve as a reminder of the rhetoricity, social constructedness, situatedness, and partiality of all knowledge claims. And ultimately, I maintain, these shifts work against the god-trick as an entrenched rhetorical feature of our received epistemologies.

In the next chapter, I turn away from method in terms of rhetorical enactment toward method in the more traditional terms of performing the research. I discuss in detail how I determined my survey sample and how I executed the survey itself. It is, admittedly, a less ruminative and selfintrospective chapter than the present one. However, in it I continue to employ - as I have striven to throughout this study - the rhetorical strategies that I believe characterize a feminist-sophistic method. 


\section{Chapter 4: \\ Method for Surveying United States Baccalaureate and Certificate Programs in Technical Communication}

In the previous chapter, I discussed my strategies for enacting a feminist-sophistic method in terms of the rhetorical stance I adopt as a researcher. In this chapter, I discuss my method in (the perhaps more traditional) terms of how I executed the research. My first step in this process was to seek approval for this study from Michigan Technological University's Institutional Review Board (IRB). On 1 February 2008 was granted approval and exemption from further IRB review under protocol \#M0291. From there, I turned to the survey itself. Because the survey was to be mailed, I elected to restrict the sample to programs in the United States for reasons of cost. And because the original call from the CPTSC was for research into academic programs, I also elected to restrict the sample to academic programs alone. With these basic parameters established, I then set about determining the survey sample and composing and executing the survey itself. I discuss each of these procedures in detail in the remainder of the chapter.

\section{Determining the Sample}

Previous studies of technical communication academic programs take a number of varied approaches to determining their samples. In his 1995 work "Assumptions about Technical Communication Programs" appearing in the proceedings of the STC, Kenneth T. Rainey surveys a "representative sample of 50 schools" selected from the 140 programs "that we know about" (40). His survey method remains largely unarticulated, 
however: Rainey makes no mention of how the 140 programs were identified or how the 50 surveyed programs were chosen, and he provides no elaboration on his claim to the representativeness of the sample.

In his 2001 National Communication Association presentation, "A Curricular Profile of United States Technical Communication Departments at the Beginning of the 21st Century," Earl McDowell draws his sample of programs from the STC Academic Programs database (then at <http://www.stc-va.org/scripts.school>). McDowell attempts to visit the websites of 100 of the 148 baccalaureate programs in technical communication found in the database, and he is able to find "significant information" online for the curricula for 60 of those programs (16 community colleges and 44 four-year institutions) (7). It is not clear, however, how McDowell selected his sample 100 programs from the initial population of 148 programs. He does not provide criteria for which programs were excluded, why programs were excluded, or if the selection of excluded programs was systematic. He also provides no discussion of how limiting his study to those programs with curriculum information available online might affect the results (i.e. selection bias).

In my 2003 study of certificate programs in technical communication ("Looking"), I also rely on the STC database (then at $<$ http://www.stc.org/academicDatabase.asp >) as the source for my sample. Unlike McDowell, however, I place a number of qualifications on which programs I survey. I include in my study those programs from the STC database meeting all of the following criteria:

- The certificate program is expressly in "technical communication" or "technical writing";

- The certificate is an independent degree, and is not required to be earned concurrently with another degree as a minor would 
be (however, programs can prerequire a degree for admission to the program);

- Sufficient information is available online to determine the program's curriculum and course requirements; and

- The program information is available in English and courses are taught in English.

Applying these criteria, I exclude 60 of the 122 initial programs listed in the STC database: 6 for being duplicates of other records in the database, 32 for being misidentified as certificate programs or offering no identifiable certificate program in technical communication, 9 for requiring a concurrent degree (specifically, a bachelor's degree), 9 for not having sufficient program information available online, and 4 for being offered in a foreign language. Although I express my belief that these exclusions do not "significantly impair the usefulness of the data," I do speculate on how my sample selection could introduce some bias:

By excluding nine programs for not having sufficient information online, for instance, I may have encouraged an overrepresentation of digital technology courses, as the lack of sufficient web presence at those institutions may conceivably also reflect the lack of major technology initiatives, training, or funding. In addition, by limiting the study to independent certificate programs (which do not require a concurrent degree), I may have also encouraged a small overrepresentation of industry-connected programs in the surveys [...] Such programs, lacking the "captive audience" of an undergraduate student body, may have a greater incentive to recruit students and feedback from local industry.

In their 2004 study "TPC Program Snapshots: Developing Curricula and Addressing Challenges," Nancy Allen and Steven T. 
Benninghoff take a slightly different approach to selecting their sample.

They actively, if unsystematically, augment a program directory maintained by the Association for Teachers of Technical Writing (ATTW) with "other schools whose faculty members are frequent contributors to discussion of program issues on ATTW-L (ATTW email-discussion list)" (160). They don't specify which programs came from which source, but in all they indentify 73 baccalaureate programs for participation in their survey. Regarding the representativeness of this sample, they acknowledge that "Although the list of participating schools includes only a slice of all the programs in the county, it represents a broad range of large and small schools spanning the Carnegie Corporation's categories from baccalaureate/associate's colleges to doctoral/research universitiesextensive" (160).

And in their 2005 study, Sandi Harner and Anne Rich rely on the STC Academic Programs Database (then at <http://www.stc.org/ academicDatabase.asp $>$ ) to determine the programs in their sample. Using a method much like McDowell's and Nugent's, of the 133 baccalaureate programs they find in the STC database, they examine the online curricula for 80 programs across 75 different institutions (210). Like McDowell, Harner and Rich do not discuss how and why programs were excluded from their sample. But they make an notable move to foreground some of their assumptions about the types of programs in their sample:

The introduction to the STC database states, "To assist those interested in pursuing a career in technical communication, STC provides a database of academic programs worldwide. Schools are welcome to add their programs to the database." So we assume that if a program director has entered information, the goal of that program 
is to prepare students "interested in pursuing a career in technical communication.” (210)

Most of these studies on academic programs draw at least some portion of their sample from a major program directory, and in doing so, make assumptions (whether articulated or not) about the completeness and representativeness of those directories. Each study also makes assumptions about "what counts" as a program for the purposes of their research, and assumes that the programs that "count" are represented in their samples. These assumptions, and the diverse methods these studies ultimately employ, demonstrate just how challenging sample determination is for research on academic programs in technical communication. As I identify, determining the sample breaks down into two corollary problems:

1. finding what programs are in existence, and

2. determining meaningful criteria for which programs to survey.

In the following sections, I discuss how I address both of these problems in the present research.

\section{Finding What Programs are in Existence}

Beginning with the first problem, despite previous studies' reliance on program directories, no complete and authoritative list of programs in technical communication can be said to exist, making it difficult to initiate systematic research of technical communication programs. While independent directories of academic and commercial programs in technical communication are maintained by each the STC, the CPTSC, and the ATTW, a close examination of their contents reveals notable gaps and oversights: a number of programs appear in one directory but not the others; some programs are absent entirely from the directories; and, as I 
came to find, programs offering certificates are notably underrepresented across all three directories.

The STC Academic Programs database (available at <http:// www.stc.org/academic >) has been hosted by the society since at least the year 2001 (DuBay). However, the database contents are not maintained by any central authority. Rather, all of the information in the database is selfreported, and is frequently incomplete or inaccurate (see Latterell 323). In response to efforts to improve the quality of the directory, the STC Academic Programs Database underwent “major changes” in 2007, including the deletion of a significant number of records. A call was circulated that year for programs to re-enter their data using a new database web interface (Henschel), which led to a reduction in the number of listed programs. For instance, in 2005 the STC database reported 133 baccalaureate programs in technical communication (Harner and Rich 210), but in March 2008 the database reported only 65 such programs. While the STC Academic Programs database is one of the largest and most complete technical communication program directories-not to mention an invaluable resource to the field-it is by no means complete, comprehensive, and stable.

To generate a more comprehensive sample source for this study, I set about creating my own directory of United States programs in technical communication at all levels (certificates, baccalaureates, baccalaureate concentrations, minors, associates, masters, and doctorates). To provide a starting point, I first aggregated the contents of the existing program directories into one database. On 9 March 2008, I visited the websites of the STC, CPTSC, and ATTW directories, and-through a monotonous routine of "copy/paste" from my web browser-I pulled program information appearing in them into a single Microsoft Access 
database. I first copied all 100 entries for United States academic programs from the STC Academic Programs Database. I then turned to the CPTSC Program List, first created in September 2007 (Bridgeford, “CPTSC") and available at <http://www.cptsc.org/proglist>. Of the 64 total entries in the CPTSC Program List, I found and copied into my database 21 entries for United States academic programs not already appearing in the STC Academic Programs Database. Finally, of the 77 total entries appearing in the ATTW programs directory (available at <http://cms.english.ttu.edu/ attw/programs >), I found and copied into my database 13 entries for United States programs not appearing in either the STC Academic Programs Database or the CPTSC Program List. This yielded an aggregated directory of 134 unique technical communication programs34 programs (34\%) more than found in the STC Academic Programs Database alone.

However, after performing a few subsequent, informal web searches, I identified webpages for additional programs not appearing in any of the three major program directories. In attempt to correct such omissions, I systematically searched the web for overlooked technical writing and technical communication programs. Over the course of 9-14 March 2008, I performed web searches using Google (at <http:// www.google.com>), querying in order-and without quotation marksthe following phrases:

1. technical writing program,

2. technical communication program,

3. technical communication certificate, and

4. technical writing certificate. Reading each of the top 600 results for each of these queries, I recorded every program I came across that met all of these criteria: 
- it was an academic program offered in the United States;

- it did not already appear in my aggregated programs database;

- it offered a certificate, baccalaureate degree, or graduate degree expressly in technical communication, technical writing, professional communication, or professional writing;

- it did not already appear in my previous search results. The four queries listed above yielded, in sequence, 11, 9, 12, and 6 additional programs meeting these criteria. Adding these programs to my aggregated program database yielded a comprehensive directory of 172 United States technical communication programs-72 programs (72\%) more than the STC Academic Programs Database alone and 38 programs $(28 \%)$ more than the major three directories combined. Although it is obviously impossible to verify if every U.S. technical communication program is contained in this directory, I believe that it represents a more comprehensive sample source for program research than any other currently available.

I also turned to the web to insure the completeness of program data within the comprehensive directory. The types of data recorded in the STC, CPTSC, and ATTW directories vary considerably. In the case of the STC Academic Programs Database, the information available include the name of the institution; the official names and types of programs offered; the name, email address, mailing address, and phone number of a contact person; and the URL of the program webpage. The information I gathered from the CPTSC Program List varies by each program entry, but all entries provide at least the name of the institution and the URL of the program webpage. Some entries also provide the official name of the program and the name and email address of a contact person. The information available from the ATTW programs directory is limited strictly the name of the 
institution and the URL of the program webpage. Regardless of the source of the information, however-whether it was the STC, CPTSC, or ATTW directories, or whether it was from a web search-I amended as necessary each of the 172 entries in the comprehensive database to include all of the following data:

- the name of the institution;

- the name of the department;

- the names and types of degrees offered;

- the URL of the program webpage; and

- information for a contact person or department head, including

$\circ$ name,

$\circ$ mailing address,

$\circ$ email address (when available), and

$\circ$ phone number (when available).

I gathered these additional data during 9-14 March 2008 by visiting program webpages, navigating university websites, and by performing Google web searches as needed. The names and addresses of programs contained in the comprehensive program directory appear in Appendix A.

Through the process of aggregating and examining existing program directories, and later by systematically searching the web for overlooked programs, I was not only able to develop a more comprehensive database of United States technical communication programs to use as the sample for the present survey, but I was also able to reveal a number of oversights in our current accounting of programs. As I found, programs offering a certificate are disproportionately underrepresented in the three major program directories. Of the 134 total U.S. technical communication programs listed in the combined major program directories, 56 (41\%) offer a certificate. Of the 38 additional 
programs that I found through Google web searches, 33 (86\%) offer a certificate. That is, programs excluded from the three major program directories are more than twice as likely to offer a certificate than those that were included. Correcting this underrepresentation is, of course, particularly important in light of the present research.

\section{Determining Which Programs to Study}

The second major challenge for program research is determining criteria for which programs to survey. Since, as I found, the major program directories are inadequate sample sources for this study, I had to augment them with web research to create a more comprehensive program list. In compiling this list, I was immediately faced with an important (if fraught) methodological question: what exactly defines a program in "technical communication"? What set of criteria can I apply to a given program to systematically determine whether it actually "counts" as a technical communication program? As I develop the directory through web searches, what terms do I use for the queries? For instance, on top of querying "technical communication program," "technical writing program," "technical communication certificate," and "technical writing certificate," should I also query the phrases "professional writing program" and "professional writing certificate"? Are technical communication/ writing programs the same as professional communication/writing programs, or are they essentially different?

To many teachers and scholars in the field of technical communication-where the prefixes "technical," "professional," or even "business" are frequently conflated-this last question may seem moot. As reflected in the titles of the field's most prominent scholarly journals, we're 
apparently comfortable with a wide range of descriptors for "what we do" in technical communication:

- Journal of Technical Writing and Communication,

- Journal of Technical and Business Communication,

- Business Communication Quarterly,

- Institute of Electrical and Electronics Engineers Transactions on Professional Communication,

- Technical Communication, and

- Technical Communication Quarterly.

And as I found, of the 139 programs listed in the STC, CPTSC, and ATTW directories combined - that is, programs that have self-identified as technical communication/writing programs-60 (43\%) offer at least one program (certificate, baccalaureate, baccalaureate concentration, minor, associates, masters, or doctorate) containing the word "professional," such as professional writing, professional communication, public and professional writing, etc. At least superficially, it seems, the distinction between "technical" and "professional" is not immediately apparent.

In fact, many "professional" writing/communication programs prove on close examination to be indistinguishable from programs expressly in technical communication. However a significant number of such programs also prove themselves to be substantively afield. For instance, in performing a Google web query for "professional writing program" in August 2008, the first listed result is for the website of The University of Maryland's Professional Writing Program (PWP). According to their website,

The program offers courses in Science Writing (English 390), Argumentation/Advanced Composition (English 391), Legal Writing (English 392), Technical Writing 
(English 393), Business Writing (English 394), and Writing for the Health Professions (English 395), and Special Topics in Professional Writing (English 398). For each of these Professional Writing courses, syllabi are designed to permit and foster growth in rhetorical and language skills:

- students will become more aware of the ethos they project, and more adept at defining and analyzing audiences.

- students will learn how to research topics in the "real world" and will engage in research; all PWP courses entail a significant research component.

- students will learn to plan their work according to audience and purpose.

- students will learn when and how to reveal their rhetorical plan to facilitate readability.

- students will write in a style suitable to audience and occasion.

- students will participate in draft workshop sessions, allowing groups of students to test their claims, and to engage in the sort of dialogue that joins an expert in one field with an expert in another.

- students will be prepared for writing, communication, and research beyond the classroom. ("PWP's Program")

The emphases here on audience, purpose, ethos, process, and real-world contexts reflects the rhetorical orientation of the PWP curriculum: an orientation consistent with the current best practices in technical communication pedagogy. By those measures—even with the program's "professional writing" moniker-I think few educators or scholars in the 
field would find significant differences between it and a majority of other programs expressly in technical communication. Nor do I believe they would they hesitate to declare the PWP curriculum an adequate professional preparation for a technical communicator.

In marked contrast, however, is the second listed result from the same Google web query: the University of Southern California (USC) Master of Professional Writing program ("Master"). The program boasts "An interdisciplinary approach uniting five disciplines: fiction, creative non-fiction, poetry, screenwriting, and playwriting." The website also touts the program's "Proximity to Los Angeles' entertainment and literary industries." While USC's program, like Maryland's PWP, is expressly in "professional writing," I think few educators or scholars in the field would recognize it as a "technical communication" or even "technical communication-related" program. And given USC's apparent goal of preparing writers for the entertainment and literary professions, I think even fewer would agree that the program represents adequate professional preparation for a technical communicator. (They might, however, find some amusement in the program's particular use of the word "interdisciplinary.")

These examples demonstrate that the common belief that "professional" and "technical" are interchangeable does not always hold. In fact, in my examination of the 98 subsequent results from the same web search, I found that 7 of the 10 new programs I came across (that is, the programs not already listed in my comprehensive program directory) appeared to offer more preparation in creative, literary, or dramatic writing than in technical, scientific, non-fiction, or workplace communication-a pattern I did not witness in my search for "technical writing" and "technical communication" programs/certificates. This is, of course, a 
casual and unsystematic interpretation of these programs' offerings, and given the intractable challenges of methodically quantifying or qualifying these "outlier" programs, I don't intend to represent these as anything more than anecdotal findings. However, they seem to suggest that differences between expressly "professional" programs and expressly "technical" programs are more substantive than frequently acknowledged.

Rather kairotically, a discussion arose on the ATTW listserv in April 2008 about this very issue. While the discussion is wide-ranging and illuminating, the respondents-who include notable scholars in the field of technical communication - are far from unanimous in their stance or approach to the issue. Most contributors to this conversation seem to agree, however, that "professional" and "technical" communication/writing are not identical. The discussion begins with a request from Thomas Orr: "Could someone point me to some generally-agreed-upon definitions of "professional communication" and "technical communication" that clarify the differences between the two?" By the following day, this request had elicited 13 responses.

Brenton Faber is the first to reply, and discusses some of the implications of the debate for the project of professionalizing the field. He suggests that, "Other than for reasons of efficiency (which is generally not a quality of professional work) or exigence (again....) we have little actual theoretical or emprical $[s i c]$ support for combining professional and technical the way we usually do." Daniel Tripp seconds Faber's assertion that professional and technical are not synonymous:

While searching through job ads over the past two years, I have noticed a lot of variances in what English department's consider to be "professional writing." For some, it means technical writing, business writing, etc. Others consider it to be creative non-fiction, freelance 
writing, etc. Some even seem to mean journalism or public relations/marketing.

Meanwhile, other respondents take a stab at providing firm distinctions between technical and professional. Stephen A. Bernhardt offers a very succinct definition:

I use professional to include a broader reach than technical, which tends to include engineering, computer science, agriculture. Professional includes the broad classes of college educated workers. There is also the meaning of "professional schools," such as law, medicine, pharmacy, etc. ("Reminder")

Peter England, offers a definition by way of hearsay:

I heard someone outside our field make an excellent argument distinguishing professional from technical communication. She said that technical communication is distinguished by the level of detailed knowledge. Professional communication could be something shared by human resources, engineers, lawyers, nurses, etc. Professional communication is the thing we do to make our jobs work. Technical communication, however, is something we do to make our specific jobs work-communicating something about your individual field. In this sense, "technical" means specialized or detailed.

Thomas Barker concedes his doubt that "accepted scholarly distinctions exist" between technical and professional, but he goes on to relate in detail a working list of distinctions between the two. The multiple points of difference he identifies concern mostly the context of professional practice. For instance, he describes technical communicators as "persons in .com organizations writing product use documents, marketing communication, help systems" while professional communicators are "lone writers in org or gov settings writing proposals, white papers, and policy." And Susan L. 
Popham takes a notably different tack by turning her critical attention not to the word "professional," but to the word "technical." She asks if we "can we come to an equally theoretical definition of 'technical,' something besides 'writing in workplaces' or 'writing about technologized things'?"

Several respondents turn to the context of local programs to explain the field's loose terminology. Stuart Selber notes "I love the theory talk, but I think the different uses are more strategic than anything: people find language for their local context that allows them to claim a special campus expertise." Rob Irish describes how our terminology might function strategically not only as a form of marketing to students, but also on behalf of a larger profession:

Could it be that "professional" is a wish label to elevate our courses into the realm of desireable [sic] to students who are skeptical? Perhaps, the label is to persuade students that this course could lead to employment (unlike say, "creative writing" or "literature"). That is, this is for "college educated workers" who also want a job (or should I say, employment, or a profession-latinized euphemisms for good Old Engish $[s i c]$ work). This is not to say that we are misleading students, only that we are employing the power of language to simultaneously compose the profession and elevate its status.

And Stephen A. Bernhardt likewise emphasizes a strategic function, noting that "sometimes terms are useful because loose. It is often useful to distinguish professionals who write from professional writers" ("Professional").

In all, the broad range (and tangential nature) of this discussion suggests that the question at its origin is a deceptively hard one to answer. Defining technical communication-even just in defining the ways it might stand distinct from "professional" writing or "professional" 
communication - is a particularly thorny undertaking, as it necessarily touches on a number of lingering disciplinary, professional, and political issues. Calls to draw up lists of "core competencies," to certify practitioners, and to professionalize the field are seemingly permanent features of technical communication scholarship and commentary (see Turner and Rainey; Savage, "Process”; Savage and Kynell-Hunt). Given the lack of consensus among researchers, practitioners, and teachers about what constitutes the ideal course of professional preparation for technical communicators, an axiomatic, universally held definition of a "technical communication program" is unlikely to emerge soon. In addition, as reported in in-depth curricular studies, technical communication curricula are wildly disparate at both the certificate and undergraduate levels. As far as we can tell, there is no such thing as a "core" or "standard" curriculum in technical communication (Nugent, "Looking"; Harner and Rich). So even efforts to empirically derive a working definition of a "technical communication program" are likely to be met with frustration.

The question of defining our field will doubtlessly receive further study - not just in the form of program research but also in the form of debate about the more abstract issues of what "counts" professionally and disciplinarily as technical communication. While I return to this issue and offer some commentary of my own in the final chapter, I concede here that to definitively settle the questions surrounding the identity of technical communication lies well beyond the scope of this study. Nonetheless, my method requires that I provide at least provisional answers to these thorny questions, if only for the purpose of determining the survey sample. So,

- given the deficiencies in the major program directories and the need to actively supplement them through web searches; 
- given that a significant number of programs expressly in "professional writing" are clearly not intended to prepare students for careers in technical communication or related lines;

- given the apparent consensus among teacher/scholars that meaningful differences do exist between "technical" and "professional" programs;

- given the lack of consensus on what those differences might specifically be; and

- given that examining individual program curricula to assess their status as a "technical communication" program or otherwise would be untenable - not only because such an undertaking would exceed the scope of the current study, but because it would also imply that established criteria exist for making such a determination-;

I had to determine a systematic means of my own for identifying the relevant programs to survey. For this, I elected to rely on program names to determine their inclusion in this study. Specifically, I restricted my sample to programs in the comprehensive directory offering at least one baccalaureate degree, baccalaureate concentration, certificate, or graduate degree having the word "technical" in its title (such as "technical communication," "technical writing," "technical and business communication," etc.). That is, "professional" degrees and certificates were excluded from my sample except in cases where the program also offered a "technical" degree or certificate. Of the 172 programs listed in the comprehensive directory of programs, 141 met this qualification.

My final step in determining the sample was to restrict the survey only to those programs offering baccalaureates or certificates. That is, since 
this study is intended to provide a comparison between baccalaureate and certificate programs, I did not want to survey programs offering only, say, an associate's degree, an undergraduate minor, or graduate degrees. Of the 141 remaining programs in my sample, 27 offered no apparent certificate, baccalaureate degree, concentration of any kind, leaving 114 programs in the final sample. These 114 programs comprising the sample are noted in Appendix A.

\section{The Survey Instrument}

With the sample selected, I then worked to compose and execute the survey. The survey instrument I composed is four pages long, contains 14 questions, and asks questions soliciting 40 pieces of data about applicable certificate or baccalaureate programs (see appendix B for a facsimile of the survey). I estimated it would take a knowledgeable program administrator approximately 15 minutes to complete. On page one of the survey, I ask questions about the program's institution: its status as public or private, its size, the department or academic unit containing the program, the types of professional or technical communication/writing degrees offered by the department or academic unit, and the types of degrees (of all kinds) offered by the department or academic unit.

On page two of the survey, I ask questions about the program's professional or technical communication/writing baccalaureate degree or baccalaureate concentration, if offered. The data I sought include: the year the program conferred its first baccalaureate, the current enrollment in the baccalaureate program, the number of degrees conferred in the 2006-2007 academic year, the total number of degrees conferred in the lifetime of the program, the total number of courses required for program completion, the number of hours per week that courses in the baccalaureate program typically meet for, the number of weeks in a term of study, the number of 
terms required for program completion, the portion of the degree that can be earned online, and whether an internship is required for program completion.

On page three of the survey, I ask questions about the program's professional or technical communication/writing certificate, if offered, and these questions parallel the questions appearing on page two. The data I sought include: the year the program conferred its first certificate, the current enrollment in the certificate program, the number of certificates conferred in the 2006-2007 academic year, the total number of certificates conferred in the lifetime of the program, the total number of courses required for program completion, the number of hours per week that courses in the certificate program typically meet for, the number of weeks in a term of study, the number of terms required for program completion, the portion of the certificates that can be earned online, and whether an internship is required for certificate completion. In addition, I asked whether enrollment in some other program (such as a baccalaureate program) was required for certificate enrollment.

On page four of the survey, I ask questions about instructors in the department or academic unit housing the professional or technical communication/writing baccalaureate or certificate. The data I sought include: the total number of instructors teaching in the department or academic unit (including full-time, part-time, faculty, adjunct, and graduate students, regardless of their specialization); the number of graduate student teaching in the department or academic unit; the number of tenure-track instructors teaching in the department or academic unit; the number of instructors regularly teaching technical communication courses, the number of instructors regularly teaching technical communication courses holding a degree expressly in the disciplines of 
- technical communication,

- technical writing,

- business writing, or

- professional writing;

the specializations of instructors regularly teaching technical communication courses that don't hold the above-listed degrees; and, of instructors regularly teaching technical communication courses, the number that

- have industry or professional experience,

- hold a bachelor's degree as their highest degree earned,

- hold a master's degree as their highest degree earned,

- hold a doctorate as their highest degree earned,

- are graduate students, and

- hold tenure-track positions.

After composing, laying out, and duplicating the survey, on 3 April 2008 I mailed the survey to the 114 selected programs along with a cover letter explaining the research (see Appendix $\mathrm{C}$ for a facsimile of the letter) and a prepaid-postage return mailer. On 12 May 2008, I sent reminder postcards (reproduced in Appendix D) to the 80 programs who had not yet responded by that date. On 18 June 2008, I sent new duplicate surveys and cover letters (again with a prepaid-postage return mailer) to the 73 programs who had not yet responded by that date. By 15 September 2008, I received a total of 59 completed surveys - a response rate of $52 \%$. In the following chapter, I discuss the results and conclusions from these surveys, and I conclude this work by presenting some theorization of technical communication certificate programs most broadly. 


\section{Chapter 5: Results and Conclusions}

In this chapter, I present the results of this study in the form of descriptive statistics about technical communication certificate programs and I conclude by discussing what these results might signify, both practically and theoretically, for our understanding of certificates. But first, in keeping with the feminist-sophistic methodology I articulated in chapters 2 and 3, I make a brief, reflexive digression to resolve a few remaining methodological issues.

\section{Feminist-Sophistic Methodology and the "God-Trick"}

As I describe in chapter 3, in my attempt to enact a feministsophistic methodology I eschew the "god-trick" in the rhetorical performance of this study. I describe three major rhetorical techniques I employ toward this end: remaining present in the text, remaining grounded in a practical disciplinary context, and remaining aware of the inherent rhetoricity of scholarship. So far I have attempted to remain present in the text both grammatically and ethically through my use of the active voice and personal pronouns. I have also attempted to remain grounded in a practical disciplinary context by identifying my audience and framing the study as a response to conversations within the academic field of technical communication. And I have attempted to selfconsciously foreground the rhetoricity of this work by identifying it as a persuasive act that I intend to accomplish a particular purpose, with a particular audience, within a particular context.

According to the generic conventions of empirical research, however, this is the point in the study where-after the background, methodology, and methods have been displayed — the major findings are 
revealed in the form of results and conclusions. At this point, I believe, I am faced most directly with the dilemma I discuss at the outset of chapter 2: how do I make broad, persuasive claims about certificate programs nationwide while resisting the foundationalizing impulses of a traditional methodology? Convention holds that this portion of the study should focus almost exclusively on the "objects" of research and put forward broadly aggregative results and summative conclusions about those "objects." Such results and conclusions are typically composed in the declarative mood with an almost godlike authorial voice, a rhetorical form that, like the passive voice, represents an evasion of grammatical and ethical agency. The god-trick, it would seem, looms large over this chapter, deeply encoded within the empirical research genre.

What alternative rhetorical form could this chapter take to remain consistent with a feminist-sophistic methodology? How can I present knowledge that actually claims to say something about certificate programs - knowledge with persuasive effect and distinct practical application, but without the pretense and stylistic artifice of objective Truth? One possible approach would be for me to use the sophistic rhetorical techniques of antithesis, parataxis, dissoi logoi, and paradoxologia to present multiple, differing — even contradictory—conclusions from the data I generate. Such an approach would counter the prevalent, foundationalist notions of non-contradiction and objectivity, and would work against the god-trick as a feature of the empirical research genre. However, this approach also presents its own unique problems. In its almost Derridian insistence that texts must necessarily work against themselves - even to the end of their own political incapacitation - this approach might also subvert the possibility for making practical meaning in the first place. Further, such an approach could serve to keep my positionality and mediate role as a rhetor-researcher obscured: the various 
conclusions that I presented under such an approach, for instance, would still be of my own devising, finite in number, and persuasive in intent.

Instead, I will take an approach that perhaps allows me to more productively address both sides of this "god-trick" dilemma. As I describe in chapter 2, a feminist-sophistic methodology retains a optimism toward the possibility of exercising political agency and making meaning. In that chapter I cite Haraway's invocation of the coyote-trickster, a figure who "suggests our situation when we give up mastery but keep searching for fidelity, knowing all the while we will be hoodwinked" (Simians 199). I also cite Jasper Neel's parallel commentary that, "In contrast to Derrida [...] the sophists allow themselves to be persuaded by an argument, while never forgetting the inadequate, deceitful foundation that enabled the argument" (207). Consistent with these critical, yet optimistic epistemic perspectives, I will assert the knowledge of this study in a direct and declarative rhetorical style largely consistent with the empirical research genre. However, in attempt to contravene the looming god-trick, I will also foreground some of the wily and deceptive strategies that undergird my claims to knowledge in this study.

This approach is suggested by Scott Consigny's characterization of Gorgias' "parodic" style: a performative style in which the ancient rhetor deliberately draws attention to both the conventions and the rhetoricity of localized discourses. As Consigny describes, Gorgias' use of this style is a reflection of his sophistic epistemology:

by displaying the rhetoricity of every text, he shows his audience that all arguments, including his own, are contingent, situated fabrications that are "true" only insofar as they are endorsed by specific audiences. Gorgias' objective is not to transmit objective truth or to inculcate universal moral principles, but to encourage people to become engaged in the agons of their culture. (Gorgias 30 1) 
By displaying the rhetoricity of the present text in a similar fashion, I believe that I both avoid the "Pyrrhonian skepticism" of deconstruction (Bizzell) and undermine the foundationalizing rhetorical ploys of traditional scientific scholarship. ${ }^{10}$ Toward both of these ends, I acknowledge the following as rhetorical strategies in my accounts of technical communication programs:

- I use the declarative mood to lend a sense of certainty and unassailability to my claims. This linguistic feature serves rhetorically to obscure my agency as a rhetor-researcher, to erase the appearance of ambiguity from my knowledge claims, and to draw the audience's attention away not only from my active role in the construction of this text, but also from the very notion that this text was constructed to begin with.

- I am selective of what results and conclusions I present from this research. I don't present the full range of possible outcomes and interpretations from this study. Rather, I compile a finite number of results and conclusions that I think are rhetorically feasible to assert and that I assume are significant. What counts as "feasible" or "significant," of course, is

\footnotetext{
${ }^{10}$ For a contrasting perspective, see Michelle Ballifs Seduction, Sophistry, and the Woman with the Rhetorical Figure (182-6). As a scholar closer to the deconstructive school than myself, I suspect that Ballif might fault the sort of middle-ground, or neopragmatic, stance that I describe here. To Ballif, such a stance "is not sophistic enough" (183) and serves "once again (in the name of antifoundationalism) to stabilize language" (182). Such a stance "emanates from a rhetorical subject who controls language who can chose to abuse it or not-or to abuse others via its power" (183). Although Ballif grants that such a position is "released from ontological foundations, metaphysical presumptions and truth," it is nonetheless bound by its "dependence on techne," and as such, "serves to maintain the boundaries and limits of a particular discourse and is motivated by the desire of the 'we' to colonize every 'they."' (183).
} 
informed by my subject position and the particular audience(s), purpose(s), and context(s) that this study speaks to.

- I structure my presentation of information with the intent to close off alternative interpretations. For instance, I often first present a summative statement or conclusion, followed by a recitation of the data from the study that I believe supports that conclusion (again, in the declarative mood). Ordering my argument in this way engages my audience enthymematically by encouraging them to think through the connections between the conclusion and the premises on their own. But stating the conclusion first can be seen as an attempt on my part to attain control over the audience's likely interpretation of the data and to forestall the possibility of my audience arriving at alternative conclusions.

- I use verb tense to perform a sort of "epistemic elision" between the particular and the general. This survey offers a snapshot of descriptive statistics about technical communication programs in the context of 2008. Despite the fact that the survey is situated in the past, however, the results and conclusions that follow are largely in the present tense. This works rhetorically to obscure the circumstantiality - and to affirm the universality — of my results and conclusions. As I explore in chapter 3 , the artful use of verb tense in this way can give knowledge the seductive appearance of timelessness.

- I rely on categories of my own construction to give suasive power to information. Tables 1, 2, and 3 show the results of sorting information into discrete categories. Although I was systematic in performing these categorizations, devising the categories themselves was an iterative and ad hoc process of 
looking at the survey results and identifying areas of commonality and difference. This process was informed not only by my reading of similar research (for example, Harner and Rich) but also by my particular, situated understanding of disciplinary politics. Establishing discrete categories in this way (a rhetorical tactic that summons back to Aristotle) lends the appearance of priority and transcendence to intellectual constructs that are, at best, kairotic and heuristic. Alternative and equally meaningful categories are, of course, possible.

- I use visual design to establish a sense of credibility. For instance, the tidy tables of data that follow bear no resemblance to the relatively casual Microsoft Excel spreadsheets that the data came from or even to the pile of handwritten surveys sitting on my desk. My careful and hygienic visual presentation of the data works to establish my ethos as a careful researcher. Similarly, the overall visual layout of these pages works to establish the ethos of a staid, scholarly monograph. My consistent use of only one serif font and the general absence of non-textual visual features in this document, for instance, are my attempts to tap into a long visual tradition of alphabeticcentric scholarship.

This isn't, of course, a catalog of all the rhetorical strategies employed in this chapter, and these strategies certainly aren't unique to the present study. But by foregrounding the rhetoricity of this work in such a self-reflexive and confessional way-even at the risk of ultimately reducing its suasive power-I hope to engage in the creation of positive, usable knowledge while still making apparent my mediate role as a rhetorresearcher. My intent here is not to undermine this study, or, again, to reveal it as a load of opportunistic, untethered blather. Rather, by laying 
bare some of the rhetorical machinations of this study, my intent is to draw attention to the rhetorical machinations - that is, the "trickery" and "deception" - at the heart of all knowledge claims. In this way, the more fully present and accountable "coyote tricks" of a feminist-sophistic epistemology come to replace the largely invisible and coercive "godtricks" of our received epistemologies. As I articulate in chapter 3, such a feminist-sophistic epistemology holds promise as both a more ethical and rigorous means of knowledge production.

\section{Results}

In preparing the data for analysis, I transcribed the 59 returned surveys into a Microsoft Access database. As I performed this transcription, I obeyed two conventions. First, I did not record the responses to questions left blank, answered "N/A," or answered "unknown." Second, when answering questions soliciting a numeric answer (such as the total number of instructors in a program), some respondents provided an estimated range instead of a single number. In these cases, I recorded the midpoint of the range. For instance, if a respondent answered "12-14," I recorded "13." After transcribing the surveys, I moved the data into an Excel spreadsheet for calculation and analysis. I discuss the results in detail in the following sections.

\section{Programmatic Locations}

In table 1, I classify responding programs into major categories according to the name of their department or academic unit. According to this breakdown, 59\% of programs offering a baccalaureate degree are 
housed in departments of language and literature or English. ${ }^{11} \mathrm{By}$ comparison, $43 \%$ of programs offering a certificate are housed in such departments, suggesting that certificates enjoy relative freedom from technical communication's traditional academic home of English. In addition, certificates also show up in a greater diversity of programmatic locations, including those outside of traditional academic departments. The programs that I classified as "other" (each of which offer only certificates) belong to the following departments or academic units:

- College of Extended and International Education,

- Community Education and Training,

- Business and Professional Development,

- Continuing Studies, and

- Business and Management.

${ }^{11}$ See also Harner and Rich's 2005 study, "Trends in Undergraduate Curriculum in Scientific and Technical Communication Programs." Of the 80 programs they study, 61\% belong to departments of English (214). 
Table 1. Department or academic unit for all responding programs, for programs offering a bachelor's (or concentration), and for programs offering a certificate.

\begin{tabular}{|c|c|c|c|c|c|c|}
\hline \multirow[b]{2}{*}{ Department or unit } & \multicolumn{2}{|c|}{ All } & \multicolumn{2}{|c|}{ Baccalaureate } & \multicolumn{2}{|c|}{ Certificate } \\
\hline & $n$ & $\%$ & $n$ & $\%$ & $n$ & $\%$ \\
\hline English/Language and Lit. & 32 & 55 & 22 & 59 & 15 & 43 \\
\hline Technical Communication & 9 & 16 & 7 & 19 & 8 & 23 \\
\hline Communication & 4 & 7 & 3 & 8 & 2 & 6 \\
\hline Writing & 5 & 9 & 3 & 8 & 2 & 6 \\
\hline Humanities & 3 & 5 & 3 & 8 & 3 & 9 \\
\hline Other & 5 & 9 & 0 & 0 & 5 & 1 \\
\hline Total: & 58 & 100 & 37 & 100 & 35 & 100 \\
\hline
\end{tabular}

\section{Age and Size of Programs}

The following are the major results that I developed regarding the age and size of responding programs, as reported in questions $6 \mathrm{a}-\mathrm{d}$ and $7 \mathrm{a}-\mathrm{d}$ of the survey:

- Certificate programs in technical communication-while certainly an established phenomenon-are newer relative to baccalaureate degree programs. The average age of baccalaureate programs, in 2008, was 18 years, with programs ranging in age from 0 to 50 years $(S D=11.1)$. The average reported age of certificate programs was 14.3 years, with programs ranging in age from 1 to 28 years $(S D=8.3)$.

- Program sizes vary widely, but baccalaureate programs have larger enrollments than certificate programs. Baccalaureate programs reported an average of 40.4 enrolled students at the time of the survey, and ranged from 2 to 250 students $(S D=45.0)$. Certificate 
programs reported an average of 26.2 enrolled students, and ranged from 0 to 370 students $(S D=54.8)$.

- Baccalaureate programs outpace certificates in graduating students. Responding baccalaureate programs conferred an average of 10.4 baccalaureate degrees during the course of the 2006-07 academic year $(S D=8.30)$. During the same year, certificate programs conferred an average of 9.0 certificates $(S D=8.97)$. Responding programs conferred a lifetime total of 5,597 baccalaureate degrees over 660 baccalaureate program-years - a historical average of 8.5 degrees awarded per year per program. They also conferred a lifetime total of 2,935 certificates over 431 certificate programyears-a historical average of 6.8 certificates awarded per year per program.

\section{Degree and Certificate Requirements}

The following are the major results that I developed regarding degree and certificate requirements, as reported in the multipart questions 6 and 7 :

- Most certificates $(86 \%, n=34)$ can be earned independently of any other degree, and do not require students to be concurrently enrolled in some other degree program.

- The average certificate requires roughly one-fourth the coursework of the average baccalaureate degree. Baccalaureate programs require an average of 29.3 courses (both within and without the department) for program completion, while certificates require an average of 7.6 courses $(S D=4.34)$. Expressed in terms of semester hours, baccalaureate programs require an average of 91.1 semester hours $(S D=50.9)$, while certificates require an average of 25.5 semester hours $(S D=14.5)$. 
- Certificates are slower paced than baccalaureates. The average anticipated time to completion for certificates is about half that of baccalaureate degrees, despite the fact that certificates only require around one-fourth the coursework. When asked how much time students are anticipated to spend completing their program, respondents indicated an average of 6.8 terms for baccalaureate degrees $(S D=2.52)$ and 3.3 terms for certificates $(S D=1.45)$. Expressed in weeks of instruction, respondents anticipate on average 99 weeks for baccalaureate degree completion $(S D=33.2)$ and 48 weeks for certificate completion $(S D=23.5)$.

- While they are just as likely as baccalaureate programs to offer at least some course content online, certificates are much more likely to be obtainable entirely online. Nearly two-thirds of baccalaureate degrees $(66 \%, n=35)$ offer some online courses, as do an equal portion of certificate programs $(66 \%, n=35)$. However, only $6 \%$ of baccalaureate degree programs can be completed entirely online $(n=35)$, while $31 \%$ of certificate programs can $(n=35)$.

- Baccalaureate programs are much more likely to require an internship than certificate programs are. Fifty-eight percent of baccalaureate programs require an internship for program completion $(n=33)$, while only $17 \%$ of certificate programs do $(n=$ $35)$.

\section{Instructor Degrees and Professional Status}

The following are the major results I developed concerning the degrees and professional status of instructors who regularly teach technical communication, as reported in questions 11,12 , and $14 \mathrm{a}-\mathrm{f}$ (see table 2 ):

- Few technical communication instructors hold degrees specifically in the disciplines of technical communication, technical writing, business writing, or professional writing. About one in three 
instructors in all responding programs can claim such academic preparation. ${ }^{12}$ In programs offering a certificate and only a certificate, this ratio falls to one in five.

- Certificate program instructors have less professional status. Although they possess more industry and professional experience, certificate program instructors hold fewer academic credentials and are less likely to be on the tenure track. More specifically, if a program offers a certificate, compared to instructors in programs offering a baccalaureate degree or concentration its technical communication instructors are:

- about one and one-half times as likely to have industry or professional experience,

○ just as likely to have a degree specifically in the disciplines of technical communication, technical writing, business writing, or professional writing;

○ three-fourths as likely to have a doctorate; and

○ four-fifths as likely to hold a tenure-track position.

- Technical communication instructors in programs that offer a certificate and only a certificate have even less professional status. That is, such instructors, relative to the instructors in programs offering a baccalaureate degree or concentration, are:

\footnotetext{
${ }^{12}$ This is consistent with data on hiring reported in Carolyn Rude and Kelli Cargile Cook's study "The Academic Job Market in Technical Communication, 2002-2003." In that year, "While $\mathrm{PhDs}$ in technical or professional communication were the most commonly hired, they filled fewer than one-third (29\%) of the primary positions that advertised for someone with their specialty" (61). Rude and Cook attribute this to the fact that "current doctoral programs cannot graduate sufficient doctorates to fill the market's need," as well as the lack of exclusive demand for technical communication specialists (61).
} 
○ about one and two-thirds times as likely to have industry or professional experience,

o two-thirds as likely to have a degree specifically in the disciplines of technical communication, technical writing, business writing, or professional writing;

○ three-fifths as likely to have a doctorate; and

○ three-fifths as likely to hold a tenure-track position. 


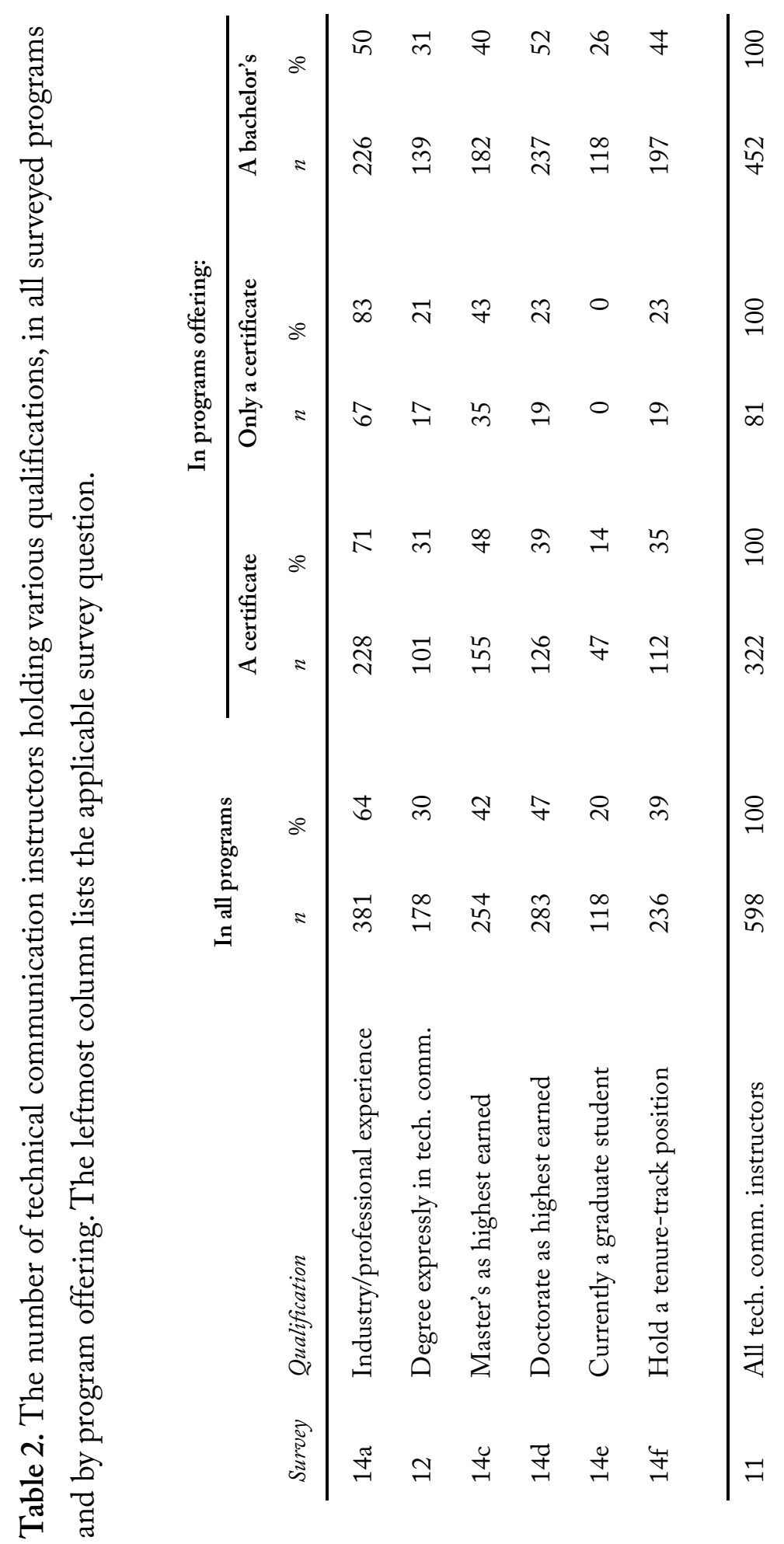

8 


\section{Academic Specializations of Instructors}

In question 13, I asked participants about the academic specializations of program instructors who regularly teach technical communication courses in their program, but who do not hold degrees expressly in technical communication, technical writing, business writing, or professional writing. Their responses, which I categorized by major type, are listed in table 3 . Across all programs, instructors who regularly teach technical communication courses demonstrate a diverse range of academic specializations. Their most commonly listed specializations, however, are the English-related fields of composition and rhetoric, literary studies, and English (general or unspecified). The 19 responses comprising the "other" category of specializations are as follows:

- Design

- Engineering

- Film/Media Studies

- Graphic Arts/Graphic Design (2)

- Information Design

- Instructional Design

- Journalism (2)

- Law

- Liberal Arts

- Management

- Nuclear Engineering

- Philosophy

- Psychology

- Science and Technology Studies (2)

- Systems Engineering

- Web Design 
Table 3. Reported specializations of instructors who regularly teach technical communication, but who do not have a degree specifically in the disciplines of technical communication, technical writing, business writing, or professional writing.

\begin{tabular}{|lc|}
\hline Specialization & Responses \\
Composition and Rhetoric & 30 \\
Literary Studies & 29 \\
English (general or unspecified) & 16 \\
Education & 5 \\
Communication & 5 \\
Linguistics & 4 \\
Creative Writing & 3 \\
Other & 19 \\
\hline
\end{tabular}

\section{Summary of Results}

In all, compared to baccalaureate programs, certificate programs in technical communication:

- are less likely to be housed within departments of English;

- are younger;

- are smaller in enrollment;

- graduate fewer students;

- are more likely to be earnable completely online;

- are much less likely to require an internship;

- have instructors with more industry experience;

- have fewer instructors holding technical communicationspecific degrees;

- have fewer instructors on the tenure track; and

- have instructors with fewer academic credentials overall. 
As rules of thumb, technical communication certificates can be earned independently of any other degree, and they require about one-fourth the coursework of a baccalaureate but take half the time to complete.

Regardless of whether their program offers a certificate or a baccalaureate, only one in three technical communication instructors hold a degree specifically in technical communication, technical writing, professional writing, and business writing. However, if a program offers a certificate and only a certificate, this ratio drops to one in five.

\section{Conclusions}

As I noted in the introduction, in my 2003 study of certificate programs, "Certificate Programs in Technical Communication: Looking Closer, through Sophistic Eyes," I found that certificate programs enjoy great flexibility at both the curricular and programmatic levels. In that study, I performed an examination of certificate program curricula nationwide and concluded that such programs "vary wildly," are "disparate and wide-ranging," and that "no core curriculum can be said to exist among them." In a survey I conducted for that study, I also found that certificate programs demonstrate a strong concern for the needs of local industry (as compared, say, to broader professional standards). I found that a majority of programs make use of an industry advisory board, recruit from local industry, and/or employ some other means of gathering feedback from local industry. As I concluded, the curricular flexibility and the local orientation of certificates

are consistent with a conception of technical communication as a postmodern profession in a market where no standard, universally-required skill set has emerged-whether from the collective needs of industry or as a result of professionalizing gestures from elsewhere. 
I believe that the present study further corroborates this depiction of certificates as a flexible and indeterminate course of preparation for a field whose contours remain - likewise-flexible and indeterminate.

In general, technical communication certificate programs are not as established as baccalaureate programs are (as indicated by program age, enrollments, and graduation rates). Compared to baccalaureates, certificate program instructors have less professional status in the form of academic credentials, access to the tenure track, and technical communicationspecific degrees. And since certificate programs are much less likely to require an internship for program completion, their curricula appear to offer less by way of experiential learning (see Little "Technical"). At first glance, then, it is tempting to declare certificates to be relatively impoverished on grounds of their curricula, the professional status of their instructors, and their "establishedness" as programs.

However, certificates also show signs of being less tradition-bound than baccalaureate degrees. That is, certificate programs are less tied to the brick-and-mortar university (in that they are more likely to be earnable online) and they are less tied to the traditional departmental home of English (in that they are more likely to fall into a diverse range of programmatic locations outside of English). In addition, instructors in certificate programs are much more likely to have industry or professional experience than instructors in baccalaureate programs-while they cannot claim the same level of academic preparation as baccalaureate instructors, they can claim more practical, non-academic experience. I believe that these results support the notion that certificates are more flexible and less academically oriented than their baccalaureate counterparts.

Certificate programs' precise impact on the status of technical communication as a profession and a discipline remains uncertain. Given that certificate programs are less established and have instructors with less 
professional status, certificates may - at least on the academic side-serve to undermine efforts to achieve material security for those in the field. However, this study also suggests a number of other, more telling conclusions about the status of the field and its instructors. Across all programs, fewer than one in three instructors of technical communication hold degrees in the disciplines of technical communication, technical writing, business writing, or professional writing. Of those instructors not holding technical communication-specific degrees, their most commonly listed specializations are in English-related areas. Some three out of every five baccalaureate programs are housed within departments of English, as are about two out of every five certificate programs. ${ }^{13}$

While these results are hardly surprising, they do serve as an immediate confirmation and reminder that technical communication-at least as reflected in the staffing and location of academic programs-is far from achieving disciplinary autonomy and professionalization. Technical communication's lack of practical distinction from English studies suggests that it has yet to attain many of what Gerald J. Savage enumerates as the defining features of a modernist profession ("Process"; "Tricksters" 169), particularly the features of market closure, self-regulation, and a formalized body of knowledge. Beyond the present survey, of course, there are other signs that the goal of modernist professionalization remains unrealized: the lack of standard—or even consistent—curricula for certificates and baccalaureate degrees (Harner and Rich; Nugent, "Looking"); the failure to establish certification for instructors or

\footnotetext{
${ }^{13}$ I don't mean here to join the fray concerning English departments' status as the predominant scholarly home for technical communication (see Dragga), nor do I intend to speak to the larger disciplinary-political shifts occurring in English studies (see Ostergaard et al.). Rather, I intend for these results to speak only to the current status of the projects of professionalization and discipline formation within technical communication.
} 
practitioners (Turner and Rainey); and even the broad range of names that are used for our academic programs, scholarly journals, and the field itself (see chapter 4). In light of the much larger hurdles still facing the projects of professionalization and disciplinary legitimization, I suggest that the particular anxieties surrounding certificate programs are, at least for the time being, misplaced. Particularly as certificate programs do not show signs of surpassing baccalaureate programs in enrollments or graduation rates, there likely remain more productive battles to wage in technical communication's war for professional and disciplinary status (to use a fraught, but possibly apt, metaphor).

Certificates may, in fact, be poised to advance the status of technical communication by encouraging the growth of academic programs. Because of the reduced barriers to setting up new certificates compared to other types of programs (Little, "Designing" 275), certificates could help bring a certain strength in numbers to technical communication, achieving at least one important measure of disciplinary and professional standing: ubiquity. Further, thoughtfully designed certificates could play a role in ensuring that technical communication's growth remains healthy. As Robert R. Johnson suggests, one strategy for long-term sustainability

is for programs to become more focussed and specialized. Each program, in other words, could have distinct and recognizable purposes beyond the pail of general technical communication. In short, we could consider creating programs that present "pockets of specialties": programs where students can go to focus on strong and well developed areas of curriculum and scholarship that will be fruitful for students and faculty alike. ("Deeply" 117)

Because of their flexibility and concern for local needs (Little, "Designing" 275; Nugent, "Looking"), certificates could be ideally positioned to help establish these sorts of strategic programs. For example, Bowling Green 
State University and the University of Wisconsin-Milwaukee have each recently inaugurated certificates with a special emphasis on international technical communication, and the University of Washington Educational Outreach currently offers a user-centered design certificate. These existence of these programs suggests that certificates are flexible enough to accommodate emerging issues in the field and are able to offer specializations in the way that Johnson advocates.

I should note, though, that the possibilities I sketch here remain largely speculative. More in-depth research is called for-research on the students, the graduates, the individual contexts, and the administration of certificate programs, both qualitative and quantitative - in order to more accurately gauge certificates' impact on the field. However, in the next section, I suggest how certificates may speak in a more potent and theoretical way to our current professional and scholarly conversations about the disciplinary and professional status of technical communication. As I find, neosophistic theory may suggest a way to step outside of these conversations entirely as they are currently framed.

\section{Discussion and Theoretical Implications}

I would like to conclude this chapter by reiterating and expanding on a framework for theorizing the technical communication certificate program that I first articulated in my earlier study ("Looking"). As Gerald J. Savage demonstrates in his chapter "Tricksters, Fools, and Sophists:

Technical Communication as Postmodern Rhetoric," the sophist provides a compelling model for the identity of the technical communicator:

[T] he work of technical writing seems to be consistent with a sophistic practice in which knowledge is always contingent, in which rhetorical purpose must be reconciled to the needs of a particular audience at a particular time and place. Technical writing as we find it today has emerged in relation to particular economic, political, and 
technological circumstances which combine in complex and contradictory ways that make the work our practitioners do both useful and disruptive, both materially rewarding and risky [...] Yet these circumstances present us with the strongest argument for accepting the apparently weak role of the non-expert, unrecognized, incompletely professionalized, uncertified, hard to define sophisttechnical communicator. (189)

By conceiving of technical communication as a sophistic profession, its members become "politically and socially engaged communicators who recognize the inevitability of their texts as socially transformative" (171). Its members also embrace their status as "liminal subjects," "occupying marginal zones between the subject matter expert and the lay audience, trading status both in the corporation and in larger society for relative freedom to travel across the boundaries of these social-cultural domains" (180).

Here Savage is drawing on the concept of the "liminal subject," as characterized in the work of Joseph Jeyaraj. In his 2004 article "Liminality and Othering: The Issue of Rhetorical Authority in Technical Discourse" Jeyaraj depicts liminal spaces and subjects as such:

Liminal spaces are different from normal spaces located within particular discourses because of their flexibility and openness. Well-established discourse communities have clearly developed discursive patters, social structures, mores, and conventions. [...] However, people in liminal positions $[\ldots]$ because they are not located firmly within the discursive patterns of a community, have more opportunities to form practices that transgress some of those discursive patters. (16)

I contend that the certificate program in technical communication can be theorized as occupying a liminal zone: a particularly sophistic space between academy and industry, theory and practice, education and 
training, local and universal. Just as sophism concentrates on the individual locations and contexts of knowledge production at the expense of "predictive, generalizing models" (Savage, "Tricksters" 186), certificate programs often situate themselves to meet the practical needs of local industry (Little, "Designing" 278, Nugent, "Looking"). Just as sophism threatens the modernist distinction between theory and practice (Leff 24; J. Scott 193), the situation of the certificate program between academy and industry lends it the potential to collapse theory and practice into new conceptions of professional identity. Certificate programs, I assert, are theoretically consistent with - and are situated to support the work oftechnical communication as a sophistic profession.

In Savage's characterization of technical communication as sophistic, the field avoids the impulse to achieve market closure and the vestments of a modernist profession. In exchange for giving up a determinate set of professional knowledges - not to mention their attendant status and security — the field wins the ability to remain flexible in the face of an ever-changing postindustrial workplace ("Tricksters," 188-9). To Savage, such flexibility is a source of strength for technical communication, particularly in a world "in which no position can be counted on to last, in which change seems to rule and the ability to adapt to change is most valued" (189). As I find, certificate programs demonstrate a number of decidedly sophistic traits that are consistent with Savage's characterization.

As John Poulakos notes in his volume Sophistical Rhetoric in Classical Greece, the ancient, traveling sophists were compelled in their practice to "adjust themselves to different laws and institutions, accommodate a variety of students, and tailor their messages to suit the sensibilities and tastes of their diverse audiences" (25; see also Savage, “Tricksters" 187). Similarly, I find in my 2003 study that certificate 
programs demonstrate diverse and flexible curricula that are informed by the needs of local industry. The ancient sophists also "lived and worked more according to the circumstances they encountered and less according to established custom or principle" (Poulakos, Sophistical 25; see also Savage, "Tricksters" 186). Similarly, I find in the present study that, relative to baccalaureate programs, certificates are less established and traditionbound. Finally, the ancient sophists, while quite successful in their own right, were deprived of many traditional forms of status in ancient Greece (Savage, "Tricksters" 186). Similarly, I find that certificate program instructors have less status in the form of academic preparation and tenure-track appointments. The certificate in technical communication is, I conclude, a particularly sophistic credential for a particularly sophistic field.

Of course, sophistic theory offers more than just descriptive frameworks: I believe that it also offers important prescriptions for the successful design and implementation of certificate programs. Platonic curricula - which sophistic curricula can be said to be articulated againstwould hold that the practices of technical communication are entirely reducible to formalizable first principles, and therefore such curricula only demand sufficient classroom time to facilitate the "transfer" of formalized knowledge from teacher to student. These curricula are what a number of recent commentators have in mind when they call for the drafting of fixed lists of "core competencies" and a "codified body of knowledge" for the field of technical communication (see Turner and Rainey; Rainey, "Approaches"). In contrast to such curricula, a thoroughly sophistic curriculum recognizes that the practice of technical communication is contingent, localized, and social, and therefore it makes space beyond the classroom for students to develop appropriate professional capacities in 
context. A sophistic curriculum, in other words, demands social engagement.

As Jarratt notes in Rereading the Sophists, "the sophists could be termed the first public intellectuals in a democracy" (98). Sophism is, by its nature, publicly accountable and "immersed in the adjudication of immediate cultural concerns" (Crowley 318), an attribute that Savage also foregrounds in his characterization of the sophist technical communicator ("Tricksters" 171). In his 1995 article "Sophistic Ethics in the Technical Writing Classroom: Teaching Nomos, Deliberation, and Action," J. Blake Scott calls for the incorporation of sophistic ethics into technical communication pedagogy:

We can begin by teaching technical writing as praxis or social action, as others have proposed. A praxis pedagogy approaches writing as social enculturation [...] We should help our students problematize their enculturation and roles as writers in different communities by addressing issues of politics and power. (195)

Internships, Scott notes, are a particularly effective means "to teach ethical enculturation," as are orientation videos, sample texts, guest speakers, participation in "virtual businesses" and digital communities, and the use of case studies (196). Although I find in my earlier study that certificates are socially engaged insofar as they are committed to the interests of local industry, the present study suggests that fewer than two in five certificates require an internship for program completion. Given that certificates are also slower-paced than baccalaureate degrees, this discrepancy cannot be attributed solely to lack of time or curricular space. With regards to 
internships, it appears that certificate programs need to do more to prepare students for their social roles in a sophistic profession. ${ }^{14}$

Another strategy that neosophistic theory recommends for program design is the incorporation of reflexive professional development. As J. Blake Scott notes, "perhaps the most important kind of deliberation to the sophists [...] was inner deliberation through the internalization of logos. [...] The sophists' students entered dialogues with themselves in order to master logos and develop their own ethical codes" (192-3). When seen as a sophistic profession, the qualification of a technical communicator is not a discrete skill set that he or she possesses; rather it is a professional ethos that he or she has developed. Phrased another way, the identity of the sophist-technical communicator can be seen not so much as a subjectivity (one who possesses knowledge in the Platonic sense), but rather as an intersubjectivity (one possessed of a certain ethos, or way of acting within and among social realms). This intersubjectivity is not assumable by rote and it cannot be taught through a Platonic curriculum of disjointed courses; it must be developed instead by allowing students to make the connections between their coursework and the social realm of technical communication in practice. This development can be facilitated, I believe, through self-conscious reflexivity.

Such reflexivity is comprised of an explicit engagement on behalf of the student with the issue of what it means to be a practitioner of technical communication. It can take the curricular form of retrospective portfolios, capstone projects, student symposia, close instructor advising, or

\footnotetext{
${ }^{14}$ Nonetheless, it remains to be seen if programs enact social engagement at other levels: for instance if students already work extensively in local industry, or if individual courses and pedagogical methods already emerge from local needs. These possibilities again suggest the need for more in-depth, quantitative and qualitative research on the individual contexts of certificate programs.
} 
even developmental journals; but the end goal of these activities should be for students to self-consciously adopt the professional ethos of a technical communicator within — and as shaped by — their specific social and cultural contexts. To be sure, such reflexive practice is conceived here not as a Platonic act of philosophical contemplation but as a sophistic act of rhetorical engagement: each of these activities should be constructed with a genuine audience, purpose, and context. Through these kinds of reflexive activities, students are provided with the curricular space to make developmental connections through social and discursive means. Although it is not certain the extent to which the kind of reflective professional development that I am sketching here is a part of current certificate programs, it remains an intriguing question for future researchers, as well as a compelling consideration for the design of any technical communication curriculum.

Of course, technical communication certificate programs are not completely unproblematic. While they are characteristically sophistic in their flexibility, this feature is also suggests the possibility for misuse. Little observes that the flexible nature of the certificate and its relative lack of administrative oversight

could result in questions about its quality. Without the application of standards, either legislated or mandated by educational codes as they are for degrees, certificates may not gain much acceptance as credentials for hiring or promotion, especially beyond the regional area the institution serves. ("Designing” 276)

To be sure, the kind of broad curricular standards that Little alludes to do not exist. Despite Roy K. Turner and Kenneth T. Rainey’s expressed optimism that an empirical examination of existing programs "would move the profession a long way toward standardized essential competencies" (222), research into the curricula of both baccalaureate (Harner and Rich) 
and certificate (Nugent, "Looking") programs reveals very few areas of curricular overlap that could support such nationwide standards. Nonetheless, Little presents us with an important caution: by embracing flexibility or location alone, it is possible for certificates to become simply "value added" credentials that serve the most immediate material interests of schools or students while failing to provide relevant preparation for the situated practice of technical communication. Without broader standards, the argument runs, what is to stop "anything goes" from becoming the sole guiding principle for certificate programs?

Sophistic theory suggests a strategy for program design that I believe addresses this possibility. Just as the sophists remain attentive to their context and the particular needs of their audiences, certificate programs should remain thoroughly attentive to the needs of their stakeholders. Whether regional or national, whether individual or collective, whether in the academy or in industry, many groups have a legitimate stake in the construction of certificate programs: universities, departments, students, instructors, administrators, neighboring academic programs, local industry, professional groups, scholarly organizations, and so on. In the continuing absence of broader curricular standards in technical communication, soliciting steady feedback from such a broad range of stakeholders may be the most effective check we have against "anything goes" program configurations.

It may also be our best chance for building programs that are successful—not just instrumentally, but also in terms of offering quality instruction. Just as J. Blake Scott contends that the nomoi of the community can be a viable source for ethics in the technical communication practice and pedagogy (192-4), the standards of rigorous and ethical instruction for certificate programs can emerge from the negotiated claims of the stakeholders that they serve. While some of the 
commentary on certificates suggests that they are attentive to both students (Worley) and local industry (Nugent, "Looking") as stakeholder groups, it remains to be seen what other groups are allowed to have a hand in shaping certificate programs, how negotiations take place among those groups, and how the dynamics of power affect the outcomes of such negotiations.

Regardless of whether technical communication will eventually enjoy the status of a modernist profession, playing to multiple stakeholder audiences and balancing their competing interests remains our best (if only) available guide in the absence of broader curricular standards, fixed knowledges, and core competencies. More importantly, we should be prepared for the possibility that, given the sophistic rhetorical character and kairotic nature of technical communication, these kinds of foundational standards may never emerge. As Savage notes, the "path of professionalization for technical communication" may very well be "a blind maze - many branches but with no way out to the goal we envision." ("Tricksters" 170). As an alternative to this, he implores,

Let us, rather than waging a tiresome and increasingly frustrating war of position for professional status, consider the possibility of teaching for a postmodern practice, a navigating practice, like the wily Odysseus, not mastering but negotiating continually shifting technologies, institutions, discourses, and cultures. ("Tricksters" 189)

As I contend, the thoughtful design and implementation of certificate programs should be seen as an important strategy for realizing the alternative, sophistic conception of technical communication that Savage illustrates.

Perhaps more radically, however, we may also want to consider that the "alternative" Savage describes here is, in fact, no alternative at all. That is, the instrumental success of technical communication as a profession 
and discipline may not just be a matter of placing new, postmodern notions of professionalism alongside our received, modernist conceptions. Instead, we may want to consider that all professions, academic disciplines, and educational programs are always already constructed by the activities of negotiation and navigation that Savage describes. We may want to entertain the notion that all disciplines and professions are constituted rhetorically (i.e. discursively), and further, sophistically (i.e. without reference to an extra-discursive or transcendent reality). Lastly, we may also want to consider that nomoi and the competing claims of stakeholders, audiences, and communities are the only measures of ethical rectitude that we will ever possess-not just within technical communication, but anywhere. With the full articulation of these notions of sophistic disciplinarity, professionalization, and ethics lying beyond the scope of the present study, however, I offer these ideas only as possibilities here.

I hope I have made clear that I do not see the value of sophism as a means to excuse program configurations that are convenient, but otherwise indefensible. I also do not mean to suggest that we should give up on seeking increased status for technical communication, that we should stop trying to articulate its identity as a discipline or profession, or that we should cede total control of our academic programs to a group of varied interests. Rather, in offering a model of professional identity as an alternative to those of market closure and fixity, I contend that sophistic rhetoric suggests a more situated, more responsible, and even more strategic, figuration for the technical communicator. My research on certificates shows that they are consistent with a sophistic model of programmatic flexibility, concern for local needs, and practical orientation. However, the sophistic model also provides important cautions for the design and administration of certificate programs. A sophistically informed certificate program should remain socially engaged, and it should 
present opportunities for students to work in real social contexts. In addition, a sophistically informed certificate program should be reflective: it should present opportunities for students to reflexively and selfconsciously develop their professional ethos.

Again, I make no claims to transcendence or universality in the research and interpretations I present here, and I hope that I have avoided any of the familiar "god-trick" rhetorical techniques that would suggest otherwise. I also hope that the information and discussion I have presented here are useful-either for participants in conversations within the field or for those considering the development of their own certificate programs. Sophistic rhetorical theory, I believe, provides an invaluable theoretical model - one that is both descriptive and prescriptive-for building and understanding certificate programs in technical communication. 


\section{Works Cited}

Alcoff, Linda, and Elizabeth Potter, eds. Feminist Epistemologies. New York: Routledge, 1993.

Allen, James E. "Aristotle and Social-Epistemic Rhetoric: The Systematizing of the Sophistic Legacy." Paper presented at the Annual Meeting of the Conference on College Composition and Communication, Nashville, TN, 16-19 March 1994.

Anderson, Paul V. "Evaluating Academic Technical Communication Programs: New Stakeholders, Diverse Goals.” Technical Communication 42.4 (1995): 628-33.

Aristotle. On Rhetoric: A Theory of Civic Discourse. 2nd ed. Trans. George A. Kennedy. New York: Oxford UP, 2007.

- Sophistical Refutations. The Complete Works of Aristotle. 2 vols. Ed. Jonathan Barnes. Bollingen Series LXXI. Princeton, NJ: Princeton UP, 1984. 2: 278-314.

Aronowitz, Stanley, and Henry A. Giroux. Postmodern Education: Politics, Culture, and Social Criticism. Minneapolis: U of Minnesota P, 1991.

Atwill, Janet M. Rhetoric Reclaimed: Aristotle and the Liberal Arts Tradition. Cornell UP, 1998.

Barker, Thomas. "RE: [attw-1] Professional and Technical Communication." Online posting. 16 April 2008. Association of Teachers of Technical Writing. <attw-1@1yris.ttu.edu>.

Berger, Arthur Asa. The Portable Postmodernist. Lanham, MD: AltaMira, 2003.

Berlin, James A. Rhetorics, Poetics, and Cultures: Refiguring College English Studies. 1996. West Lafayette, IN: Parlor, 2003.

Bernhardt, Stephen A. "Re:[attw-1] Professional and Technical Communication." Online posting. 16 April 2008. Association of Teachers of Technical Writing. <attw-1@lyris.ttu.edu>. 
- "RE: [attw-1] Reminder: TCQ CFP on Positioning Programs in Professional and Technical Communication” Online posting. 16 April 2008. Association of Teachers of Technical Writing. $<$ attw-1@1yris.ttu.edu>.

Biesecker, Susan. "Rhetoric, Possibility, and Women's Status in Ancient Athens: Gorgias' and Isocrates' Ecomiums of Helen.” Rhetoric Society Quarterly 22.1 (1992): 99-108.

Bizzell , Patricia. "The Praise of Folly, The Woman Rhetor, and PostModern Skepticism.” Rhetoric Society Quarterly 22.1 (1992): 7-17.

Black, Edwin. "Plato's View of Rhetoric." Quarterly Journal of Speech 40.4 (1958): 361-74.

Bosley, Deborah S. "Building a Graduate Certificate Program: Making Connections With the Community-at-Large." Proceedings of the Annual Meeting of the Council for Programs in Technical and Scientific Communication (24th, Austin, Texas, October 16-18, 1997). Ed. Carol Yee. Council for Programs in Technical and Scientific Communication, 1998. <http://www.cptsc.org/pro/1997.pdf>. 108.

_. "Collaborative Partnerships: Academia and Industry Working Together." Technical Communication 42.4 (1995): 611-19.

Bridgeford, Tracy. "The Academic Politics of Bringing Consulting Work into a Certificate Program." Conference Proceedings for the 32nd Annual Meeting of the Council for Programs in Technical and Scientific Communication. Ed. Jim Dubinsky. 20-22 October 2005, Texas Tech University. Council for Programs in Technical and Scientific Communication, 2005. <http://www.cptsc.org/pro/ 2005.pdf>. 82 .

—_. "CPTSC Program Directory.” Online posting. 2 September 2007. cptsc-1@dwc.wide.msu.edu mailing list. Council for Programs in Technical and Scientific Communication. <cptsc$1 @$ dwc.wide.msu.edu>. 
—_. "The Negotiated Boundaries of Certificate Programs." Pathways to Diversity. Ed. Jim Dubinsky. Proc. Council for Programs in Technical and Scientific Communication, 7-9 Oct. 2004, Purdue University. Council for Programs in Technical and Scientific Communication, 2005. <http://www.cptsc.org/pro/2004.pdf>. 301.

- "Repurposing v. Generating: Developing a Certificate in Technical Writing." Complicating Binaries: Exploring Tensions in Technical and Scientific Communication. Ed. Ann Blakeslee. Proc. Council for Programs in Technical and Scientific Communication, 3-5 Oct. 2002, Utah State University. Council for Programs in Technical and Scientific Communication, 2003. <http:// www.cptsc.org/pro/2002.pdf>. 79-80.

_ . "Thoughts on Designing a Master's Certificate Program." Models for Strategic Program Development: Proceedings of the Annual Meeting of the Council for Programs in Technical and Scientific Communication (27th, Menomonie, Wisconsin, October 19-21, 2000). Ed. Bruce Maylath. Council for Programs in Technical and Scientific Communication, 2000. <http://www.cptsc.org/pro/2000.pdf>. 401.

Bushnell, Jack. "A Contrary View of the Technical Writing Classroom: Notes Toward Future Discussion." Technical Communication Quarterly 8.2 (1999): 175-88.

Code, Lorraine. "Taking Subjectivity into Account.” Alcoff and Potter 1548.

Connors, Robert R. "The Rhetoric of Citation Systems, Part I: The Development of Annotation Structures from the Renaissance to 1900.” Rhetoric Review 17.1 (1998): 6-48.

—. "The Rhetoric of Citation Systems, Part II: Competing Epistemic Values in Citation." Rhetoric Review 17.2 (1999): 219-45.

- "The Rise of Technical Writing Instruction in America." Technical Writing and Communication 12.4 (1982): 329-52. 
Consigny, Scott. "Edward Schiappa's Reading of the Sophists." Rhetoric Review 14.2 (1996): 253-69.

- Gorgias: Sophist and Artist. Columbia, SC: U of South Carolina P. 2001.

Coon, Anne C., and Patrick M. Scanlon. "Does the Curriculum Fit the Career? Some Conclusions from a Survey of Graduates of a Degree Program in Professional and Technical Communication." Journal of Technical Writing and Communication 27.4 (1997): 39199.

Crockett, Andy. "Gorgias's Encomium of Helen: Violent Rhetoric or Radical Feminism?” Rhetoric Review 31.1 (1994): 71-90.

Crome, Keith. Lyotard and Greek Thought: Sophistry. New York: Palgrave Macmillan, 2004.

Crowley, Sharon. Composition in the University: Historical and Polemical Essays. Pittsburgh: U of Pittsburgh P, 1998.

—. "Let Me Get This Straight" Vitanza, Writing 1-19.

_ . "A Plea for the Revival of Sophistry." Rhetoric Review 7 (1989): $318-34$.

- Toward a Civil Discourse: Rhetoric and Fundamentalism. Pittsburgh: U of Pittsburgh P, 2006.

Dalmiya, Vrinda, and Linda Alcoff. “Are 'Old Wives' Tales' Justified?” Alcoff and Potter 217-44.

Derrida, Jacques. Dissemination. Trans. Barbara Johnson. Chicago, U of Chicago P, 1981.

Dombrowski, Paul M. "Post-Modernism as the Resurgence of Humanism in Technical Communication Studies.” Technical Communication Quarterly 4.2 (1995): 165-85.

Dragga, Sam. "Dislocating Technical Communication Programs." Tovey and Capansky 5-9. 
Dubay, William H. "Training: The Path to Certification." Proceedings of the 47th Annual Conference of the Society for Technical Communication. 2001, Arlington, VA: Society for Technical Communication, 2001. $<$ http://www.stc.org/ConfProceed/2001/PDFs/ STC48-000047.pdf >.

Eagleton, Terry. After Theory. New York: Basic Books, 2003.

- Literary Theory: An Introduction. Second edition. Minneapolis: $\mathrm{U}$ of Minnesota P, 1996.

England, Peter. "RE: [attw-1] Professional and Technical Communication." Online posting. 16 April 2008. Association of Teachers of Technical Writing. <attw-1@lyris.ttu.edu>.

Enos, Richard Leo. Greek Rhetoric Before Aristotle. Prospect Heights, IL: Waveland, 1993.

Faber, Brenton. "Re:[attw-1] Professional and Technical Communication." Online posting. 15 April 2008. Association of Teachers of Technical Writing. <attw-1@1yris.ttu.edu>.

Giroux, Henry A., David Shumway, Paul Smith, and James Sosnoski. "The Need for Cultural Studies: Resisting Intellectuals and Oppositional Public Spheres." Dalhousie Review 64.2 (1984): 472-486.

Gross, Alan G. Starring the Text: The Place of Rhetoric in Science Studies. Carbondale, IL: Southern Illinois UP, 2006.

Guthrie, W.K.C., The Sophists. Cambridge: Cambridge UP, 1971.

Haage, John. "Ethics, Words, and the World in Moore's and Miller's Accounts of Scientific and Technical Discourse." Journal of Business and Technical Communication 10.4 (1996): 461-75.

Hamilton, Edith, and Huntington Cairns, eds. The Collected Dialogues of Plato. Bollingen Series LXXI. Princeton, NJ: Princeton UP, 1961.

Haraway, Donna J.Modest_Witness@Second_Millennium.Female-Man ${ }^{\odot}$ ${ }_{\text {Meets_OncoMouse }}{ }^{T M}$. Feminism and Technoscience. New York: Routledge, 1996. 
- Simians, Cyborgs, and Women: The Reinvention of Nature. New York: Routledge, 1991.

Harding, Sandra. "Introduction." Harding, Feminist 1-15.

_. "Rethinking Standpoint Epistemology: What is 'Strong Objectivity'? Harding, Feminist 127-40.

- ed. The Feminist Standpoint Theory Reader. New York: Routledge, 2004.

—. The Science Question in Feminism. Ithaca, NY: Cornell UP, 1986.

Harner, Sandi, and Anne Rich. "Trends in Undergraduate Curriculum in Scientific and Technical Communication Programs." Technical Communication 52.2 (2005): 209-20.

Harris, James F. Against Relativism: A Philosophical Defense of Method. LaSalle, IL: Open Court, 1992.

Hawhee, Debra. "Bodily Pedagogies: Rhetoric, Athletics, and the Sophists' Three Rs.” College English 65.2 (2002): 142-62.

Hayes, Laurie Schultz. Proceedings of the Annual Meeting of the Council for Programs in Technical and Scientific Communication (15th, Minneapolis, Minnesota, October 19-21, 1988). Council for Programs in Technical and Scientific Communication, 1988. <http://www.cptsc.org/pro/1988.pdf>.

Hekman, Susan. Gender and Knowledge: Elements of a Postmodern Feminism. Boston: Northeastern UP, 1990.

—_. "Truth and Method: Feminist Standpoint Theory Revisited." Harding, Feminist 225-41.

Henschel, Sally. "New STC Academic Database." Online posting. 5 September 2007. cptsc-1@dwc.wide.msu.edu mailing list. Council for Programs in Technical and Scientific Communication. 5 September 2007. <cptsc-1@dwc.wide.msu.edu>.

Jaggar, Allison M. "Feminist Politics and Epistemology: The Standpoint of Women." Harding, Feminist 55-66. 
Jarratt, Susan C. "Feminism and Composition: The Case for Conflict." Contending with Words: Composition and Rhetoric in a Postmodern Age. Eds. Patricia Harkin and John Schilb. New York: MLA, 1991. $105-23$.

_ . "The First Sophists and the Uses of History." Rhetoric Review 6 (1987): 67-77.

- "Reflections on "Feminism and Composition: The Case for Conflict'." Feminism and Composition: A Critical Sourcebook. Eds. Gesa E. Kirsch, Faye Spencer Maor, Lance Massey, Lee NickosonMassey, and Mary P. Sheridan-Rabideau. Urbana, IL: NCTE, 2003.342-3.

- Rereading the Sophists: Classical Rhetoric Refigured. Carbondale: Southern Illinois UP, 1991.

- . "Speaking to the Past: Feminist Historiography in Rhetoric." PRE/TEXT11.3 (1990): 190-209.

—_. "Toward a Sophistic Historiography." PRE/TEXT 8.1-2 (1987): $10-26$.

Johanek, Cindy. Composing Research: A Contextualist Paradigm for Rhetoric and Composition. Logan, UT: Utah State UP, 2000.

Johnson, Robert R. "Complicating Technology: Interdisciplinary Method, the Burden of Comprehension, and the Ethical Space of the Technical Communicator." Technical Communication Quarterly 7.1 (1998): 75-98.

- . "(Deeply) Sustainable Programs, Sustainable Cultures, Sustainable Selves: Essaying Growth in Technical Communication." Kynell-Hunt and Savage 2:101-19.

- . "Johnson Responds." Technical Communication Quarterly 8.2 (1999): 223-6.

Kauffman, Charles. "The Axiological Foundation of Plato's Theory of Rhetoric." Landmark Essays on Classical Greek Rhetoric. Ed. Edward Schiappa. Davis, CA: Hermagoras P, 1994. 
Kerferd, G.B. The Sophistic Movement. Cambridge: Cambridge UP, 1981.

Krestas, Shirley A., Lori H. Fisher, and JoAnn T. Hackos. "Future

Directions for Continuing Education in Technical Communication." Technical Communication 42.4 (1995): 642-45.

Kinneavy, James L. "Contemporary Rhetoric." The Present State of Scholarship in Historical and Contemporary Rhetoric. Ed. Winifred Bryan Horner. Revised ed. Columbia: U of Missouri P, 1990. 186246.

Kreth, Melinda. "Comments on 'Instrumental Discourse is as Humanistic as Rhetoric'." Journal of Business and Technical Communication 10.4 (1996): 476-82.

Kynell-Hunt, Teresa, and Gerald J. Savage. Power and Legitimacy in Technical Communication. 2 vols. Baywood's Technical Communications Series. Amityville, NY: Baywood, 2003-04.

Leff, Michael C. "Modern Sophistic and the Unity of Rhetoric." The Rhetoric of the Human Sciences. Eds. Allan Megill, John S. Nelson, and Donald N. McCloskey. Madison: U of Wisconsin P, 1987. 1937.

Leitch, Vincent B., ed. The Norton Anthology of Theory and Criticism. New York: Norton, 2001.

Lindblom, Kenneth J. “Toward a Neo-Sophistic Writing Pedagogy.” Rhetoric Review 15.1 (1996): 93-107.

Little, Sherry Burgus. "Designing Certificate Programs in Technical Communication." Foundations for Teaching Technical Communication: Theory, Practice, and Program Design. Ed. Katherine Staples and Cezar Ornatowski. ATTW Contemporary Studies in Technical Communication. Greenwich, CT: Ablex, 1997. 273-85.

—. "The Problem with Certificate Programs." Rude 55-6. 
- "The Proof Is in the Pudding: Evaluating Quality in Technical Communication Certificate Programs." Proceedings of the Annual Meeting of the Council for Programs in Technical and Scientific Communication (13th, Portland, Oregon, April 17-18, 1986). Ed. Sam C. Geonetta. Council for Programs in Technical and Scientific Communication, 1986. <http://www.cptsc.org/pro/ 1986.pdf>. 3-8.

- "The Technical Communication Internship: An Application of Experiential Learning Theory." Journal of Business and Technical Communication 7.4 (1993): 423-51.

Mailloux, Steven. Disciplinary Identities: Rhetorical Paths of English, Speech, and Composition. New York: MLA, 2006.

- Reception Histories: Rhetoric, Pragmatism, and American Cultural Politics. Ithaca, NY: Cornell UP, 1998.

- Rhetoric, Sophistry, Pragmatism. Cambridge: Cambridge UP, 1995.

Mann, Susan A., and Lori R. Kelley. "Standing at the Crossroads of Modernist Thought: Collins, Smith, and the New Feminist Epistemologies." Gender E' Society 11.4 (1997): 391-408.

Marback, Richard. "Introduction." Plato's Dream of Sophistry. Columbia, SC: U of South Carolina P, 1999.1-16.

"Master of Professional Writing Program." University of Southern California College of Letters, Arts, \& Sciences. 16 October 2008. $<\mathrm{http} / / /$ college.usc.edu/mpw/home/ $>$.

Matsen, Patricia P., Philip Rollinson, and Marion Sousa, eds. Readings from Classical Rhetoric. Carbondale, IL: Southern Illinois UP, 1990.

McComiskey, Bruce. "Gorgias and the Art of Rhetoric: Toward a Holistic Reading of the Extant Gorgianic Fragments." Rhetoric Society Quarterly 27.4 (1997): 5-24.

- Gorgias and the New Sophistic Rhetoric. Carbondale, IL: Southern Illinois UP, 2002. 
McDowell, Earl E. “A Curricular Profile of United States Technical Communication Departments at the Beginning of the 21st Century." Annual Meeting of the National Communication Association. Atlanta, Georgia. 1-4 Nov. 2001.

Miller, Carolyn R. "Comments on 'Instrumental Discourse is as Humanistic as Rhetoric'." Journal of Business and Technical Communication 10.4 (1996): 482-86.

_. "A Humanistic Rationale for Technical Writing." College English 40.6 (1979): 610-17.

Moore, Patrick. "Instrumental Discourse is as Humanistic as Rhetoric." Journal of Business and Technical Communication 10.1 (1996):10017.

—. "Myths about Instrumental Discourse: A Response to Robert R. Johnson." Technical Communication Quarterly 8.2 (1999) 210-23.

_. "Rhetorical vs. Instrumental Approaches to Teaching Technical Communication.” Technical Communication 44.2 (1997): 163-73.

- "A Response to Miller and Kreth." Journal of Business and Technical Communication 10.4 (1996): 491-503.

Neel, Jasper. Plato, Derrida, and Writing. Carbondale, IL: Southern Illinois UP, 1988.

Nugent, Jim. “Certificate Programs in Technical Communication.” Tovey and Capansky 17-9.

—. "Certificate Programs in Technical Communication: Looking Closer, through Sophistic Eyes." Design Discourse: Composing and Revising the Professional and Technical Writing Program. Eds. David Franke and Alexander Reid. Fort Collins, CO: WAC Clearinghouse. Forthcoming.

Orr, Thomas. "Re: [attw-1] reminder: TCQ CFP on Positioning Programs in Professional and Technical Communication." Online posting. 15 April 2008. Association of Teachers of Technical Writing. <attw-1@1yris.ttu.edu>. 
Ostergaard, Lori, Jeff Ludwig, and Jim Nugent, eds. Transforming English Studies: New Voices in an Emerging Genre. West Lafayette, IN:

Parlor, 2009.

Pfeiffer, William S. "Southern Tech's Technical Writing Certificate." Proceedings of the Annual Meeting of the Council for Programs in Technical and Scientific Communication (14th, Orlando, Florida, October 7-9, 1987). Ed. Sam C. Geonetta. Council for Programs in Technical and Scientific Communication, 1987. <http:// www.cptsc.org/pro/1987.pdf>. 1-7.

Plato. Gorgias. Trans. W.D. Woodhead. Hamilton and Cairns 229-307.

. Phaedrus. Trams R. Hackforth. Hamilton and Cairns 475-525.

Popham, Susan L. "RE: [attw-1] Professional and Technical Communication." Online posting. 16 April 2008. Association of Teachers of Technical Writing. <attw-1@lyris.ttu.edu>.

Poulakos, John. "Interpreting Sophistical Rhetoric: A Response to Schiappa" Philosophy and Rhetoric 23.3 (1990): 218-28.

. "Rhetoric, the Sophists, and the Possible." Communication Monographs 51 (1986): 35-48.

_- "Testing and Contesting Classical Rhetorics." Rhetoric Society Quarterly 36.2 (2006): 171-79.

_ . "Terms for Sophistical Rhetoric." Rethinking the History of Rhetoric. Ed. Takis Poulakos. Boulder, CO: Westview, 1993. 53-74.

_ . "Toward a Sophistic Definition of Rhetoric." Philosophy and Rhetoric 16 (1983): 35-48.

- Sophistical Rhetoric in Classical Greece. Columbia, SC: U of South Carolina P, 1995.

Poulakos, Takis. Speaking for the Polis: Isocrates' Rhetorical Education. Columbia, SC: U of South Carolina P, 1997.

Powell, James N. Postmodernism for Beginners. Illus. Joe Lee. New York: Writers and Readers Publishing, 1998. 
Pullman, George L. "Reconsidering Sophistic Rhetoric in Light of Skeptical Epistemology.” Rhetoric Review 13.1 (1994): 50-68.

"PWP's Pedagogy." The University of Maryland English Department. 26 May 2008.16 October 2008. <http://www.engl-pw.umd.edu/ AboutPWP/WPPedagogy.html>.

Rainey, Kenneth T. "Assumptions About Technical Communication Programs." Proceedings of the 42nd Annual Conference of the Society for Technical Communication. 1995, Arlington, VA: Society for Technical Communication, 1995. 40-43. <http://www.stc.org/ confproceed/1995/PDFs/PG4043.PDF $>$.

Redish, Janice (Ginny). "Comments on 'Instrumental Discourse is as Humanistic as Rhetoric'." Journal of Business and Technical Communication 10.4 (1996): 486-90.

Rehling, Lu. "Charting and Evolutionary Path for Certificate Programs." Rude 51-2.

Rude, Carolyn, ed. The Ecology, the Environment, and the Evolution of Technical Communication: Proceedings of the Annual Meeting of the Council for Programs in Technical and Scientific Communication (25th, Lewes, Delaware, October 15-17, 1998). Council for Programs in Technical and Scientific Communication, 1999. $<$ http://www.cptsc.org/pro/1998.pdf .

Rude, Carolyn, and Kelli Cargile Cooke. "The Academic Job Market in Technical Communication, 2002-2003." Technical Communication Quarterly 13.1 (2004): 49-71.

Savage, Gerald J. "The Process and Prospects for Professionalizing Technical Communication." Journal of Technical Writing and Communication. 29.4 (1999): 355-81.

_. "Tricksters, Fools, and Sophists: Technical Communication as Postmodern Rhetoric." Kynell-Hunt and Savage 2:167-93.

Schiappa, Edward. "Did Plato Coin Rhetorike?" American Journal of Philology 111.4 (1990): 457-70. 
- . "History and Neo-Sophistic Criticism: A Reply to Poulakos." Philosophy and Rhetoric 23.3 (1990): 192-217.

—_. "Neo-Sophistic Rhetorical Criticism or the Historical Reconstruction of Sophistic Doctrines." Philosophy and Rhetoric 23.2 (1990): 192-217.

- Protagoras and Logos: A Study in Greek Philosophy and Rhetoric. 2nd ed. Columbia, SC: U of South Carolina P, 2003.

- "Some of My Best Friends are Neosophists: A Response to Consigny.” Rhetoric Review 14 (1996): 272-79.

_. "Sophistic Rhetoric: Oasis or Mirage?" Rhetoric Review 10.1 (1991): 5-17.

Scott, J. Blake. "Sophistic Ethics in the Technical Writing Classroom: Teaching Nomos, Deliberation, and Action.” Technical Communication Quarterly 4.2 (1995): 187-99.

Scott, Robert L. "On Viewing Rhetoric as Epistemic." Contemporary Rhetorical Theory: A Reader. Eds. John Louis Lucaites, Celeste Michelle Condit, and Sally Caudill. New York: Guilford, 1999. 131-39.

Selber, Stuart. "Re: [attw-1] Reminder: TCQ CFP on Positioning Programs in Professional and Technical Communication" Online posting. 16 April 2008. Association of Teachers of Technical Writing. <attw-1@lyris.ttu.edu>.

Shirk, Henrietta Nickels. "Education or Training? Issues for Certificate Programs in Technical Communication." Hayes 1-5.

Shirk, Henrietta, Katherine Staples, Susan Feinberg, Diana Reep, and Daniel Riordan. "The Certificate in Technical Communication." Hayes 28-30.

Simons, Herbert W. "Introduction: The Rhetoric of Inquiry as an Intellectual Movement." The Rhetorical Turn: Invention and Persuasion in the Conduct of Inquiry. Ed. Herbert W. Simons. Chicago: U of Chicago P, 1990.1-31. 
“Sophism.” American Heritage Dictionary. 2004.

“Sophism.” Webster's Revised Unabridged Dictionary. 1913.

“Sophism.” Webster's Third International Dictionary. 1961.

Snow, C.P. The Two Cultures and the Scientific Revolution. New York: Cambridge UP, 1959.

Sprague, Joey. Feminist Methodologies for Critical Researchers: Bridging Differences. Lanham, MD: AltaMira, 2005.

Sprague, Rosamond Kent, ed. The Older Sophists. Columbia, SC: U of South Carolina P, 1972.

Strathausen, Carsten, ed. A Leftist Ontology: Beyond Relativism and Identity Politics. Minneapolis: U of Minnesota P, 2009.

Swearingen, C. Jan. "Plato's Feminine: Appropriation, Impersonation, and Metaphorical Polemic." Rhetoric Society Quarterly 22.1 (1992): $109-23$.

Tovey, Janice, and Trish Capansky. Proceedings of the 33rd Annual Conference, Council on [sic] Programs in Technical and Scientific Communication. 12-14 October 2006, San Francisco State University. Council for Programs in Technical and Scientific Communication, 2008. <http://www.cptsc.org/pro/2006.pdf>.

Turner, Roy K., and Kenneth T. Rainey. "Certification in Technical Communication." Technical Communication Quarterly 13.2 (2004): 211-34.

Vitanza, Victor J. "Critical Sub/Versions of the History of Philosophical Rhetoric.” Rhetoric Review 6.1 (1987): 41-66.

- Negation, Subjectivity, and the History of Rhetoric. Albany, NY: State U of New York P, 1997.

- ed. Writing Histories of Rhetoric. Carbondale, IL: Southern Illinois UP, 1994.

Weeks, Kathi. "Truth and Method: Feminist Standpoint Theory Revisited.” Harding, Feminist 181-93. 
Wick, Audrey. "The Feminist Sophistic Enterprise: From Euripedes to the Vietnam War." Rhetoric Society Quarterly 22.1 (1992): 27-38.

Worley, Wanda L. "Using Marketing Research to Improve Certificate Program [sic].” Tovey and Capansky 110-13.

Yee, Carole. "Can We Be Partners?: Industry/Corporate Advisory Boards for Academic Technical Communication Programs." Publications Management: Essays for Professional Communicators. Eds. Jane O. Allen and Lynn H. Deming. Baywood's Technical Communications Series. Amityville, NY: Baywood, 1994.

Zimmerman, Donald E., and Marilee Long. "Exploring the Technical Communicator's Roles: Implications for Program Design." Technical Communication Quarterly 2.3 (1993): 301-17. 


\section{Appendix A:}

\section{Program Directory}

The following are the U.S. academic institutions offering a certificate, undergraduate degree or concentration, or graduate degree in technical or professional writing/communication. The programs surveyed in this study are noted $(\dagger)$.

Appalachian State University

Sanford Hall

Boone, NC 28608

Arcadia University

Department of English

S. Easton Rd.

Taylor 211

Glenside, PA 19038

$\dagger \quad$ Arizona State University

Multimedia Writing and Technical Communication

7001 E. Williams Field Rd.

Mesa, AZ 85204-2896

$\dagger \quad$ Auburn University

Department of English

9030 Haley Center

Auburn University, AL 36849-5203

$\dagger \quad$ Austin Community College

11928 Stonehollow

Austin, TX 78758-3190

Austin Peay State University

Department of Languages and Literature

PO Box 4487

Clarksville, TN 37044 
$\dagger \quad$ Bellevue Community College

Department of Business and Professional Development 10700 Northup Way

Bellevue, WA 98004-1416

Bentley College

Adamian Graduate Center 083

175 Forest Street

Waltham, MA 02452

Boise State University

Department of English

Boise, ID 83725-0399

Bowling Green State University

Department of English

Bowling Green, OH 43403-0001

$\dagger \quad$ Brigham Young University

English Department

Provo, UT 84602-0002

$\dagger \quad$ Brooklyn College

2900 Bedford Ave

Brooklyn, NY 11210-2889

$\dagger \quad$ California Polytechnic State University

Technical Communication Program

San Luis Obispo, CA 93407-0001

$\dagger \quad$ California State University Channel Islands

Department of English

Camarillo, CA 93012

$\dagger \quad$ California State University, Dominguez Hills

College of Extended and International Education

1000 E. Victoria St.

Carson, CA 90747-0001 
$\dagger \quad$ California State University, East Bay Continuing and International Education 25800 Carlos Bee Blvd.

Hayward, CA 94542-3000

$\dagger \quad$ California State University, Fullerton

College Park, Suite 100

2600 Nutwood Ave.

Fullerton, CA 92834-6870

$\dagger \quad$ California State University, Long Beach

Department of English

1250 Bellflower Boulevard

Long Beach, CA 90840-0001

$\dagger \quad$ California State Universtiy, Chico

English Department

400 West First Street

Chico, CA 95929-0001

$\dagger \quad$ Carnegie Mellon University

Department of English

5000 Forbes Avenue

Pittsburgh, PA 15213-3890

$+\quad$ Cedarville University

251 Main Street

Cedarville, $\mathrm{OH} 45314-8564$

$\dagger \quad$ Chicago State University

Department of English and Speech

9501 South King Drive, SCI 320

Chicago, IL 60628-1598

$\dagger \quad$ Christopher Newport University

Department of English

Newport News, VA 23601-3301 
Clemson University

Strode Tower

English Department

Clemson, SC 29634

$\dagger \quad$ Cleveland State University

Division of Continuing Education

2121 Euclid Avenue

Cleveland, OH 44115-2214

$\dagger \quad$ College of DuPage

Liberal Arts Division

425 Fawell Boulevard

Glen Ellyn, IL 60137-6599

$\dagger \quad$ College of Lake County

Technical Communication And Multimedia Programs

19351 West Washington Street

Grayslake, IL 60030-1198

Colorado State University

Department of Journalism and Technical Communication

Fort Collins, CO 80523-1785

Columbus State Community College

550 E. Spring St.

Columbus, OH 43216

$\dagger \quad$ DeAnza College

Department of Technical Writing

21250 Stevens Creek Blvd.

Cupertino, CA 95014-5797

Delta College

English Division

1961 Delta Rd.

University Center, MI 48710-0001 
$\dagger \quad$ Drexel University

Department of Culture and Communication

Philadelphia, PA 19104-2816

$\dagger \quad$ Duke University

Continuing Studies

Box 90700

Durham, NC 27708-0700

$\dagger \quad$ East Carolina University

Department of English

2100 Bate Building

Greenville, NC 27858-4353

$\dagger \quad$ Eastern Kentucky University

Case Annex 497

521 Lancaster Avenue

Richmond, KY 0475-3102

† Eastern Michigan University

612 Pray Harrold Hall

Ypsilanti, MI 48197-2207

$\dagger \quad$ Eastern Washington University

Department of English

250 Patterson Hall

Cheney, WA 99004-2430

Elon University

Campus Box 2349

Elon, NC 27244

Fairfield University

1073 N. Benson Rd.

DMH 130

Fairfield, CT 06824-5195 
Farmingdale State College

Knapp Hall

Farmingdale, NY 11735

$\dagger \quad$ Ferris State University

Department of Languages and Literature

820 Campus Drive

ASC 3080-A

Big Rapids, MI 49307-2225

Florida State University

Academic and Professional Program Services

Center for Professional Development

C3500 University Center

Tallahassee, FL 32306-2550

Francis Marion University

McNair 101-F

Florence, SC 29501

Gateway Technical College

1001 S. Main Street

Racine, WI 53403

George Mason University

Department of English

Robinson A 487

4400 University Drive, MSN 3E4

Fairfax, VA 22030

$\dagger \quad$ Georgia Southern University

Writing and Linguistics Department

1118 Newton Bldg.

P.O. Box 8026

Statesboro, GA 30460-0002

Hilbert College

5200 South Park Avenue

Hamburg, NY 14075 
$\dagger \quad$ Illinois Institute of Technology

3301 S. Dearborn

Chicago, IL 60616-2973

Illinois State University

English Department

Campus Box 4240

Normal, IL 61790-4240

$\dagger \quad$ Indiana University East

Whitewater Hall 254

2325 Chester Blvd.

Richmond, IN 47374-1289

$\dagger \quad$ Indiana University South Bend

Department of English

1700 Mishawaka Ave.

P.O. Box 7111

South Bend, IN 46634-7111

$\dagger \quad$ Indiana University-Purdue University Indianapolis

Technical Communication Program

799 W. Michigan St. ET 324F

Indianapolis, IN 46202-2896

$\dagger \quad$ Iowa State University

Department of English

203 Ross Hall

Ames, IA 50011-1201

$\dagger \quad$ James Madison University

Institute of Technical and Scientific Communication

MSC 2108

Harrisonburg, VA 22807-0002

$\dagger \quad$ Kansas State University

108-C English

Counseling Services Building

Manhattan, KS 66506-0305 
† Kaplan University 6301 Kaplan University Ave.

Ft. Lauderdale, FL 33309-1905

Kennesaw State University

English Department, EB155

1000 Chastain Rd. \#3301

Kennesaw, GA 30144-5588

$\dagger \quad$ King College

Department of Technical and Professional Communication 1350 King College Road

Bristol, TN 37620-2649

Kutztown University

Department of English

Lytle Hall

Kutztown, PA 19530

$\dagger \quad$ Lawrence Technological University

College of Arts and Sciences

21000 West Ten Mile Road

Southfield, MI 48075-1058

Louisiana State University in Shreveport

One University Place

Shreveport, LA 71115

$\dagger \quad$ Louisiana Tech University

School of Literature and Language

P.O. Box 3162

Ruston, LA 71272-0001

$+\quad$ Madison Area Technical College

3550 Anderson Street

Room 246

Madison, WI 53704-2599 
† Madonna University

English and Communication Arts

36600 Schoolcraft Road

Livonia, MI 48150-1176

$\dagger \quad$ Mercer University

Mercer University School of Engineering

1400 Coleman Avenue

Macon, GA 31207-0001

$\dagger \quad$ Metropolitan State College of Denver

Department of Technical Communication and Media

P.O. Box 173362

Campus Box 35

Denver, CO 80217-3362

$\dagger \quad$ Metropolitan State University

Suite 205, Energy Park Place

1380 Energy Lane

St. Paul, MN 55108-5253

$\dagger \quad$ Miami University

English Department

Bachelor Hall

Oxford, OH 45056-3506

$\dagger \quad$ Michigan Technological University

Department of Humanities

1400 Townsend Dr.

Houghton, MI 49930

† Middlesex Community College

591 Springs Road

Bedford, MA 01730-1197

$\dagger \quad$ Milwaukee School of Engineering

1025 N. Broadway

Milwaukee, WI 53202-3109 
$\dagger \quad$ Minnesota State University, Mankato

Department of English

230 Armstrong Hall

Mankato, MN 56001-6079

$\dagger \quad$ Missouri University of Science and Technology

Department of English and Technical Communication

Rolla, MO 65409-0001

$\dagger \quad$ Missouri Western State University

222 Eder Hall

4525 Downs Dr.

St. Joseph, MO 64507-2294

$\dagger \quad$ Montana Tech of the University of Montana

PTC Department

Engineering Hall 208D

Butte, MT 59701-8997

$\dagger \quad$ Montgomery College

Department of Communications

20200 Observation Drive

Germantown, MD 20876-4067

$\dagger \quad$ Moraine Park Technical College

235 N. National Avenue

Fond du Lac, WI 54935-2884

$\dagger \quad$ Murray State University

Department of English and Philosophy

7C Faculty Hall

Murray, KY 42071

Nazareth College

4245 East Ave.

Rochester, NY 14618-3703 
$\dagger \quad$ New Jersey Institute of Technology

Department of Humanities

Newark, NJ 07102-1982

$\dagger \quad$ New Mexico Institute of Mining and Technology

Technical Communication Program

801 Leroy Place

Socorro, NM 87801-4750

New Mexico State University

English Department MSC 3E

P.O. Box 30001

Las Cruces, NM 88003

$\dagger \quad$ New York Institute of Technology

Department of English

Northern Blvd.

Old Westbury, NY 11568-1036

$\dagger \quad$ North Carolina State University at Raleigh

Department of English

Box 8105, NCSU

Raleigh, NC 27695-8105

$\dagger \quad$ Northeastern University

360 Huntington Ave.

270 Ryder Hall

Boston, MA 02115-5000

Northern Arizona University

English Department

Flagstaff, AZ 86011

Northern Illinois University

Department of English

DeKalb, IL 60115 
† Oklahoma State University

OSU Department of English

205 Morrill Hall

Stillwater, OK 74078-0002

Old Dominion University

Department of English, BAL 5000

Norfolk, VA 23529

$\dagger \quad$ Orange Coast College

Department of Literature and Languages

2701 Fairview Rd.

Costa Mesa, CA 92626-5563

Penn State

College of Liberal Arts

143 Burrowes Building

University Park, PA 16802

$\dagger \quad$ Pikes Peak Community College

Department of English

5675 S. Academy Blvd.

Colorado Springs, CO 80906-5498

$\dagger \quad$ Pima Community College

West Campus

English Department

2202 West Anklam Rd.

Tucson, AZ 85709-0170

$\dagger \quad$ Pittsburg State University

426 Grubbs Hall

Pittsburg, KS 66762-7500

$\dagger \quad$ Polytechnic University

Department of Humanities and Social Sciences

6 MetroTech Center

Brooklyn, NY 11201-2990 
Portland State University

Department of English

Portland, OR 97207-0751

$\dagger \quad$ Purdue University

Department of English

500 Oval Dr.

West Lafayette, IN 47907-2038

$\dagger \quad$ Radford University

English Department, 6935

Radford, VA 24142-0002

$\dagger \quad$ Regis University

Department of English

3333 Regis Boulevard

Denver, CO 80221-1099

$\dagger \quad$ Rensselaer Polytechnic Institute

Department of Language, Literature, and Communication

110 Eighth Street

Troy, NY 12180-3590

† Rhetoric and Writing @ Michigan State University

5 Olds Hall

East Lansing, MI 48824-1020

$\dagger \quad$ Rochester Institute of Technology

Department of Communication

College of Liberal Arts

Rochester, NY 14623-5698

$\dagger \quad$ Rutgers

Technical Writing Program

96 Davidson Road

Piscataway, NJ 08854-8062 
$\dagger \quad$ Sacramento State University

College of Continuing Education

3000 State University Drive East

Sacramento, CA 95819-6103

$\dagger \quad$ Saginaw Valley State University

Brown Hall 330

University Center, MI 48710-0001

$\dagger \quad$ San Diego State University

Department of Rhetoric and Writing Studies

5500 Campanile Dr.

San Diego, CA 92182-4452

$\dagger \quad$ San Francisco State University

Technical and Professional Writing Program

1600 Holloway Avenue

San Francisco, CA 94132-4162

$\dagger \quad$ San José State University

Department of English

One Washington Square

San José, CA 95192-0001

Shepherd College

Department of English

P.O. Box 5000

Knutti Hall

Shepherdstown, WV 25443

Southeastern Louisiana University

English Department SLU 10861

Hammond, LA 70402

$\dagger \quad$ Southern Polytechnic State University

English, Technical Communication, and Media Arts

Marietta, GA 30060-2896 
St. Edward's University

Box 103

3001 South Congress Avenue

Austin, TX 78704

State University of NY Institute of Technology

Rt. 12 North Horatio St

Utica, NY 13504

Stevens Institute of Technology

1 Castle Point on Hudson

Morton 208

Hoboken, NJ 07030

SUNY-Cortland

English Department

Old Main, Room 115-A

Cortland, NY 13045

Tennessee Technological University

English Department

Box 5053

Cookeville, TN 38505

Texas A\&M University

Writing Programs Office

234 Blocker Bldg.

College Station, TX 77843-4227

Texas State University

Department of English

San Marcos, TX 78666

$\dagger \quad$ Texas Tech University

English Department

P. O. Box 43091

Lubbock, TX 79409-0001 
$\dagger \quad$ Three Rivers Community College

TRCC Humanities and Performing Arts Division 2080 Three Rivers Blvd.

Poplar Bluff, MO 63901-2350

Towson University

College of Graduate Studies

8000 York Road

Towson, MD 21252

Troy University, Montgomery Campus

Building 136, Room 104

241 Montgomery ST

Montgomery, AL 36104

University of Akron

Department of English

Olin Hall 301

Akron, OH 44325-1906

$\dagger \quad$ University of Alabama in Huntsville

English Department

Huntsville, AL 35899-0001

$\dagger \quad$ University of Arkansas at Little Rock

Department of Rhetoric and Writing

2801 S. University Ave.

Little Rock, Arkansas 72204-1099

$\dagger \quad$ University of California Berkeley Extension

1995 University Ave. - Suite 110

Berkeley, CA 94704-7000

$\dagger \quad$ University of California San Diego Extension 9500 Gilman Dr - MC 0170A

La Jolla, CA 92093

$\dagger \quad$ University of California Riverside Extension

Riverside, CA 92521-0112 
$\dagger \quad$ University of California Santa Cruz Extension Cupertino Campus

Business and Management Department 10420 Bubb Road

Cupertino, CA 95014-4150

$\dagger \quad$ University of Central Florida

Department of English

Orlando, FL 32816-1346

$\dagger \quad$ University of Colorado at Denver

Department of Communication

P. O. Box 173364 - Campus Box 176

Denver, CO 80217-3364

$\dagger \quad$ University of Delaware

University of Delaware Department of English

Office 135 Memorial

Newark, DE 19716-5600

University of Hartford

200 Bloomfield Avenue

West Hartford, CT 06117

University of Hawaii at Manoa

English Department

1733 Donaghho Road

Honolulu, HI 96822

$\dagger \quad$ University of Houston-Downtown

One Main Street

Suite S-1045

Houston, TX 77002-1001

$\dagger \quad$ University of Massachusetts Amherst

481 Bartlett Hall

University of Massachusetts

Amherst, MA 01003 
University of Massachusetts Dartmouth

UMD - Group 1, Room 341

285 Old Westport Road

North Dartmouth, MA 02747-2300

$\dagger \quad$ University of Massachusetts Lowell

Department of English

One University Avenue

Lowell, MA 01854-5096

$\dagger \quad$ University of Michigan-Flint

English Department

303 E. Kearsley Street

Flint, MI 48502-1950

$\dagger \quad$ University of Minnesota

64 Classroom Office Building

Buford Avenue

Minneapolis, MN 55108-1004

$\dagger \quad$ University of Minnesota Rochester

111 South Broadway

Rochester, MN 55904-4945

$\dagger \quad$ University of Nebraska at Omaha

English Department - ASH 189P

Omaha, NE 68182-0175

University of Nevada Las Vegas

Department of English

4505 Maryland Parkway, Box 455011

Las Vegas, NV 89154-5011

University of New Mexico

One University of NM

Department of English MSC 032170

Albuquerque, NM 87131-0001 
University of North Carolina at Charlotte

Department of English

276F Fretwell Building

Charlotte, NC 28223-0001

University of North Carolina at Wilmington

Department of English

601 S. College Road

Wilmington, NC 28403

University of Northern Iowa

117 Baker

Mail Code 0502

Cedar Falls, IA 50614-0502

University of Pittsburgh

526 CL/English Department

42005 th Ave.

Pittsburgh, PA 15260

$\dagger \quad$ University of South Florida

Department of English, CPR 107

4202 E. Fowler Avenue

Tampa, FL 33620-9951

University of Southern California-Santa Barbara

Writing Program

South Hall 1520

Santa Barbara, CA 93106-3010

$\dagger \quad$ University of Tennessee

Department of English

301 McClung Tower

Knoxville, TN 37996-0001

$\dagger \quad$ University of Texas at San Antonio

Department of Communication

One UTSA Circle

San Antonio, TX 78249-0643 
† University of Washington

14 Loew Hall, Box 352195

Seattle, WA 98195-0005

$\dagger \quad$ University of Wisconsin-Madison

Department of Engineering Professional Development

432 North Lake Street

Madison, WI 53706-1498

$\dagger \quad$ University of Wisconsin-Milwaukee

Department of English

Curtin Hall

Milwaukee, WI 53201-0413

$\dagger \quad$ University of Wisconsin-Stout

150C Harvey Hall

Menomonie, WI 54751-0790

Utah State University

English Department,

3200 Old Main Hill

Logan, UT 84322-3200

Virginia Tech

Department of English, 0112

Blacksburg, VA 24061

Washington State University Vancouver

Department of English

14204 NE Salmon Creek Ave.

Vancouver, WA, 98686-9600

Washington State University

Department of English

Avery Hall

Pullman, WA 99164 
$\dagger \quad$ Washtenaw Community College

WCC Department of English/Writing 4800 E. Huron River Dr.

PO Box 1610

Ann Arbor, MI 48106-1610

$\dagger \quad$ Weber State University

1201 University Circle

Department of English

Ogden, UT 84408-1201

West Chester University

Main Hall 530

West Chester, PA 19383

$\dagger \quad$ West Texas A\&M University

Department of English

Box 60908

Canyon, TX 79016-0001

West Virginia University

230 Stansbury Hall

Morgantown, WV 26506

Western Wisconsin Technical College

304 Sixth Street N.

La Crosse, WI 54601

Widener University

One University Place

Chester, PA 19013-5792

Worcester Polytechnic Institute

ME Department

100 Institute Rd

Worcester, MA 01609 
$\dagger \quad$ Wright State University

Department of English

Dayton, OH 45435-0002

Youngstown State University

Department of English

One University Plaza

Youngstown, OH, 44555 


\section{Appendix B: Survey Instrument}

\section{A Survey of Professional and Technical Communication/ Writing Programs}

Your cooperation with this research project is greatly appreciated, and will greatly contribute to our knowledge of certificate and undergraduate degree programs in professional and technical communication/writing. This survey should take approximately 15 minutes to complete. Please return your completed survey using the enclosed, prepaid mailer.

\section{About Your Institution}

1. Which of the following best describe your institution? (Check all that apply):

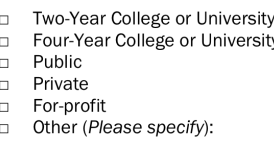

2. How many students attend your institution? (Check one):

$$
\begin{array}{ll}
\square & 500 \text { or fewer } \\
& 501-2,000 \\
& 2,001-5,000 \\
& 5001-15,000 \\
\quad & 15,001-25,000 \\
\quad & \text { More than } 25,000
\end{array}
$$

3. What is the official name of your department or academic unit?

4. Which of the following are conferred by your department or academic unit expressly in professional or technical writing/communication? (Check all that apply):

$\square$ Certificates

Associate's degree

Minors

Concentrations within a bachelor's degree

Bachelor's degrees

Master's degrees

Doctorates

Other (Please specify):

5. Which of the following are conferred by your department or academic unit, in any specialization? (Check all that apply):

Certificates

Associate's degrees

Bachelor's degrees

Master's degrees

Doctorates

Dother (Please specify): 
About Your Professional or Technical Writing/Communication Bachelor's Program (If Applicable)

6. If your department or academic unit offers a professional or technical writing/communication bachelor's degree or non-minor degree concentration, please answer the following questions (a-k):

a. In what year did your program confer its first professional or technical writing/communication bachelor's degree or degree concentration?

b. How many students are currently enrolled in your professional or technical writing/communication bachelor's program?

c. How many professional or technical writing/communication bachelor's degrees and degree concentrations did your program

d. Over the lifetime of your program, approximately how many professional or technical writing/communication bachelor's degrees and degree concentrations has your program conferred?

e. How many total courses-from all departments or academic unitsare required for completion of your professional or technical writing communication bachelor's degree program?

f. Of those courses required for completion, how many are offered exclusively by your department or academic unit?

g. A course in your professional or technical writing/communication bachelor's degree program typically meets for how many hours per bachelor's

h. How many weeks are in a term of study for your professional or technical writing/communication bachelor's degree program?

i. How many terms are anticipated for a student to complete you professional or technical writing/communication bachelor's degree program?

j. What portion of your professional or technical writing/communication bachelor's degree or degree concentration can be earned online? (Check one):

$\square \quad$ No portion

$\square$ Only some portion

$\square$ The entire degree

k. Does your professional or technical writing/communication bachelor's program require an internship for completion? (Check one):

$\square \quad$ Yes

No 
About Your Professional or Technical Writing/Communication Certificate Program (If Applicable)

7. If your department or academic unit offers a certificate in professional or technica writing/communication, please answer the following questions (a-l):

a. In what year did your program confer its first professional or technical writing/communication certificate?

b. How many students are currently enrolled in your professional or technical writing/communication certificate program?

c. How many professional or technical writing/communication certificates did your program confer over the course of the certificates did your program

d. Over the lifetime of your program, approximately how many professional or technical writing/communication certificates has your program conferred?

e. How many total courses-from all departments or academic unitsare required for completion of your professional or technical writing/communication certificate?

f. Of those courses required for completion, how many are offered exclusively by your department or academic unit?

g. A course in your professional or technical writing/communication certificate typically meets for how many hours per week?.

h. How many weeks are in a term of study for your professional or technical writing/communication certificate?.

i. How many terms are anticipated for a student to complete you professional or technical writing/communication certificate program?

j. Can your professional or technical writing/communication certificate(s) (Check one): - be earned independently of another degree, or

$\square$ does it require concurrent enrollment in any other degree program?

k. What portion of your professional or technical writing/communication certificate(s) can be earned online? (Check one):

$\square \quad$ No portion

․ Only some portion

- The entire certificate

I. Does your professional or technical writing/communication certificate(s) require an internship for completion? (Check one):

$\begin{array}{ll}\square & \text { Yes } \\ \square & \text { No }\end{array}$ 
Instructors in Your Program

8. How many instructors teach in your department or academic unit? Please include all faculty, adjunct, graduate, full-time, and part-time instructors, regardless of their specialization.

9. How many graduate students, if any, teach in your department or academic unit?

10. How many instructors in your department or academic unit hold tenure-track positions?

11. How many instructors in your department or academic unit regularly teach courses in professional or technical writing/communication? Please include faculty, adjunct, graduate, full-time, and part-time instructors.

12. Of the instructors in your department or academic unit who regularly teach courses in professional or technical writing/communication, how many hold degrees specifically in the disciplines of Technical Communication, Technical Writing, Business Writing, or Professional Writing?

13. Of the instructors in your department or academic unit who regularly teach professional or technical writing/communication courses and who do not hold the degrees listed in the previous question, what are their areas of primary academic specialization? (Please list):

14. Of the instructors in your department or academic unit who regularly teach professional or technical writing/communication courses,

a. How many have industry or professional experience?

b. How many hold a bachelor's as their highest degree earned?

c. How many hold a master's as their highest degree earned?

d. How many hold a doctorate as their highest degree earned?

e. How many are graduate students?

f. How many hold tenure-track positions?

\begin{tabular}{|ll}
\hline This research is supported by a grant from the Council for \\
Programs in Technical and Scientific Communication (CPTSC).
\end{tabular}




\section{Appendix C: Survey Cover Letter}

«Name»
"Add1»
"Add2»
"Add3»
3 April 2007

Dear Dr. «Name»:

I would like to ask a few questions about your program in professional or technical writing/communication. This is part of a study supported by the Council for Programs in Technical and Scientific Communication (CPTSC) and the Michigan Technological University Department of Humanities to assess the faculty and curricular makeup of bachelor's and certificate programs. This study is undertaken as part of approved doctoral research under the direction of Dr. Robert R. Johnson.

I understand that this is a busy part of the year, but your time in filling out the enclosed survey will be greatly appreciated. In addition, you will be contributing greatly to our knowledge of professional and technical communication/writing programs. The survey should take approximately 15 minutes to complete.

You have been selected to participate in this study from contact information gathered through publicly available sources: the Society for Technical Communication Academic Programs Database (http://www.stc.org/academic/index.aspx), the CPTSC program list (http:// |www.cptsc.org/proglist), the Association of Teachers of Technical Writing program directory (http://cms.english.ttu.edu/ attw/programs), or from your program's webpage. Your participation in this survey is completely voluntary; failure to respond will incur no penalty or loss of benefit for you. Any information that you offer will be kept confidential. Identifying information will be removed from any data that you provide, and under no circumstances will you be identifiably quoted in any publication resulting from this research.

If you have any questions or concerns about this research, please contact the Principal Investigator of this study, Dr. Robert R. Johnson, at (rrjohnson@mtu.edu) or (906) 487-3236; or contact Joanne Polzien of Michigan Technological University's Research Compliance Office at (906) 487-2902.

Thank you for your time in filling out and returning the enclosed survey, and thank you for your contribution to the field.

Sincerely,

Jim Nugent

jdnugent@mtu.edu 


\section{Appendix D: Survey Reminder Postcard}

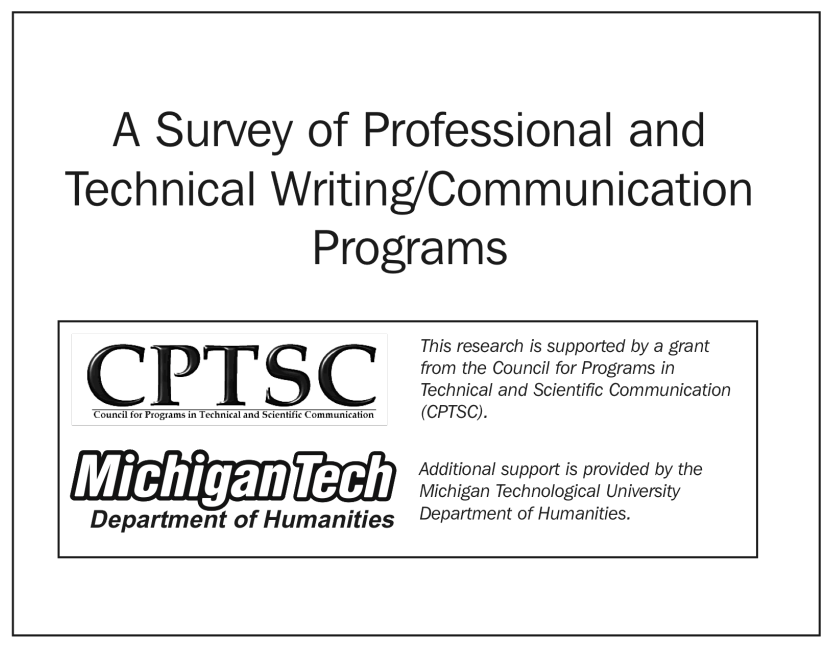

Several weeks ago, I sent a survey
to you to ask a few questions about
your technical communication or
professional writing program.
If you haven't already, I hope you'll
take a few minutes to complete
and return this survey. Your time
and contribution will be greatly
appreciated, and will help develop
much-needed administrative data
about programs nationwide.
Sincerely,
Jim Nugent
Michigan Tech University
jdnugent@mtu.edu 